CIGS The Canon Institute for Global Studies

CIGS Working Paper Series No. 17-002E

\title{
Debt-Ridden Borrowers and Economic Slowdown
}

\author{
Keiichiro Kobayashi \\ Keio University/The Canon Institute for Global Studies \\ Daichi Shirai \\ The Canon Institute for Global Studies
}

November 2017 (Substantial revision. First version: March 2012)

※Opinions expressed or implied in the CIGS Working Paper Series are solely those of the author, and do not necessarily represent the views of the CIGS or its sponsor.

※ CIGS Working Paper Series is circulated in order to stimulate lively discussion and comments.

※Copyright belongs to the author(s) of each paper unless stated otherwise.

General Incorporated Foundation

The Canon Institute for Global Studies

一般財団法人 キヤノングローバル戦略研究所

Phone: +81-3-6213-0550 http://www.canon-igs.org 


\title{
Debt-Ridden Borrowers and Economic Slowdown
}

\author{
Keiichiro Kobayashi and Daichi Shirai *
}

November 2017 (Substantial revision. First version: March 2012)

\begin{abstract}
Economic growth slows for an extended period after a financial crisis. We construct a model in which a one-time buildup of debt can depress the economy persistently, even when there is no financial technology shock. We consider the debt dynamics of firms under endogenous borrowing constraints, with lenders having an option to forgive defaulting borrowers. A firm is referred to as debt-ridden when it owes maximum debt and pays all income in each period as an interest payment. In the deterministic case, a debt-ridden firm continues inefficient production permanently. Further, if the initial debt exceeds a certain threshold, the firm intentionally chooses to increase borrowing and, thus, to become debt-ridden. The emergence of a substantial number of debt-ridden firms lowers economic growth persistently. A debt restructuring policy or the relief of debt-ridden borrowers from excessive debt may be able to restore their efficiency and economic growth.
\end{abstract}

JEL Classification Numbers: E30, G01, O40

Keywords: borrowing constraint, debt overhang, debt supercycle, labor wedge, secular stagnation.

*Kobayashi: Faculty of Economics, Keio University, CIGS, and RIETI; Address: 2-15-45 Mita, Minatoku, Tokyo, 108-8345 Japan; E-mail: kobayasi@econ.keio.ac.jp; Phone: +81-3-5418-6703; FAX: +81-3-32171251. Shirai: The Canon Institute for Global Studies(CIGS); E-mail: shirai.daichi@gmail.com. Previous versions of this paper were circulated under the title "Debt-Ridden Borrowers and Productivity Slowdown." We thank Kosuke Aoki, Hiroki Arato, R. Anton Braun, Yasuo Hirose, Selahattin Imrohoroglu, Masaru Inaba, Nobuhiro Kiyotaki, Huiyu Li, Daisuke Miyakawa, Tsutomu Miyagawa, Kengo Nutahara, Ryoji Ohdoi, Vincenzo Quadrini, Yosuke Takeda, Ichihiro Uchida, Yuichiro Waki, and the seminar participants at the CIGS Conference on Macroeconomic Theory and Policy 2012, the 2012 JEA autumn meeting, Aichi University, the 2012 GRIPS macro conference, the Summer Workshop on Economic Theory (SWET 2015) at Otaru University of Commerce, the 11th Dynare conference, the 2015 JEA autumn meeting, 2016 AMES (Kyoto), 2016 ESEM (Geneva), the 18th Macro Conference (Osaka), 2017 CEF (New York), and 2017 EEA (Lisbon) for their insightful comments and valuable discussions. Kobayashi gratefully acknowledges the financial support from the JSPS Grant-in-Aid for Scientific Research (C) (No. 23330061) for the project "Analysis of dynamic models with systemic financial crises." All remaining errors are ours. 


\section{Introduction}

The decade after a financial crisis tends to be associated with low economic growth (Reinhart and Rogoff, 2009; Reinhart and Reinhart, 2010). A growing concern related to the economic slowdown after a financial crisis is secular stagnation (Summers, 2013; Eggertsson and Mehrotra, 2014). This situation occurred in the aftermath of the Great Recession of 2007-2012, causing concern that the US and European economies could stagnate persistently in the coming decades. It has also been pointed out that financial constraints were tightened both during and after the Great Recession (e.g., Altavilla, Darracq Paries and Nicoletti, 2015). However, which factors caused the tightening of these financial constraints and whether this tightening can cause a persistent slowdown in economic growth remain unclear.

In this study, we propose a theoretical model in which the buildup of debt tightens borrowing constraints and lowers growth persistently, even if there is no technology shock. Our theory demonstrates that inefficiency due to the buildup of debt can continue very persistently, which is rather consistent with the debt supercycle hypothesis (Rogoff, 2016; Lo and Rogoff, 2015), whereas existing theories of secular stagnation posit that a permanent or persistent technological shock causes persistent stagnation (see Eggertsson and Mehrotra, 2014; Gordon, 2012). Thus, our theory provides a rationale for heterodox policy recommendations to restore economic growth, that is, government interventions that facilitate partial debt forgiveness in the private sector (see Geanakoplos, 2014).

Recent empirical studies show that large corporate debt has a negative effect on GDP growth (e.g., Cecchetti, Mohanty and Zampolli, 2011; Mian, Sufi and Verner, 2017). Giroud and Mueller (2017) find that the establishments of more highly leveraged firms experienced larger employment losses during the Great Recession in the United States. Duval, Hong and Timmer (2017) also show that highly leveraged firms experienced large and persistent drops in total factor productivity (TFP) growth in the aftermath of the Great Recession. These results seem to be consistent with our hypothesis.

Our model of financial contracts is a version of those models with endogenous borrowing constraints in which the constraints arise due to borrowers' lack of commitment and lenders can choose whether to liquidate defaulting firms or to forgive them. The market is incomplete, and debt and equity are the only available financial instruments. Firms cannot relax the borrowing constraints by raising funds from outside investors because of market frictions that prevent them from issuing new equity quickly. There is a distinction between inter-period and intra-period loans in this economy. The borrowing constraint binds more tightly as the initial amount of inter-period debt increases. As the borrowing constraint tightens, firms cannot raise sufficient intra-period debt for working capital, which leads to inefficient production. When the initial amount of inter-period debt reaches the maximum 
sustainable amount, firms fall into a debt-ridden state in which they can repay only the interest even though they pay all of their income in each period. As a result, the amount of debt does not decrease. Therefore, debt-ridden firms continue inefficient production permanently (in the deterministic case). Moreover, when the initial debt exceeds a certain threshold, a firm may choose to increase borrowing and intentionally become debt-ridden because the gain from additional borrowing can exceed the inefficiency of the additional tightening of the borrowing constraint. This result implies that an overly indebted firm may rationally choose to become and, then, stay debt-ridden. Although our model is a simple modification of that of Jermann and Quadrini (2012), there is a significant difference in that the debt-ridden state arises naturally in our model, whereas it does not exist in Jermann and Quadrini (2012). This distinction is due to a slight difference in settings; a portion of output can serve as the collateral for borrowing in our model, whereas it cannot do so in Jermann and Quadrini's model.

We embed the model of firms' debt into a general equilibrium model of endogenous growth in which productivity grows as a result of firms' $R \& D$ activities. If a substantial number of firms become debt-ridden, their borrowing capacities decline persistently. Tighter borrowing constraints discourage firms' R\&D activities and, thus, the entries of new firms. Then, productivity stagnates persistently, as does the labor wedge. These features of our model seem to be consistent with the facts observed in persistent recessions after financial crises (see Section 2).

Our contribution to the literature is to show that a one-time buildup of debt can persistently tighten borrowing constraints and, thus, can cause aggregate inefficiency, even if there is no technological shock. In existing models, persistent recessions are usually caused by persistent shocks. See, for example, Christiano, Eichenbaum and Trabandt (2015) for the Great Recession, Cole and Ohanian (2004) for the Great Depression, and Kaihatsu and Kurozumi (2014) for the lost decade of Japan. In our study, the buildup of debt, which is a one-time shock, can change the economy persistently. Many authors have argued that persistent shocks that cause persistent recessions are exogenous changes in the financial technology parameters, such as the risk shock in Christiano, Motto and Rostagno (2014) and the financial shock in Jermann and Quadrini (2012). In this study, we consider that an exogenous one-time shock (i.e., a redistribution shock) increases debt substantially, redistributing wealth from borrowers to lenders, whereas there is no change in the structural parameters of financial technology. One example of such a redistribution shock is the boom and bust of the asset-price bubble, which changed the value of collateral for debt. The increase in the amount of debt tightens borrowing constraints persistently even though there is no technological change.

Thus, our model implies a policy recommendation distinct from those of most existing models, in which exogenous shocks on technological parameters cause persistent recessions 
and the policymaker can only mitigate the shocks by setting accommodative monetary and fiscal policies or by designing ex-ante financial regulations. In our model, debt restructuring or debt forgiveness for overly indebted borrowers restores aggregate efficiency and enhances economic growth. Note that restoring economic growth does not necessitate the physical liquidation of debt-ridden firms but rather their relief from excessive debt. This argument is in line with the policy recommendations of partial debt forgiveness by Geanakoplos (2014).

Intuitive example: To illustrate how persistent inefficiency can arise in our model, we consider a simple model of a firm that produces output $f(\sigma)$ from input $\sigma$, where $f^{\prime}(\sigma)>0$ and $f^{\prime \prime}(\sigma)<0$. The first best solution that maximizes the social surplus, $f(\sigma)-\sigma$, is attained by $\sigma^{*}$, where $\sigma^{*}$ solves $f^{\prime}(\sigma)=1$. This firm initially holds debt $b_{-1}$ and then borrows new debt $\frac{b}{R}$, where $R$ is the loan rate. Thus, the firm's cash flow is $\pi=f(\sigma)-\sigma-b_{-1}+\frac{b}{R}$. Here, we assume that $b_{-1}$ and $b$ are given exogenously, such that $\pi \geq 0$. The dividend $\pi$ cannot be negative because current equity-holders are protected by limited liability. The firm chooses $\sigma$ to maximize $f(\sigma)-\sigma$, subject to the borrowing constraint

$$
\sigma \leq \phi f(\sigma)+\max \left\{\xi S-\frac{b}{R}, 0\right\},
$$

where $\phi$ and $\xi S$ are constants that satisfy $0 \leq \phi<1$ and $\xi S>0$. This borrowing constraint is derived in Section 3. Considering the Lagrangean $\mathcal{L}(\sigma, \mu)=f(\sigma)-\sigma+$ $\mu\left[\phi f(\sigma)-\sigma+\max \left\{\xi S-\frac{b}{R}, 0\right\}\right]$, the first-order condition (FOC) is equal to

$$
f^{\prime}(\sigma)=\frac{1+\mu}{1+\phi \mu}
$$

When the Lagrange multiplier with respect to the borrowing constraint is positive $(\mu>0)$, the above FOC implies that $f^{\prime}(\sigma)>1$, which means that the input is smaller than $\sigma^{*}$ and production becomes inefficient. To make this example interesting, we assume that the constant $\xi S$ satisfies $\sigma^{*}<\phi f\left(\sigma^{*}\right)+\xi S$. If $\frac{b}{R}$ is smaller than $\xi S$, the borrowing constraint becomes

$$
\sigma \leq \phi f(\sigma)+\xi S-\frac{b}{R}
$$

This borrowing constraint is qualitatively similar to those in Jermann and Quadrini (2012) and Kiyotaki and Moore (1997). If $b$ is small, such that $0 \leq b \leq b^{*}$, where $b^{*}=\left[\phi f\left(\sigma^{*}\right)-\right.$ $\left.\sigma^{*}+\xi S\right] R$, then the first best outcome is achieved: $\sigma=\sigma^{*}$ and $\mu=0$. If $b^{*}<b<R \xi S$, the borrowing constraint binds tightly $(\mu>0)$ and production becomes inefficient. However, in the dynamic model, the firm repays as much of its debt as possible in order to reduce $b$ and to relax the borrowing constraint. Thus, when the borrowing constraint is (1), inefficiency is temporary. This result is similar to those of existing models. When debt $\frac{b}{R}$ 
is larger than $\xi S$, the borrowing constraint becomes

$$
\sigma \leq \phi f(\sigma)
$$

We define $\sigma_{z}$ as the solution to $\sigma=\phi f(\sigma)$. Assuming that $\phi$ is sufficiently small, we posit that $\sigma_{z}<\sigma^{*}$ and production is inefficient. The Lagrange multiplier $\mu_{z}$ is calculated from $f^{\prime}\left(\sigma_{z}\right)=\frac{1+\mu_{z}}{1+\phi \mu_{z}}(>1)$. Thus, we can show that inefficiency can continue permanently if $b_{-1}$ is sufficiently large, as follows. We define $b_{z}=\frac{f\left(\sigma_{z}\right)-\sigma_{z}}{1-\frac{1}{R}}$ and assume that $\frac{b_{z}}{R}>\xi S$. When the borrowing constraint is (2) (i.e., $\frac{b}{R}>\xi S$ ), the cash flow is $\pi=f\left(\sigma_{z}\right)-\sigma_{z}-b_{-1}+\frac{b}{R}$. The value of $b$ must satisfy $\pi \geq 0$. Suppose that $b_{-1}=b_{z}$. In this case, $b$ must be chosen such that $b \geq b_{z}$ in order to satisfy $\pi \geq 0$. Therefore, in the dynamic model, once the debt to be repaid in the current period $\left(b_{-1}\right)$ is equal to $b_{z}$, the debt to be repaid in the next period (b) must also be equal to $b_{z}$, and this chain continues forever. Then, the borrowing constraint continues to be (2), and production is permanently inefficient $\left(\sigma=\sigma_{z}\right)$. In summary, when $b_{-1}<b_{z}$, inefficiency continues temporarily, but it continues permanently if $b_{-1}=b_{z}$. Permanent inefficiency arises from the accumulation of debt, not from changes in financial or production technology. A caveat is that the constraint $\pi \geq 0$ is necessary for permanent inefficiency. This constraint means that equity finance from the incumbent firm-owner or outside investors is infeasible due to unspecified market frictions.

Related literature: Our theory is related to the literature on debt overhang, such as Myers (1977), Krugman (1988), and Lamont (1995). Debt overhang is an inefficiency that is typically due to coordination failure between incumbent lenders and new lenders, whereas inefficiency is generated in our model even though incumbent lenders also provide new money. Debt overhang typically causes inefficiency in the short run. However, in our study, inefficiency can continue permanently. Our study is also closely related to the work of Caballero, Hoshi and Kashyap (2008). They analyze "zombie lending," defined as the provision of a de facto subsidy from banks to unproductive firms, and they argue that congestion by zombie firms hinders the entry of more productive firms and lowers aggregate productivity. In this study, we make the complementary point to their argument that even an intrinsically productive firm can become unproductive when it is debt-ridden. This point results in a notably different policy implication. Caballero, Hoshi and Kashyap (2008) implied that the physical liquidation of zombie firms is desirable to restore a higher level of productivity. However, our theory implies that zombie firms can restore a high level of productivity if they are relieved of excessive debt. In the macroeconomic literature, endogenous borrowing constraints are introduced by the seminal work of Kiyotaki and Moore (1997). ${ }^{1}$ Then, the constraints in an economy where intra-period and inter-period

\footnotetext{
${ }^{1}$ Kobayashi and Shirai (2016) analyze the effects of wealth redistribution on an economy using a similar borrowing constraint model.
} 
loans exist are analyzed by Albuquerque and Hopenhayn (2004), Cooley, Marimon and Quadrini (2004), and Jermann and Quadrini (2006, 2007, 2012). The modeling method in this study is closest to that of Jermann and Quadrini (2012). Our model is also closely related to that of Kobayashi and Nakajima (2017), who analyze endogenous borrowing constraints and nonperforming loans (NPLs). Furthermore, our model is similar to that of Guerrón-Quintana and Jinnai (2014) in that a temporary shock persistently affects economic growth, although there is a significant difference in the policy implications. In our model, the emergence of debt-ridden borrowers due to a redistribution shock causes a persistent recession. Thus, debt restructuring (i.e., wealth redistribution from lenders to borrowers) restores aggregate efficiency. In contrast, debt restructuring has no effect in the model of Guerron-Quintana and Jinnai because, in their model, the financial crisis is caused by a shock to the parameters of financial technology. Another study closely related to ours is Ikeda and Kurozumi (2014). They build a medium-scale DSGE model with financial friction, à la Jermann and Quadrini (2012), and endogenous productivity growth, à la Comin and Gertler (2006). Their study is different from ours in that Ikeda and Kurozumi (2014) also posited a financial crisis as an exogenous technological shock.

The remainder of this paper is organized as follows. In the next section, we review the facts on persistent recessions after financial crises. Section 3 presents the partial equilibrium model of the lender-borrower relationship and analyzes the debt dynamics. In Section 4, we construct the full model by embedding the financial frictions of the previous section into an endogenous growth model, showing that stagnation can continue persistently when a substantial number of debt-ridden borrowers emerge. Section 5 presents our concluding remarks.

\section{Facts on persistent recessions after financial crises}

There exist numerous examples of decade-long stagnation after a financial crisis. The most notable episode was the Great Depression in the 1930s in the United States, along with the similar depressions during that period globally. Ohanian (2001) highlights the large productivity decline during the Great Depression in the US that is unexplained by usual demand-side factors, such as capital utilization and labor hoarding. Kehoe and Prescott (2007) draw attention to the fact that many countries have experienced decadelong recessions, which they call the "great depressions" of the 20th century. The studies presented in their book unanimously emphasize that declines in the growth rate of TFP were the primary causes of those great depressions.

A well-known example of a decade-long recession was the 1990s in Japan, during which the growth rates of GDP and TFP in the 1990s were both lower than those in the 1980s. The kink is apparent at the beginning of the 1990s, when huge asset-price bubbles 


\begin{tabular}{rrrr}
\hline & HP & KI & JIP2014 \\
\hline $1971-1980$ & 0.83 & & 2.04 \\
$1981-1990$ & 1.93 & 2.87 & 2.02 \\
$1991-2000$ & 0.36 & 0.58 & 0.03 \\
$2001-2005$ & & 0.90 & 1.39 \\
$2006-2011$ & & & -0.28 \\
\hline
\end{tabular}

Table 1: TFP growth rate in Japan

Note: HP, KI, and JIP2014 are taken from updated versions of Hayashi and Prescott (2002), Kobayashi and Inaba (2006) (revised data), and Fukao and Miyagawa (2008), respectively.

burst in the stock and real estate markets. Table 1 presents various estimates of the TFP growth rate in Japan. Hayashi and Prescott (2002) emphasizes that growth in TFP slowed in the 1990s. Kobayashi and Inaba (2006) confirm this result using the business cycle accounting method (Chari, Kehoe and McGrattan, 2007; see the last paragraph of this section). Fukao and Miyagawa (2008) estimates TFP using an industry-level data set called the Japan Industrial Productivity (JIP) database and confirms the substantial TFP slowdown in the 1990s.

One notable feature in the 1990s in Japan was the significant decrease in entry and the increase in exit of firms. Figure 1 compares the entry and exit of firms in Japan and in the United States. In the literature, the procyclicality of net entry is well known (Bilbiie, Ghironi and Melitz, 2012). Net entry also contributes significantly to TFP growth for US manufacturing establishments (Bartelsman and Doms, 2000). ${ }^{2}$

Another characteristic of Japan in the 1990s that may be related to the productivity slowdown was persistently lingering NPLs in the banking sector. NPLs represent the excess debt of non-financial firms, mainly in the real estate, wholesale, retail, and construction sectors. Figure 2 shows the NPLs in Japan from 1992 to 2012. The delayed disposal of huge NPLs was seen as a de facto subsidy to non-viable firms (i.e., zombie lending). This zombie lending is also considered to be the cause of Japan's persistent recession (Peek and Rosengren, 2005; Caballero, Hoshi and Kashyap, 2008).

A labor wedge reduction is also a characteristic of an economic slowdown in the aftermath of a financial crisis. Recently, a growing body of literature on business cycle accounting (Chari, Kehoe and McGrattan, 2007) has analyzed various episodes of business fluctuations, including decade-long stagnations. Business cycle accounting focuses on four wedges as the driving forces of business cycles: the efficiency wedge, the labor wedge, the investment wedge, and the government wedge. ${ }^{3}$ Chari, Kehoe and McGrattan

\footnotetext{
${ }^{2}$ Nishimura, Nakajima and Kiyota (2005) argues that the malfunctioning entry and exit contributed substantially to the fall in Japan's TFP in the late 1990s.

${ }^{3}$ The efficiency wedge is the observed TFP; the labor wedge, $1-\tau_{L}$, represents market frictions that
} 

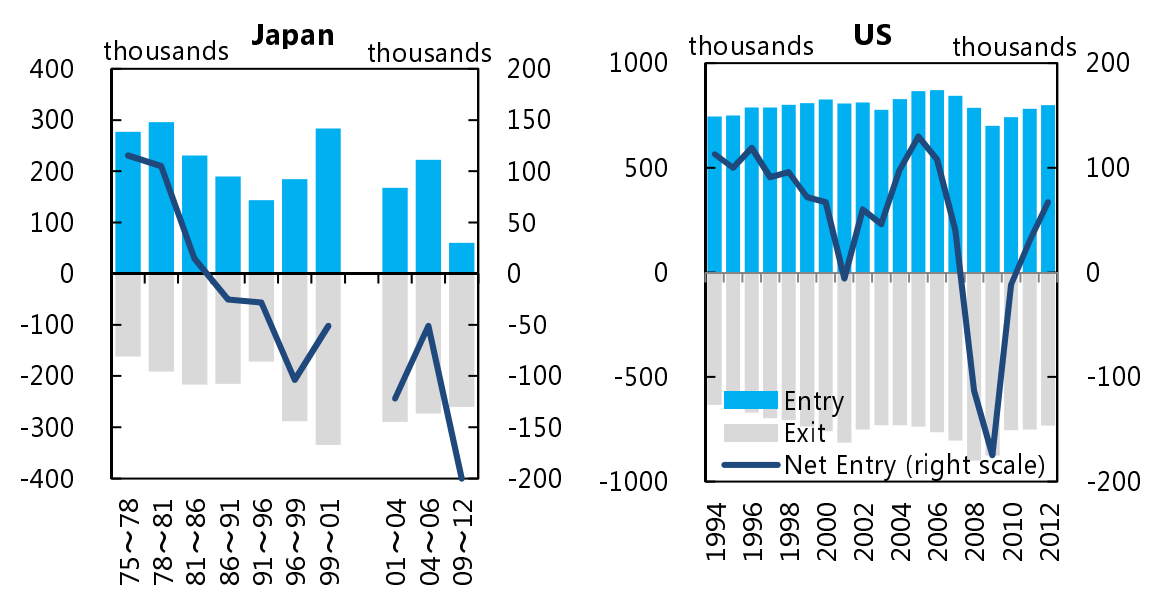

Figure 1: Entry and exit of private sector establishments: United States and Japan Note: Japan's figures after 2001 are based on the 1993-basis industry classification.

Sources: (Japan) Ministry of Internal Affairs and Communications, "Establishment and Enterprise Census;" (US) Bureau of Labor Statistics, "Business Employment Dynamics."

(2007) notes that reductions in the efficiency wedge and labor wedge were the two primary factors that drove the Great Depression of the 1930s. Kobayashi and Inaba (2006) and Otsu (2011) emphasize the same factors for the lost decade of Japan in the 1990s. The macroeconomic literature has recently focused considerable attention on the effects of a reduction in the labor wedge in recessions (see Mulligan, 2002; Shimer, 2009). A sharp decline in the labor wedge was also observed in the US economy during the financial crisis of 2007-2009 (Kobayashi, 2011; Pescatori and Tasci, 2011).

\section{A model of corporate debt with borrowing constraints}

In this section, we consider the partial equilibrium model of debt contracts. We derive the borrowing constraint and analyze the debt dynamics under exogenously given prices. We then embed this model into the endogenous growth model in Section 4.

\subsection{Setup}

Time is discrete and continues from zero to infinity: $t=0,1,2, \cdots, \infty$. There are three agents in this model: a bank (lender), a firm (borrower), and a household (worker). The main players are the bank and the firm; the household only supplies labor and capital at the market prices and buys consumer goods from the firm. The real prices $\left\{w_{t}, r_{t}^{K}, r_{t}, m_{t}\right\}$ are taken as given, where $w_{t}$ is the wage rate, $r_{t}^{K}$ is the rental rate of capital, $r_{t}$ is the inter-

manifest as an imaginary labor income tax with tax rate $\tau_{L}$ in a prototype real business cycle model; the investment wedge represents market frictions that manifest as an imaginary investment tax; and the government wedge is a deadweight loss that manifests as government consumption. 


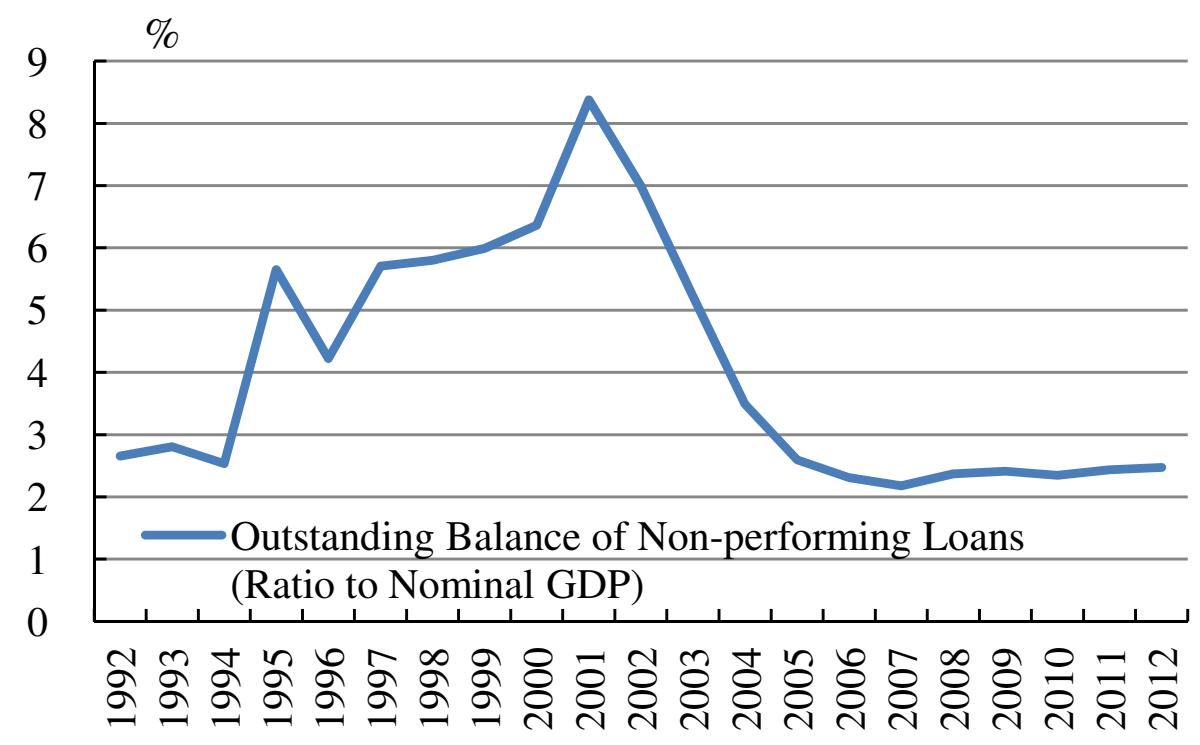

Figure 2: Development of NPLs

Note: These NPLs are the risk management loans defined in the Banking Act in Japan. They consist of loans to bankrupt borrowers, delayed loans, three-month overdue loans, and loans with modified terms and conditions. Risk management loans do not include securitized loans.

Sources: Financial Services Agency,Status of Non-Performing Loans; Cabinet Office, Government of Japan, Annual Report on National Accounts.

temporal rate of interest for safe assets, and $m_{t}$ is the stochastic discount factor. These prices are later determined in the general equilibrium model. The stochastic discount factor satisfies

$$
\frac{1}{1+r_{t}}=\mathbb{E}_{t} \frac{m_{t+1}}{m_{t}}
$$

where $\mathbb{E}_{t}$ is the expectation operator at $t$.

Consumer goods are produced by the firm from the labor and capital inputs. The firm's gross revenue in period $t$ is given by

$$
F\left(A_{t}, k_{t}, l_{t}\right)=A_{t} k_{t}^{\alpha \eta} l_{t}^{(1-\alpha) \eta}
$$

where $k_{t}$ and $l_{t}$ are the capital and labor inputs, respectively, chosen in period $t, A_{t}$ is a time-variant revenue parameter, and $0<\eta<1$. Firms use equity and debt, where debt is not state-contingent. We focus on the case with initial debt stock $b_{-1}$ at $t=0$, where $\frac{b_{-1}}{R_{-1}}$ is the amount of inter-period debt at the end of the previous period and $R_{t}$ is the gross rate of corporate loans. In this study, following Jermann and Quadrini (2012), we assume that firms hold inter-period debt because it offers tax advantages. ${ }^{4}$ Thus, $R_{t}$ is

\footnotetext{
${ }^{4}$ This assumption is a shortcut to formulate the motivation for holding debt. As is well known, with asymmetric information and costly state verification, the optimal contract does take the form of debt (e.g., Townsend, 1979; Gale and Hellwig, 1985).
} 
determined by

$$
R_{t}=1+(1-\tau) r_{t}
$$

where $\tau$ represents the tax benefit. The debt $\frac{b_{t-1}}{R_{t-1}}$ at the end of period $t-1$ grows at the gross rate $R_{t-1}$ to become $b_{t-1}$ at the beginning of period $t$. The amount of initial debt $b_{-1}$ is given as an exogenous shock in this model. This amount may be inefficiently large, as we see in the following sections. One explanation, which falls outside our model, for why $b_{-1}$ can be inefficiently large is as follows. The debt in this model can be interpreted as unsecured debt. Suppose that a firm puts up a valuable asset (e.g., real estate or corporate stocks) as collateral and the corporate debt $b_{-1}$ is initially completely secured by this collateral. Then, the asset price collapses in period 0 , when the financial crisis breaks out, and the value of the collateral asset decreases to, say, zero, meaning that $b_{-1}$ becomes unsecured debt. In this way, the asset-price collapse can generate the initial (unsecured) debt $b_{-1}$, which may be inefficiently large.

In period $t$, the firm employs labor $l_{t}$ and capital $k_{t}$ from the household to produce and sell consumer goods, and it earns revenue $F\left(A_{t}, k_{t}, l_{t}\right)=A_{t} k_{t}^{\alpha \eta} l_{t}^{(1-\alpha) \eta}$. The cost of the capital and labor inputs for the firm is

$$
\sigma_{t}=r_{t}^{K} k_{t}+w_{t} l_{t}
$$

The firm needs to borrow working capital, $\sigma_{t}$, from the bank as an intra-period loan and pay the household in advance of production. ${ }^{5}$ When production is completed, the firm receives revenue $F\left(A_{t}, k_{t}, l_{t}\right)$. Let us denote the exogenous state variables at $t$ by $x_{t}$. Here, $x_{t}=\left\{A_{t}, r_{t}^{K}, w_{t}, r_{t}, m_{t}\right\}$. We denote the space of $x_{t}$ by $\Lambda$ (i.e., $x_{t} \in \Lambda$ ). State $x_{t}$ follows a Markov process with the transition function $Q\left(x_{t}, d x_{t+1}\right)$. Thus, the expectation of a variable $q\left(x_{t}, x_{t+1}\right)$ is given by

$$
\mathbb{E}_{t}\left[q\left(x_{t}, x_{t+1}\right)\right] \equiv \int q\left(x_{t}, x_{t+1}\right) Q\left(x_{t}, d x_{t+1}\right) .
$$

We define $f\left(\sigma_{t}, x_{t}\right)$ by

$$
\begin{array}{r}
f\left(\sigma_{t}, x_{t}\right)=\max _{k, l} F\left(A_{t}, k, l\right), \\
\text { subject to } r_{t}^{K} k+w_{t} l \leq \sigma_{t} .
\end{array}
$$

\footnotetext{
${ }^{5}$ The reason that the firm does not use inter-period debt to finance working capital for production is the limited commitment due to agency problems. Suppose that the firm pays the wage for production in period $t+1$ in period $t$. In this case, the worker cannot commit to providing the labor input in period $t+1$. Suppose the firm saves a part of inter-period borrowing $\frac{b_{t}}{R_{t}}$ in the form of safe assets with the intention to use it in period $t+1$ for working capital. In this case, employees in the firm can easily steal and consume the safe asset privately in period $t$, and the firm cannot use it for working capital in period $t+1$.
} 
Thus, the solution implies

$$
f\left(\sigma_{t}, x_{t}\right)=A_{t}\left(\frac{\alpha}{r_{t}^{K}}\right)^{\alpha \eta}\left(\frac{1-\alpha}{w_{t}}\right)^{(1-\alpha) \eta} \sigma_{t}^{\eta} .
$$

The budget constraint for the firm is given by

$$
\pi_{t} \leq f\left(\sigma_{t}, x_{t}\right)-\sigma_{t}-b_{t-1}+\frac{b_{t}}{R_{t}}
$$

where $\pi_{t}$ is the payment to the firm's owner as a dividend. The payment of the intraperiod loan $\sigma_{t}=w_{t} l_{t}+r_{t}^{K} k_{t}$ is subject to the following borrowing constraint (derived in the next subsection):

$$
\sigma_{t} \leq \phi f\left(\sigma_{t}, x_{t}\right)+\max \left\{\xi S\left(x_{t}\right)-\frac{b_{t}}{R_{t}}, 0\right\}
$$

where $0 \leq \phi<1, \quad 0 \leq \xi \leq 1$, and $S\left(x_{t}\right)$ is defined by (7), which is the value that the lender can obtain by taking control of the firm. Throughout this analysis, we assume that

$$
\phi<\eta
$$

which means that production becomes inefficient when the borrowing constraint is $\sigma_{t} \leq$ $\phi f\left(\sigma_{t}\right)$. The firm's owner has no liquid assets in hand and is protected by limited liability, as in Albuquerque and Hopenhayn (2004). Therefore, the dividend must be non-negative:

$$
\pi_{t} \geq 0
$$

The firm cannot avoid the limited liability constraint (5) by soliciting equity investment from outside investors because of market frictions. The details of the market frictions are not specified in this analysis, and we simply assume that the firm cannot issue new equities in a timely manner, even if the new money can generate a positive surplus by relaxing the borrowing constraint, and even if outside investors are willing to buy new equities. This assumption can be justified by market frictions such as lack of commitment and asymmetric information. ${ }^{6}$

\footnotetext{
${ }^{6}$ The following are two examples of market frictions. The first example is lack of commitment. Suppose that the human capital of the firm's owner is indispensable to the firm's operations and that she cannot commit to pay the promised amount to the outside investors. In this case, the firm's owner renegotiates the payment down to zero after the outside investors provide additional money. Anticipating this outcome, outside investors do not invest in the firm. The second example is informational frictions, which are the same as in Kobayashi and Nakajima (2017). Suppose that the bargaining over the surplus between the firm and outside investors needs to be settled before the firm can issue new equities, and assume that this bargaining is associated with informational frictions à la Abreu and Gul (2000) that result in a prohibitively delayed settlement. Abreu and Gul (2000) show that if the two players in a Rubinstein-type bargaining game each suspect that their counter-party may be irrational, the bargaining experiences substantial delay.
} 
Now, we can describe the optimization problem for the firm. Denoting the value of the firm with debt stock $b_{t-1}$ at the beginning of period $t$ as $V\left(b_{t-1}, x_{t}\right)$, the firm's problem is written as the following Bellman equation:

$$
V\left(b_{t-1}, x_{t}\right)=\max _{b_{t}, \sigma_{t}, \pi_{t}} \pi_{t}+\mathbb{E}_{t}\left[\frac{m_{t+1}}{m_{t}} V\left(b_{t}, x_{t+1}\right)\right],
$$

subject to the budget constraint (3), borrowing constraint (4), limited liability constraint (5), and participation constraint of the bank (i.e., the no-Ponzi condition)

$$
b_{t} \leq b_{z}\left(x_{t}\right)
$$

where $\frac{b_{z}\left(x_{t}\right)}{R_{t}}$ is the upper limit of the amount that the bank agrees to lend in period $t$, given by (8) below.

Equilibrium condition: In the above problem (6), the firm takes $\left\{b_{z}\left(x_{t}\right), S\left(x_{t}\right)\right\}_{t=1}^{\infty}$ as given. In equilibrium, $S(x)$ is determined endogenously from the solution to the firm's problem. $S\left(x_{t}\right)$ is the maximum value that the bank can obtain from operating the seized firm by itself. Thus, in equilibrium, the following must be satisfied:

$$
S\left(x_{t}\right)=\max _{b} \mathbb{E}_{t}\left[\frac{m_{t+1}}{m_{t}} V\left(b, x_{t+1}\right)\right]+\frac{b}{R_{t}} .
$$

Upper limit of debt: The upper limit of debt $b_{z, t}=b_{z}\left(x_{t}\right)$ is the upper bound of repayable debt under any future realizations of the states $\left\{x_{t+j}\right\}_{j=1}^{\infty}$ given that $x_{t}$ is the current state. $^{7}$ We derive $b_{z}\left(x_{t}\right)$ on the premise that $\frac{b_{z}\left(x_{t}\right)}{R\left(x_{t}\right)}>\xi S\left(x_{t}\right)$, which is later justified by the parameter restriction (9). Under this assumption, the borrowing constraint becomes $r_{t}^{K} k_{t}+w_{t} l_{t} \leq \phi F\left(A_{t}, k_{t}, l_{t}\right)$ when the outstanding debt is $b_{z}\left(x_{t}\right)$. We define $\left\{k_{z, t}, l_{z, t}\right\}$ by

$$
\begin{aligned}
& \left\{k_{z, t}, l_{z, t}\right\}=\arg \max F\left(A_{t}, k_{t}, l_{t}\right) \\
& \text { subject to } r_{t}^{K} k_{t}+w_{t} l_{t}=\phi F\left(A_{t}, k_{t}, l_{t}\right),
\end{aligned}
$$

\footnotetext{
${ }^{7}$ When the amount of debt is larger than $\frac{b_{z, t}}{R_{t}}$, there is a positive probability of default. Thus, the bank agrees to lend only if the amount of debt is no greater than $\frac{b_{z, t}}{R_{t}}$ given that the loan rate is equal to the market rate for safe assets, $1+r_{t}$. In the general case, in which the loan rate can be set larger than $1+r_{t}$, the bank may agree to lend a larger amount than $\frac{b_{z, t}}{R_{t}}$ as long as the expected rate of return is no smaller than $1+r_{t}$. In this case, the upper limit of debt can be larger than $\frac{b_{z, t}}{R_{t}}$. However, even with a larger upper limit, the analyses and results in this study would not change qualitatively.
} 
and we define $\mu_{z, t}$ as the Lagrange multiplier associated with the above constraint. Since $F(A, k, l)=A k^{\alpha \eta} l^{(1-\alpha) \eta}$, these variables are given by

$$
\begin{aligned}
k_{z, t} & =\left[\phi A_{t}\left(\frac{1-\alpha}{w_{t}}\right)^{(1-\alpha) \eta}\left(\frac{\alpha}{r_{t}^{K}}\right)^{1-(1-\alpha) \eta}\right]^{\frac{1}{1-\eta}}, \\
l_{z, t} & =\left[\phi A_{t}\left(\frac{1-\alpha}{w_{t}}\right)^{1-\alpha \eta}\left(\frac{\alpha}{r_{t}^{K}}\right)^{\alpha \eta}\right]^{\frac{1}{1-\eta}}, \\
\mu_{z, t} & =\frac{\eta-\phi}{(1-\eta) \phi}
\end{aligned}
$$

We define $\sigma_{z, t}=\sigma_{z}\left(x_{t}\right)$ as the solution to $\sigma=\phi f\left(\sigma, x_{t}\right)$. Then, it is easily confirmed that

$$
\begin{aligned}
& \sigma_{z, t}=r_{t}^{K} k_{z, t}+w_{t} l_{z, t}, \\
& f\left(\sigma_{z, t}, x_{t}\right)=F\left(A_{t}, k_{z, t}, l_{z, t}\right) .
\end{aligned}
$$

Define, recursively, that for a given value of $x_{t-1}$,

$$
b_{z}\left(x_{t-1}\right)=\inf _{x_{t} \in \Lambda\left(x_{t-1}\right)}(1-\phi) f\left(\sigma_{z}\left(x_{t}\right), x_{t}\right)+\frac{b_{z}\left(x_{t}\right)}{R_{t}},
$$

where $\Lambda\left(x_{t-1}\right)$ is the domain for $x_{t}$ given that the state of time $t-1$ is $x_{t-1}$. If $\Lambda\left(x_{t-1}\right)=\Lambda$, then the upper limit is a constant (i.e., $b_{z}\left(x_{t-1}\right)=b_{z}$ ). If the condition

$$
\xi S\left(x_{t}\right)<\frac{b_{z}\left(x_{t}\right)}{R_{t}}, \text { for all } x_{t}, t
$$

is satisfied, then it is justified that $b_{z}\left(x_{t}\right)$ is truly the maximum repayable debt. To ensure the above condition, we assume the following restriction (9) on the parameters.

Definition 1. The first-best amount of input, $\sigma^{*}(x)$, is defined as the solution to

$$
\frac{\partial}{\partial \sigma} f(\sigma, x)=1
$$

The upper limit of the total surplus of the match between the bank and firm, given that the current state is $x$, is denoted by $\omega(x)$, for $x \in \Lambda$, and the unconditional upper limit is denoted by $\bar{\omega}$. These limits are defined as follows:

$$
\begin{aligned}
& \omega\left(x_{t}\right)=\left[1+\tau r\left(x_{t}\right)\right]\left\{f\left(\sigma^{*}\left(x_{t}\right), x_{t}\right)-\sigma^{*}\left(x_{t}\right)\right\}+\mathbb{E}_{t}\left[\frac{m_{t+1}}{m_{t}} \omega\left(x_{t+1}\right)\right], \\
& \bar{\omega} \equiv \sup _{x \in \Lambda} \omega(x) .
\end{aligned}
$$

Since the maximum amount of tax advantage is $\operatorname{\tau r}(x)\left\{f\left(\sigma^{*}(x), x\right)-\sigma^{*}(x)\right\}$, it is straightforward that $S(x) \leq \omega(x)$ because $S(x)$ is the value to the bank of operating the seized firm. Thus, we assume the following restriction on the parameter values:

$$
\xi \omega\left(x_{t}\right)<\frac{b_{z}\left(x_{t}\right)}{R_{t}}, \text { for all } x_{t} .
$$

This inequality ensures that the maximum repayable debt is strictly larger than the value that the bank can obtain by seizure. This result is because the bank can recover at most $\xi \omega\left(x_{t}\right)$ by seizure, where $\xi(<1)$ is the probability that the firm can be operated successfully by the bank. 
Technological difference between inter- and intra-period debt: We have the following difference between inter-period debt $b_{t-1}$ and intra-period debt $\sigma_{t}$. The firm has the chance to default on inter-period debt $b_{t-1}$ at the beginning of period $t$, and it will do so if and only if the continuation value of the firm is negative, $V\left(b_{t-1}, x_{t}\right)<0$. However, this outcome never occurs because, when $b_{t-1} \leq b_{z}\left(x_{t-1}\right)$, the firm's dividend is non-negative $\left(\pi\left(x_{t}\right) \geq 0\right)$, as is the continuation value $\left(V\left(b_{t-1}, x_{t}\right) \geq 0\right)$. Thus, as long as $b_{t-1} \leq b_{z}\left(x_{t-1}\right)$, the firm never defaults on inter-period debt $b_{t-1}$. The firm has the chance to default on intra-period debt $\sigma_{t}$ at the end of period $t$, which we analyze in the next subsection, in which the borrowing constraint (4) for $\sigma_{t}$ is given as the no-default condition. Thus, the firm does not default on $\sigma_{t}$ in equilibrium.

Timing of events: The events in a given period $t$ occur in the following way. The firm and bank enter period $t$ with outstanding debt of $b_{t-1} \cdot{ }^{8}$ At the beginning of the period, the firm has the chance to default on $b_{t-1}$, and it will do so if the continuation value is negative (which never happens, because $b_{t-1} \leq b_{z}\left(x_{t-1}\right)$ ). Then, the firm borrows intra-period debt $\sigma_{t}$, employs labor and capital by paying $\sigma_{t}$, and produces output $f\left(\sigma_{t}, x_{t}\right)$. The firm repays $b_{t-1}$ and borrows new inter-period debt $\frac{b_{t}}{R_{t}}$ by paying $b_{t-1}-\frac{b_{t}}{R_{t}}$. Finally, it repays the intraperiod debt $\sigma_{t}$ to the bank. At this point, the firm has the chance to default on $\sigma_{t}$. After repaying $\sigma_{t}$, the firm pays out the remaining amount, $\pi_{t}=f\left(\sigma_{t}, x_{t}\right)-\sigma_{t}-b_{t-1}+\frac{b_{t}}{R_{t}}$, to the firm owner as a dividend.

\subsection{Derivation of the borrowing constraint}

In this subsection, we describe the events that follow a counterfactual default on $\sigma_{t}$ and derive the borrowing constraint (4) as the no-default condition. The argument here is similar to that of Jermann and Quadrini (2012).

As described in the previous subsection, the firm owes inter-period debt $\frac{b_{t}}{R_{t}}$ and intraperiod debt $\sigma_{t}$ at the end of period $t$, where $b_{t}$ is to be repaid in period $t+1$ and $\sigma_{t}$ is to be repaid in period $t$. At the end of period $t$, the firm has the chance to default on $\sigma_{t}$.

Now, we consider what would happen if the firm defaults on $\sigma_{t}$. Once the firm defaults, the bank unilaterally seizes a part of the firm's revenue, $\phi f\left(\sigma_{t}, x_{t}\right)$, where $0 \leq \phi<1 .^{9}$ The

\footnotetext{
${ }^{8}$ More accurately, the firm owes $\left(1+r_{t-1}\right) \frac{b_{t-1}}{R_{t-1}}$ to the bank. Hence, the firm has to pay this amount to the bank, whereas it obtains a transfer from the government as a tax advantage, amounting to $\tau r_{t-1} \frac{b_{t-1}}{R_{t-1}}$. Thus, the net payment by the firm is $\left(1+r_{t-1}\right) \frac{b_{t-1}}{R_{t-1}}-\tau r_{t-1} \frac{b_{t-1}}{R_{t-1}}=b_{t-1}$.

${ }^{9}$ Because the firm has paid $b_{t-1}-\frac{b_{t}}{R_{t}}$, the remaining value of the resources it possesses is $f\left(\sigma_{t}, x_{t}\right)-$ $b_{t-1}+\frac{b_{t}}{R_{t}}$ after defaulting on $\sigma_{t}$. Thus, if the bank were to seize $\phi f(\sigma, x)$ from the remaining output only, then the seizure should have been feasible only if$$
\phi f\left(\sigma_{t}, x_{t}\right) \leq f\left(\sigma_{t}, x_{t}\right)-b_{t-1}+\frac{b_{t}}{R_{t}} .
$$

However, we assume that the bank can take $\phi f(\sigma, x)$ from the firm owner's pocket and not just from the remaining output of the firm. Because the firm owner does not have liquid assets in hand, the bank may
} 
seized amount, $\phi f\left(\sigma_{t}, x_{t}\right)$, may be interpreted as a collateral that the bank can legitimately seize when the firm defaults. Then, the firm and bank renegotiate over the conditions for the firm to continue to operate. Following Jermann and Quadrini (2012), we assume that the firm has all of the bargaining power in the renegotiation. At this stage, the bank has acquired the right to liquidate the firm. Here, liquidation is the bank's taking control of the firm. When the bank chooses liquidation, it successfully operates the firm by itself and recovers value $S_{t}$ with probability $\xi$, whereas the firm is destroyed with probability $1-\xi$. Thus, the expected value that the bank can obtain by liquidation is $\xi S_{t}$. In contrast, if the bank decides to allow the firm to continue to operate, it can recover its inter-period debt in the next period, the present value of which is $\frac{b_{t}}{R_{t}}$. The renegotiation agreement depends on whether $\xi S_{t}$ is larger or smaller than $\frac{b_{t}}{R_{t}}$.

- Case where $\xi S_{t}>\frac{b_{t}}{R_{t}}$ : The firm has to make a payment that leaves the bank indifferent between liquidation and allowing the firm to continue to operate. Thus, the firm has to make payment $\xi S_{t}-\frac{b_{t}}{R_{t}}$ and promise to pay $\left(1+r_{t}\right) \frac{b_{t}}{R_{t}}$ at the beginning of the next period. Therefore, the ex-post default value for the firm is

$$
(1-\phi) f\left(\sigma_{t}, x_{t}\right)-b_{t-1}+\frac{b_{t}}{R_{t}}-\left\{\xi S\left(x_{t}\right)-\frac{b_{t}}{R_{t}}\right\}+\mathbb{E}_{t}\left[\frac{m_{t+1}}{m_{t}} V\left(b_{t}, x_{t+1}\right)\right] .
$$

- Case where $\xi S_{t} \leq \frac{b_{t}}{R_{t}}$ : In this case, the optimal choice for the bank is to wait until the next period, when $\left(1+r_{t}\right) \frac{b_{t}}{R_{t}}$ is due. In period $t$, the bank receives no further payments. Thus, the ex-post default value is

$$
(1-\phi) f\left(\sigma_{t}, x_{t}\right)-b_{t-1}+\frac{b_{t}}{R_{t}}+\mathbb{E}_{t}\left[\frac{m_{t+1}}{m_{t}} V\left(b_{t}, x_{t+1}\right)\right] .
$$

Therefore, the default value is expressed as

$$
(1-\phi) f\left(\sigma_{t}, x_{t}\right)-b_{t-1}+\frac{b_{t}}{R_{t}}-\max \left\{\xi S\left(x_{t}\right)-\frac{b_{t}}{R_{t}}, 0\right\}+\mathbb{E}_{t}\left[\frac{m_{t+1}}{m_{t}} V\left(b_{t}, x_{t+1}\right)\right] .
$$

Enforcement requires that the value of not defaulting is no smaller than the value of defaulting, that is,

$$
f\left(\sigma_{t}, x_{t}\right)-b_{t-1}+\frac{b_{t}}{R_{t}}-\sigma_{t} \geq(1-\phi) f\left(\sigma_{t}, x_{t}\right)-b_{t-1}+\frac{b_{t}}{R_{t}}-\max \left\{\xi S\left(x_{t}\right)-\frac{b_{t}}{R_{t}}, 0\right\},
$$

which can be rearranged as (4).

not be able to collect $\phi f(\sigma, x)$ immediately, whereas it can recover this present value from the firm owner's illiquid assets within some finite periods. Thus, in this study, we assume that the bank seizure is not constrained by (10). 


\subsection{Equilibrium debt dynamics}

In this subsection, for a given variable $q_{t}$, we denote the variables in the previous period, in the current period, and in the next period by $q_{-1}, q$, and $q_{+1}$, respectively. Here, we characterize the equilibrium path that solves (6), taking $S(x)$ as given exogenously. We prove the existence of the equilibrium that satisfies (7) in Section 3.4. First, we show the existence of the solution to (6) given exogenous $S(x)$. Let $G$ be the following closed, bounded, and convex set of non-negative continuous functions, $S\left(x_{t}\right)$ :

$$
G=\{S(x) \mid 0 \leq S(x) \leq \bar{\omega}, x \in \Lambda, S(x) \in C(\Lambda)\}
$$

Proposition 1. Let $S(x)(\in G)$ be given exogenously. There exists a solution $V(b, x ; S)$ to the Bellman equation (6), and $V(b, x ; S)$ is continuous in $(b, x)$.

The proof is omitted because this proposition follows directly from Theorem 9.6 in Stokey and Lucas with Prescott (1989). ${ }^{10}$

In what follows, we assume the following two assumptions hold.

Assumption 1. The parameters satisfy the following condition:

$$
\xi \bar{\omega}<\frac{(1-\phi) \underline{\mathrm{f}}_{z}}{r_{\max }},
$$

where $\underline{\mathrm{f}}_{z} \equiv \inf _{x \in \Lambda} f\left(\sigma_{z}(x), x\right)$ and $r_{\max } \equiv \sup _{x \in \Lambda} r(x)$.

This assumption implies that once the amount of debt $\frac{b_{t}}{R_{t}}$ becomes smaller than $\xi \bar{\omega}$, it can reach the constrained-efficient level $b^{c e}(x)$ (defined below) within a finite number of periods. This implication is because the firm can repay at least $\frac{(1-\phi) \underline{\underline{f}}_{z}}{r_{\max }}$ by paying all income to the bank in all future periods. Define

$$
\mu^{c e}(x) \equiv \frac{\tau r(x)}{1+r(x)} .
$$

Then, $\sigma^{c e}(x)$ is defined as the solution to

$$
\frac{\partial}{\partial \sigma} f(\sigma, x)=\frac{1+\mu^{c e}(x)}{1+\phi \mu^{c e}(x)} .
$$

Define $b^{c e}(x ; S)$, where $S=S(x)$, by

$$
\frac{b^{c e}(x ; S)}{R(x)} \equiv \phi f\left(\sigma^{c e}(x), x\right)-\sigma^{c e}(x)+\xi S(x) .
$$

${ }^{10}$ To see that Theorem 9.6 in Stokey and Lucas with Prescott (1989) is applicable to the problem in (6), it is useful to change the variables by $\tilde{m}_{t} \equiv \beta^{-t} m_{t}$ and $\tilde{V}\left(b_{t-1}, x_{t}\right) \equiv \tilde{m}_{t} V\left(b_{t-1}, x_{t}\right)$. The Bellman equation (6) can be rewritten as

$$
\tilde{V}\left(b_{t-1}, x_{t}\right)=\max _{b_{t}, \sigma_{t}, \pi_{t}} \tilde{m}_{t} \pi_{t}+\beta \mathbb{E}_{t}\left[\tilde{V}\left(b_{t}, x_{t+1}\right)\right],
$$

subject to the same constraints. Assumptions 9.4-9.7 in Stokey and Lucas with Prescott (1989) are clearly satisfied in this problem, which allows their Theorem 9.6 to apply. 
Assumption 2. The parameters satisfy the following conditions:

$$
\sup _{x \in \Lambda} \phi f\left(\sigma^{c e}(x), x\right)-\sigma^{c e}(x)<0
$$

such that $\frac{b^{c e}(x ; S)}{R(x)}<\xi S(x)$ for all $x$, and

$$
\inf _{x, x_{-1} \in \Lambda, S \in G}\left[f\left(\sigma^{c e}(x), x\right)-\sigma^{c e}(x)-b^{c e}\left(x_{-1} ; S\right)+\frac{b^{c e}(x ; S)}{R(x)}\right]>0 .
$$

The first condition of this assumption is satisfied for a small $\tau .{ }^{11}$ The second condition of this assumption implies that once the economy enters the constrained-efficient equilibrium, it stays there forever. Constrained efficiency is defined and explained in Section 3.3.2. We define the total surplus of the match of the firm and bank, $W\left(b_{-1}, x\right)$, as

$$
W\left(b_{-1}, x\right)=\frac{1+r_{-1}}{R_{-1}} b_{-1}+V\left(b_{-1}, x\right) .
$$

Note that the bank receives $\frac{1+r_{-1}}{R_{-1}} b_{-1}$ from the firm, whereas the net payment for the firm is $b_{-1}$, because the government gives a tax advantage $\frac{\tau r_{-1}}{R_{-1}} b_{-1}$ to the firm. Thus, the firm's problem is equivalent to maximizing $W\left(b_{-1}, x\right)$ given $b_{-1}$. Function $W\left(b_{-1}, x\right)$ satisfies the following dynamic programming equation:

$$
\begin{aligned}
W\left(b_{-1}, x\right)= & \max _{\sigma, b} \frac{r_{-1} \tau}{R_{-1}} b_{-1}+f(\sigma, x)-\sigma+\mathbb{E}\left[\frac{m_{+1}}{m} W\left(b, x_{+1}\right)\right], \\
\text { subject to } & f(\sigma, x)-\sigma-b_{-1}+\frac{b}{R} \geq 0, \\
& \sigma \leq \phi f(\sigma, x)+\max \left\{\xi S(x)-\frac{b}{R}, 0\right\} \\
& b \leq b_{z}(x) .
\end{aligned}
$$

By denoting the Lagrange multipliers for (12), (13), and (14) as $\lambda_{\pi}, \mu$, and $\nu$, respectively, the FOCs and envelope condition are

$$
\begin{aligned}
& \frac{\partial}{\partial \sigma} f(\sigma, x)=\frac{1+\frac{\mu}{1+\lambda_{\pi}}}{1+\phi \frac{\mu}{1+\lambda_{\pi}}}, \\
& \begin{cases}R \mathbb{E}\left[\frac{m_{+1}}{m} \frac{\partial}{\partial b} W\left(b, x_{+1}\right)\right]+\lambda_{\pi}-\nu-\mu=0, & \text { if } \xi S(x) \geq \frac{b}{R}, \\
R \mathbb{E}\left[\frac{m_{+1}}{m} \frac{\partial}{\partial b} W\left(b, x_{+1}\right)\right]+\lambda_{\pi}-\nu=0, & \text { if } \xi S(x)<\frac{b}{R},\end{cases} \\
& \frac{\partial}{\partial b} W\left(b_{-1}, x\right)=\frac{r_{-1} \tau}{R_{-1}}-\lambda_{\pi} .
\end{aligned}
$$

The equilibrium values of the five endogenous variables $\left\{\sigma, b, \lambda_{\pi}, \mu, \nu\right\}$, and $\frac{\partial}{\partial b} W\left(b_{-1}, x\right)$ are determined by the constraints (12)-(14) and the conditions (15)-(17).

\footnotetext{
${ }^{11}$ In the steady state, where the state is time-invariant, this condition is equivalent to $\frac{\tau r}{1+r}<\frac{\eta-\phi}{(1-\eta) \phi}$.
} 


\subsubsection{Special case with $\tau=0$}

In the special case in which $\tau=0$, the firm is indifferent between debt and equity as a tool for funding as long as the amount of debt is sufficiently small that the borrowing constraint is non-binding. When $\tau=0$, the variables satisfy $\sigma^{c e}(x)=\sigma^{*}(x)$ and $b^{c e}(x)=b^{*}(x)$ in Assumption 2, which implies that once the economy enters the first-best equilibrium, where $\left\{\sigma_{t}, b_{t}\right\}=\left\{\sigma^{*}\left(x_{t}\right), b^{*}\left(x_{t}\right)\right\}$, it stays there forever: $\left\{\sigma_{t+j}, b_{t+j}\right\}=\left\{\sigma^{*}\left(x_{t+j}\right), b^{*}\left(x_{t+j}\right)\right\}$, for all $j \geq 1$. This result is because for any $b^{*}\left(x_{-1}\right)$, the firm can choose $\sigma=\sigma^{*}(x)$ because $\pi$ can be non-negative when it chooses $\sigma=\sigma^{*}(x)$ for all $x \in \Lambda\left(x_{-1}\right)$.

We define $W^{*}(x), b^{*}(x ; S), B^{*}(x ; S), B_{z}(x ; S)$, and $\bar{B}_{z}(x)$ by

$$
\begin{aligned}
& W^{*}(x) \equiv f\left(\sigma^{*}(x), x\right)-\sigma^{*}(x)+\mathbb{E}\left[\frac{m_{+1}}{m} W^{*}(x+1)\right], \\
& \frac{b^{*}(x ; S)}{R(x)} \equiv \phi f\left(\sigma^{*}(x), x\right)-\sigma^{*}(x)+\xi S(x), \\
& B^{*}(x ; S) \equiv f\left(\sigma^{*}(x), x\right)-\sigma^{*}(x)+\frac{b^{*}(x ; S)}{R(x)}, \\
& B_{z}(x ; S) \equiv f\left(\sigma_{z}(x), x\right)-\sigma_{z}(x)+\xi S(x), \\
& \bar{B}_{z}(x) \equiv f\left(\sigma_{z}(x), x\right)-\sigma_{z}(x)+\frac{b_{z}(x)}{R(x)}
\end{aligned}
$$

The meanings of the above variables are as follows: $W^{*}(x)$ is the first-best value of the match between the bank and firm in the case where $\tau=0 ; b^{*}\left(x_{t}\right)$ is the maximum amount of debt $b_{t}$ that is feasible in the first-best equilibrium, where $\sigma_{t}=\sigma^{*}\left(x_{t}\right) ; B^{*}\left(x_{t} ; S\right)$ is the maximum amount of debt $b_{t-1}$ repayable in the first-best equilibrium where $\sigma_{t}=\sigma^{*}\left(x_{t}\right)$; $B_{z}\left(x_{t} ; S\right)$ is the minimum amount of debt $b_{t-1}$ that makes $\frac{b_{t}}{R_{t}} \geq \xi S\left(x_{t}\right)$; and $\bar{B}_{z}\left(x_{t}\right)$ is the maximum amount of debt $b_{t-1}$ repayable with certainty given that the current state in period $t$ is $x_{t}$. A capital $B$ is used to represent the threshold of debt.

In the case where $\tau=0$, the equilibrium dynamics are qualitatively the same as those in Albuquerque and Hopenhayn (2004). We can show the following lemma, which is equivalent to Lemma 1 in Albuquerque and Hopenhayn (2004). The difference is that the debt in our model is not state-contingent, whereas it is state-contingent in their model.

Lemma 2. For a given state $x$,

(i) $W\left(b_{-1}, x\right)$ is weakly decreasing in $b_{-1}$.

(ii) For all $b_{-1} \leq B^{*}(x ; S), W\left(b_{-1}, x\right)=W^{*}(x)$.

(iii) For all $b_{-1}>B^{*}(x ; S), W\left(b_{-1}, x\right)<W^{*}(x)$ and $\pi=0$.

The proof is given in Appendix A. This lemma implies that if $b_{-1}>B^{*}(x ; S)$, then the firm repays as much debt as possible by setting the dividend to zero: $\pi=0$. This firm's behavior is the same as that in Albuquerque and Hopenhayn (2004). If $b_{-1}>B_{z}(x ; S)$, 
then $\sigma=\sigma_{z}(x)$, where $\sigma_{z}(x)$ is the solution to $\sigma=\phi f(\sigma, x)$. Now, we turn to the general case where $\tau>0$.

\subsubsection{Case with $\tau>0$}

The features of the equilibrium path in the case where $\tau>0$ are characterized by the initial amount of inter-period debt $b_{-1}$. We define

$$
B^{c e}(x ; S) \equiv f\left(\sigma^{c e}(x), x\right)-\sigma^{c e}(x)+\frac{b^{c e}(x ; S)}{R(x)} .
$$

Note that the definition of $b^{c e}(x ; S)$ implies that $B^{c e}(x ; S)=(1-\phi) f\left(\sigma^{c e}(x), x\right)+\xi S(x)$. Thus, the definition of $\sigma_{z}(x)$ and (9) imply that

$$
B^{c e}(x ; S)<B_{z}(x ; S)<b_{z}(x) .
$$

Constrained-efficient equilibrium with small debt: We focus on the case where initial debt $b_{-1}$ is sufficiently small (i.e., $b_{-1}<B^{c e}(x ; S)$ ). In this case, the borrowing constraint is written as

$$
\sigma \leq \phi f(\sigma, x)+\xi S(x)-\frac{b}{R}
$$

When $\mu>0$, the FOCs imply that $\frac{\partial}{\partial k} F(A, k, l)>r^{K}$ and $\frac{\partial}{\partial l} F(A, k, l)>w$. It immediately follows that inputs $k$ and $l$ are inefficiently smaller than their efficient levels, $k^{*}$ and $l^{*}$, which are given by $\frac{\partial}{\partial k} F\left(A, k^{*}, l^{*}\right)=r^{K}$ and $\frac{\partial}{\partial l} F\left(A, k^{*}, l^{*}\right)=w$, respectively. Note that the borrowing constraint is always binding (i.e., $\mu>0$ ) because the firm borrows intertemporal debt to exploit the tax advantage. We call the equilibrium constrained-efficient if $\lambda_{\pi, t}=\nu_{t}=0$ for all $t$. We assume and justify later that $\lambda_{\pi}=\lambda_{\pi,+1}=\nu=0$ when $b_{-1}<B^{c e}(x ; S)$. In this case, conditions (15)-(17) imply $\mathbb{E}\left[\frac{m_{+1}}{m}\right] \frac{r \tau}{R}=\frac{\mu}{R}$, which can be rewritten as $\mu=\mu^{c e}(x)$. Therefore, the tightness of the borrowing constraint (13) (or (19)) in the constrained-efficient equilibrium, $\mu^{c e}(x)$, is not dependent on $b_{-1}$ and is decided solely by the tax advantage. Therefore, the value of $\sigma$ in the constrainedefficient equilibrium, $\sigma^{c e}(x)$, is also independent of $b_{-1}$. The value of $b$ should be $b^{c e}(x ; S)$. Note that Assumption 2 guarantees that once the economy enters the constrained-efficient equilibrium, it stays there forever. This result is because, for any $b^{c e}\left(x_{-1} ; S\right)$, the firm can choose $\sigma=\sigma^{c e}(x)$ because $\pi$ can be non-negative when it chooses $\sigma=\sigma^{c e}(x)$ for all $x \in \Lambda\left(x_{-1}\right)$. Thus, our assumption that $\lambda_{\pi}=\lambda_{\pi,+1}=\nu=0$ is justified.

Medium-sized debt: Consider the case where initial debt $b_{-1}$ is medium-sized (i.e., $\left.B^{c e}(x ; S) \leq b_{-1}<B_{z}(x ; S)\right)$. In this case, the borrowing constraint is still (19). We focus on the cases in which the parameter values are chosen such that $\nu=0$ in equilibrium when $b_{-1}$ is medium-sized. ${ }^{12}$ Then, we have the following lemma.

\footnotetext{
${ }^{12} \nu=0$ holds if the parameters satisfy $(21)$.
} 
Lemma 3. Consider the case where $b_{-1}$ is medium-sized and $\sigma<\sigma^{c e}(x)$ in equilibrium. Then, $\lambda_{\pi}>0$, and the dividend is equal to zero, $\pi=0$, in equilibrium.

Proof. The proof is by contradiction. Suppose that $\lambda_{\pi}=0$. Then, conditions (16) and (17) imply that $\mu=R \mathbb{E}\left[\frac{m_{+1}}{m}\left(\frac{r \tau}{R}-\lambda_{\pi+1}\right)\right] \leq \frac{r \tau}{1+r}=\mu^{c e}$, which, together with (15), implies that $\sigma \geq \sigma^{c e}(x)$. This is a contradiction. Thus, $\lambda_{\pi}=0$ cannot hold in equilibrium. Hence, $\lambda_{\pi}>0$ and $\pi=0$ in equilibrium.

The values of $\{k, l, b, \mu\}$ are determined by the budget constraint (3) with $\pi=0$, the borrowing constraint (19), the FOC (15), and

$$
\frac{k}{l}=\left(\frac{\alpha}{1-\alpha}\right) \frac{w}{r^{K}},
$$

where the last equation is derived from the conditions for $k$ and $l$ to maximize $F(A, k, l)$ subject to $r^{K} k+w l \leq \sigma$. Given that the outstanding debt $b_{-1}$ is medium-sized, the firm repays as much debt as possible by setting $\pi=0$ and eventually returns to the constrained-efficient equilibrium. Assumption 1 implies that it takes a finite number of periods to return to the constrained-efficient equilibrium. These features are qualitatively the same as those of debt repayment in Albuquerque and Hopenhayn (2004).

Large debt: $\quad$ If $b_{-1} \geq B_{z}(x)$, the borrowing constraint becomes

$$
\sigma \leq \phi f(\sigma, x)
$$

Then, the FOC (16) implies

$$
\mathbb{E}\left[\frac{m_{+1}}{m} \frac{\partial}{\partial b} W\left(b, x_{+1}\right)\right]=\frac{\nu-\lambda_{\pi}}{R} .
$$

It immediately follows that

- If $\lambda_{\pi}>0$, then $\pi=0, b=R\left\{b_{-1}-f\left(\sigma_{z}(x), x\right)+\sigma_{z}(x)\right\}$, and $\nu=0$.

- If $\nu>0$, debt jumps to the upper limit (i.e., $\left.b=b_{z}(x)\right), \lambda_{\pi}=0$, and $\pi>0$.

Note that although the FOCs should be satisfied at the solution, the choice between $b=R\left\{b_{-1}-f\left(\sigma_{z}(x), x\right)+\sigma_{z}(x)\right\}$ and $b=b_{z}(x)$ cannot be determined by the FOCs alone because they are the local maxima. The firm compares the total surplus when $b=R\left\{b_{-1}-f\left(\sigma_{z}(x), x\right)+\sigma_{z}(x)\right\}$ and that when $b=b_{z}(x)$ and then chooses the higher surplus. Define $W^{(1)}\left(b_{-1}, x\right)$ and $W^{(2)}\left(b_{-1}, x\right)$ by

$$
\begin{aligned}
W^{(1)}\left(b_{-1}, x\right) & =\frac{\tau r_{-1}}{R_{-1}} b_{-1}+f\left(\sigma_{z}(x), x\right)-\sigma_{z}(x)+\mathbb{E}\left[\frac{m_{+1}}{m} W\left(b_{z}(x), x_{+1}\right)\right], \\
W^{(2)}\left(b_{-1}, x\right) & =\frac{\tau r_{-1}}{R_{-1}} b_{-1}+f\left(\sigma_{z}(x), x\right)-\sigma_{z}(x)+\mathbb{E}\left[\frac{m_{+1}}{m} W\left(R\left\{b_{-1}-f\left(\sigma_{z}, x\right)+\sigma_{z}\right\}, x_{+1}\right)\right] .
\end{aligned}
$$


Here, $W^{(1)}\left(b_{-1}, x\right)$ is the total surplus when the firm chooses $b=b_{z}(x)$ and $W^{(2)}\left(b_{-1}, x\right)$ is that when the firm chooses $b=R\left\{b_{-1}-f\left(\sigma_{z}(x), x\right)+\sigma_{z}(x)\right\}$. Then, $W\left(b_{-1}, x\right)$ is given by

$$
W\left(b_{-1}, x\right)=\max \left\{W^{(1)}\left(b_{-1}, x\right), W^{(2)}\left(b_{-1}, x\right)\right\} .
$$

We assume that the values of the parameters are chosen such that

$$
W^{(1)}\left(B_{z}(x ; S), x\right)<W^{(2)}\left(B_{z}(x ; S), x\right), \quad \text { for all } x .
$$

By definition of $\bar{B}_{z}(x)$, the following equality holds:

$$
W^{(1)}\left(\bar{B}_{z}(x), x\right)=W^{(2)}\left(\bar{B}_{z}(x), x\right), \quad \text { for all } x .
$$

Then, the following lemma holds.

Lemma 4. There exist $\underline{B}_{c}(x ; S)$ and $\bar{B}_{c}(x ; S)$ such that $B_{z}(x ; S)<\underline{B}_{c}(x ; S) \leq \bar{B}_{c}(x ; S) \leq$ $\bar{B}_{z}(x)$ and

- If $b_{-1} \in\left[B_{z}(x ; S), \underline{B}_{c}(x ; S)\right)$, then $W^{(1)}\left(b_{-1}, x\right)<W^{(2)}\left(b_{-1}, x\right), \pi=0$, and $b=$ $R\left\{b_{-1}-f\left(\sigma_{z}(x), x\right)+\sigma_{z}(x)\right\}$.

- If $b_{-1} \in\left[\bar{B}_{c}(x ; S), \bar{B}_{z}(x)\right]$, then $W^{(1)}\left(b_{-1}, x\right) \geq W^{(2)}\left(b_{-1}, x\right)$ and $b=b_{z}(x)$.

Proof. The lemma follows immediately from the continuity of $W^{(1)}\left(b_{-1}, x\right)$ and $W^{(2)}\left(b_{-1}, x\right)$ together with (21) and (22).

In the general case with stochastic shocks, we can only say that $\bar{B}_{c}(x ; S) \leq \bar{B}_{z}(x)$, whereas, in the deterministic case, where $x_{t}$ evolves deterministically, it is shown that $\bar{B}_{c, t}<\bar{B}_{z, t}$. Thus, the firm intentionally increases borrowing to $b_{z, t}$ when outstanding debt $b_{t-1}$ is sufficiently large, such that $\bar{B}_{c, t} \leq b_{t-1}<\bar{B}_{z, t}$.

Debt-ridden firms: A debt-ridden firm is defined as a firm with outstanding debt $b_{t-1}=b_{z}\left(x_{t-1}\right)$. From the definition of $b_{z}\left(x_{t}\right)$, the borrowing constraint is (20) for all $t$ in the case where $x_{t}$ evolves deterministically. In the case where $x_{t}$ evolves stochastically, there may be a nonzero probability with which the firm repays its debt and eventually returns to the constrained-efficient equilibrium.

\subsection{Existence of an equilibrium}

We show that there exists an equilibrium in which the firm solves (6) and the equilibrium condition (7) is satisfied. We need the following restriction on the parameters.

Assumption 3. The values of the parameters satisfy

$$
\frac{\eta}{2-\eta}<\phi
$$


and

$$
\inf _{x \in \Lambda}(1-\phi) f\left(\sigma_{z}(x), x\right)>\nabla
$$

where $\nabla$ is defined by

$$
\nabla=\sup _{x \in \Lambda, x_{+} \in \Lambda(x), S \in G}\left|B^{c e}(x ; S)-\frac{B^{c e}\left(x_{+1} ; S\right)}{R(x)}\right| .
$$

Note that this assumption is always satisfied in the case where the state and prices do not change over time. In this case, $\inf _{x \in \Lambda}(1-\phi) f\left(\sigma_{z}(x), x\right)>\nabla$ can be rewritten as $(1-\phi) f\left(\sigma_{z}\right)=r b_{z}>\frac{R-1}{R} B^{c e}$, which is obviously satisfied because $1<R<1+r$ and $b_{z}>B^{c e}$, as (18) implies.

Proposition 5. Let Assumptions 1-3 be satisfied. There exists an equilibrium in which the firm solves the optimization problem (6) taking $S(x)$ as given and (7) is satisfied.

The proof is given in Appendix B. We have established the existence of an equilibrium but not the uniqueness. It may not be possible to show such uniqueness analytically. However, in the deterministic case, where state $x_{t}$ evolves deterministically, we can use a numerical simulation to show that the equilibrium is unique for a range of parameter values that we consider to be relevant.

\subsection{A deterministic case}

In this subsection, we focus on the deterministic equilibrium, where state $x_{t}$ evolves deterministically. As shown in Proposition $5, S(x)$ is given endogenously by (7). In the deterministic case, the state of nature can be indicated by time. Thus, in this subsection, we use the time subscript $t$ to represent state $x_{t}$. We also use prime $\left(^{\prime}\right)$ to indicate differentiation. The firm's problem is

$$
\begin{array}{ll}
W_{t}\left(b_{t-1}\right)= & \max _{\sigma_{t}, b_{t}} \frac{r_{t-1} \tau}{R_{t-1}} b_{t-1}+f_{t}\left(\sigma_{t}\right)-\sigma_{t}+\frac{m_{t+1}}{m_{t}} W_{t+1}\left(b_{t}\right), \\
\text { subject to } & f_{t}\left(\sigma_{t}\right)-\sigma_{t}-b_{t-1}+\frac{b_{t}}{R_{t}} \geq 0, \\
& \sigma_{t} \leq \phi f_{t}\left(\sigma_{t}\right)+\max \left\{\xi S_{t}-\frac{b_{t}}{R_{t}}, 0\right\}, \\
& b_{t} \leq b_{z, t} .
\end{array}
$$

The FOCs and envelope condition are

$$
\begin{aligned}
& f_{t}^{\prime}\left(\sigma_{t}\right)=\frac{1+\frac{\mu_{t}}{1+\lambda_{\pi, t}}}{1+\phi \frac{\mu_{t}}{1+\lambda_{\pi, t}}}, \\
& \left\{\begin{array}{cl}
\frac{m_{t+1}}{m_{t}} W_{t+1}^{\prime}\left(b_{t}\right)+\frac{\lambda_{\pi, t}-\nu_{t}-\mu_{t}}{R_{t}}=0, & \text { if } \xi S_{t} \geq \frac{b_{t}}{R_{t}}, \\
\frac{m_{t+1}}{m_{t}} W_{t+1}^{\prime}\left(b_{t}\right)+\frac{\lambda_{\pi, t}-\nu_{t}}{R_{t}}=0, & \text { if } \xi S_{t}<\frac{b_{t}}{R_{t}},
\end{array}\right. \\
& W_{t}^{\prime}\left(b_{t-1}\right)=\frac{\tau r_{t-1}}{R_{t-1}}-\lambda_{\pi, t} .
\end{aligned}
$$


Permanent inefficiency of a debt-ridden firm: If a firm is debt-ridden (i.e., $b_{t-1}=$ $\left.b_{z, t-1}\right)$, inefficiency continues permanently because the firm's debt does not decrease even if it sets $\pi_{t}=0$ and repays as much debt as possible for all $t$. The following lemma is established immediately from the definition of $b_{z, t}$ in the deterministic economy (see (8)).

Lemma 6. Once $b_{t}=b_{z, t}$, then $b_{t+j}=b_{z, t+j}$ and $\sigma_{t+j}=\sigma_{z, t+j}$ for all $j \geq 0$.

This lemma means that once a firm becomes debt-ridden, it continues to be debt-ridden and production is inefficient forever. Note that the value of a debt-ridden firm is zero, because $\pi_{t}=0$ for all $t$, that is,

$$
V_{t}\left(b_{z, t-1}\right)=0 \quad \text { and } \quad W_{t}\left(b_{z, t-1}\right)=\frac{1+r_{t-1}}{R_{t-1}} b_{z, t-1} .
$$

Note that the deterministic version of our model has two steady states, the constrainedefficient and debt-ridden steady states, whereas Jermann and Quadrini's (2012) model has only the constrained-efficient steady state. The debt-ridden steady state does not exist in Jermann and Quadrini's economy because $\phi=0$ in their model. We define $W_{t}^{*}, \frac{b_{t}^{*}}{R_{t}}$, $B_{t}^{*}, B_{z, t}, \bar{B}_{z, t}$, and $B_{t}^{c e}$ using the same definitions as those of their counterparts in the stochastic case. Note that $\bar{B}_{z, t}=b_{z, t}$.

\subsubsection{Special case where $\tau=0$}

In this case, the optimal equilibrium is characterized by $\lambda_{\pi, t}=\nu_{t}=\mu_{t}=0$ and $f_{t}^{\prime}\left(\sigma_{t}\right)=1$. The FOCs and envelope condition imply the following lemma.

Lemma 7. If $\lambda_{\pi, t}=0$, the economy stays in the optimal equilibrium from $t$ onward, that is, $\lambda_{\pi, t+j}=\nu_{t+j}=\mu_{t+j}=0$ and $f_{t+j}^{\prime}\left(\sigma_{t+j}\right)=1$ for all $j \geq 0$.

Lemma 8. (i) $W_{t}(b)$ is weakly decreasing in $b$.

(ii) For all $b_{t-1} \leq B_{t}^{*}$, the economy is in the optimal equilibrium (i.e., $W_{t}\left(b_{t-1}\right)=W_{t}^{*}$ ).

(iii) For all $b_{t-1}>B_{t}^{*}, W_{t}\left(b_{t-1}\right)<W_{t}^{*}$ and $\pi_{t}=0$.

The above item (i) follows from $W_{t}^{\prime}\left(b_{t-1}\right)=-\lambda_{\pi, t}$ and $\lambda_{\pi, t} \geq 0$. This lemma implies that if $b_{t-1} \in\left(B_{t}^{*}, \bar{B}_{z, t}\right)$, where $\bar{B}_{z, t}=b_{z, t-1}$, production is inefficient $\left(f_{t}^{\prime}\left(\sigma_{t}\right)>1\right)$, and the firm sets $\pi_{t}=0$ and repays as much debt as possible to reduce the amount of remaining debt $b_{t}$. When $b_{t-1}$ becomes small and satisfies $b_{t-1} \leq B_{t}^{*}$, production becomes efficient $\left(f_{t}^{\prime}\left(\sigma_{t}\right)=1\right)$ and the firm is indifferent about the amount of debt because its value no longer changes by repaying debt. If a firm is debt-ridden (i.e., $b_{t-1}=b_{z, t-1}$ ), inefficiency continues permanently (see Lemma 6). Thus, in the case where $\tau=0$, the firm repays debt and returns to normal eventually as long as the initial debt, $b_{-1}$, is strictly smaller than the upper limit, $b_{z,-1}$. However, it remains debt-ridden and continues inefficient production permanently if the initial debt is $b_{z,-1}$. 


\subsubsection{Case with $\tau>0$}

In the case where $\tau>0$, the constrained-efficient equilibrium, characterized by $\lambda_{\pi, t}=\nu_{t}=$ $0, \pi_{t}>0, \mu_{t}^{c e}=\frac{\tau r_{t}}{1+r_{t}}, f^{\prime}\left(\sigma_{t}^{c e}\right)=\frac{1+\mu_{t}^{c e}}{1+\phi \mu_{t}^{c e}}$, and $b_{t}=b_{t}^{c e}$ for all $t$, is attained when the debt is sufficiently small (i.e., $b_{t-1}<B_{t}^{c e}$ ). For medium-sized debt (i.e., $b_{t-1} \in\left[B_{t}^{c e}, B_{z, t}\right)$ ), the firm sets the dividend to zero $\left(\pi_{t}=0\right)$ and repays as much debt as possible. Assumption 1 guarantees that it goes to the constrained-efficient equilibrium within finite periods. This result is the same as in Albuquerque and Hopenhayn (2004). For large debt (i.e., $\left.b_{t-1} \in\left[B_{z, t}, \bar{B}_{z, t}\right]\right)$, the borrowing constraint becomes (20). Note that $\bar{B}_{z, t}=b_{z, t-1}$ in the deterministic economy. When debt is large, the following two cases exist in equilibrium:

(i) $\nu_{t}=0$ : Either $\lambda_{\pi, t}>0$ or $\lambda_{\pi, t}=0$. If $\lambda_{\pi, t}>0$, then $b_{t+1}<b_{t}$, and the FOC and envelope condition imply that $\lambda_{\pi, t+j}>0$ for $j=1,2, \cdots$ as long as the borrowing constraint at $t+j$ is (20). If $\lambda_{\pi, t}=0$, then the FOC and envelope condition imply that $\lambda_{\pi, t+1}>0$ and, thus, that $\lambda_{\pi, t+j}>0$ for $j=2,3, \cdots$, as long as the borrowing constraint at $t+j$ is $(20)$. In any case, the firm eventually returns to the constrainedefficient equilibrium by setting $\pi_{t}=0$ to repay as much debt as possible.

(ii) $\nu_{t}>0$ : In this case, $b_{t}=b_{z, t}$, that is, the firm intentionally chooses to increase borrowing and become debt-ridden. Once the firm becomes debt-ridden, it stays there forever (Lemma 6).

For $b_{t-1} \in\left(B_{z, t}, \bar{B}_{z, t}\right)$, where $\bar{B}_{z, t}=b_{z, t-1}$, the equilibrium path is determined as follows. The firm compares the total surplus when $b_{t}=R_{t}\left\{b_{t-1}-f_{t}\left(\sigma_{z, t}\right)+\sigma_{z, t}\right\}$ and that when $b_{t}=b_{z, t}$ and then chooses the higher surplus. For $B_{z, t} \leq b_{t-1}<b_{z, t-1}$, the Bellman equation reduces to

$W_{t}\left(b_{t-1}\right)=\max \left\{W_{t}^{(1)}\left(b_{t-1}\right), W_{t}^{(2)}\left(b_{t-1}\right)\right\}$,

where $\quad W_{t}^{(1)}\left(b_{t-1}\right)=\frac{\tau r_{t-1}}{R_{t-1}} b_{t-1}+f_{t}\left(\sigma_{z, t}\right)-\sigma_{z, t}+\frac{1}{1+r_{t}} W_{t+1}\left(b_{z, t}\right)$,

$$
W_{t}^{(2)}\left(b_{t-1}\right)=\frac{\tau r_{t-1}}{R_{t-1}} b_{t-1}+f_{t}\left(\sigma_{z, t}\right)-\sigma_{z, t}+\frac{1}{1+r_{t}} W_{t+1}\left(R_{t}\left\{b_{t-1}-f_{t}\left(\sigma_{z, t}\right)+\sigma_{z, t}\right\}\right) .
$$

We show that there exists $\bar{B}_{c, t}$ such that $\bar{B}_{c, t}<b_{z, t-1}$ and $W_{t}^{(1)}\left(b_{t-1}\right)>W_{t}^{(2)}\left(b_{t-1}\right)$ for $b_{t-1} \in\left(\bar{B}_{c, t}, b_{z, t-1}\right)$. To prove this result, we need the following restriction on the parameter values.

$$
\inf _{t} \frac{1+r_{t}}{R_{t}}>1
$$

Proposition 9. In the deterministic case, there exist $\underline{B}_{c, t}$ and $\bar{B}_{c, t}$, where $B_{z, t} \leq \underline{B}_{c, t} \leq$ $\bar{B}_{c, t}<b_{z, t-1}$, such that

- If $B_{z, t} \leq b_{t-1}<\underline{B}_{c, t}$, then $W_{t}^{(1)}\left(b_{t-1}\right)<W_{t}^{(2)}\left(b_{t-1}\right)$. Here, the firm sets the dividend to zero (i.e., $\pi_{t}=0$ ) to repay as much debt as possible and goes to the constrainedefficient equilibrium in finite periods. 
- If $b_{t-1}>\bar{B}_{c, t}$, then $W_{t}^{(1)}\left(b_{t-1}\right)>W_{t}^{(2)}\left(b_{t-1}\right)$. In this case, the firm intentionally increases debt to the upper limit (i.e., $b_{t}=b_{z, t}$ ) and remains debt-ridden forever.

The proof is given in Appendix C. Note that the threshold $\bar{B}_{c, t}$ is strictly smaller than $b_{z, t-1}$. It is likely that

$$
\underline{\mathrm{B}}_{c, t}=\bar{B}_{c, t}\left(\equiv B_{c, t}\right)
$$

for a wide range of parameter values in our numerical experiment.

Why does a heavily indebted firm choose to become debt-ridden? The above proposition implies that there exists $b_{t-1} \in\left[B_{c, t}, b_{z, t-1}\right)$ such that the firm that owes $b_{t-1}$ intentionally increases borrowing and becomes debt-ridden (i.e., $b_{t}=b_{z, t}$ ). Intuitively, suppose, for simplicity, that all prices are constant over time. Then, suppose the initial debt $b$ is large, meaning that $R \xi S<b<b_{z}$. Then, it takes $n$ periods to reduce the debt to $R \xi S$ if the firm continues repaying as much as possible in every period. The value of $n$ is uniquely determined as a function of $b$ (i.e., $n=n(b)), n$ is increasing in $b$, and $\lim _{b \uparrow b_{z}} n(b)=\infty$. Now, we can calculate the gain and loss of choosing to become debt-ridden at $t=0$ in comparison with choosing to repay as much debt as possible. It is shown that the gain is proportional to $\frac{1}{R^{n}}$, whereas the loss is proportional to $\frac{1}{(1+r)^{n}}$, where $n=n(b)$. We know $1+r>R$ because $\tau>0$. Therefore, there exists $n_{c}$ such that if $n>n_{c}$, then the gain of choosing to be debt-ridden exceeds the loss. We define $B_{c}$ by $n_{c}=n\left(B_{c}\right)$. Then, the optimal choice for a firm with $b\left(>B_{c}\right)$ is to become debt-ridden.

Figure 3 shows the policy functions $b_{t}=b\left(b_{t-1}\right)$ and $\sigma_{t}=\sigma\left(b_{t-1}\right)$ and the value function $V_{t}=V\left(b_{t-1}\right)$ in the deterministic case in which the prices are invariant over time. The policy functions and the value function have a kink at $b_{t-1}=B_{z}=(1-\phi) f\left(\sigma_{z}\right)+\xi S$, which is the boundary of the borrowing constraint between $\sigma_{t} \leq \phi f\left(\sigma_{t}\right)$ and $\sigma_{t} \leq \phi f\left(\sigma_{t}\right)+\xi S-\frac{b_{t}}{R}$. The policy function $b\left(b_{t-1}\right)$ shows that debt decreases rapidly in the region where $b_{t-1} \leq$ $B_{z}$, whereas in the region where $B_{z}<b_{t-1} \leq B_{c}$, the slope of the graph $b_{t}=b\left(b_{t-1}\right)$ is $R$, which is very close to the slope of the 45-degree line in the standard parameter setting. Thus, the speed of the decrease in debt is extremely slow in the region where $B_{z}<b_{t-1} \leq B_{c}$. This figure indicates that the economy can suffer from extremely persistent inefficiency if $b_{t-1}$ falls into the region where $B_{z}<b_{t-1} \leq B_{c}$. Debt jumps to $b_{z}$ and stays there permanently for $b_{t-1}>B_{c}$. The value function has a kink at $b_{t-1}=B_{c}$. $V\left(b_{t-1}\right)>0$ for $B_{c}<b_{t-1}<b_{z}$ and $V\left(b_{z}\right)=0$, because $V\left(b_{t-1}\right)=b_{z}-b_{t-1}$ in this case (see Appendix C). The policy function $\sigma\left(b_{t-1}\right)$ shows that production becomes inefficient when the dividend is 0 . Production becomes the most inefficient (i.e., $\sigma_{t}=\sigma_{z}$ ) when $b_{t-1} \geq B_{z} . \sigma_{t}$ stays at $\sigma_{z}$ permanently for $b_{t-1}>B_{c}$.

A note on the kinks and jumps in the policy function: As Figure 3 shows, the policy function $\sigma_{t}=\sigma\left(b_{t-1}\right)$ has a kink at the boundary $b_{t-1}=B_{z}$. The reason that this kink appears is the structural change in the borrowing constraint at $b_{t-1}=B_{z}$, which 

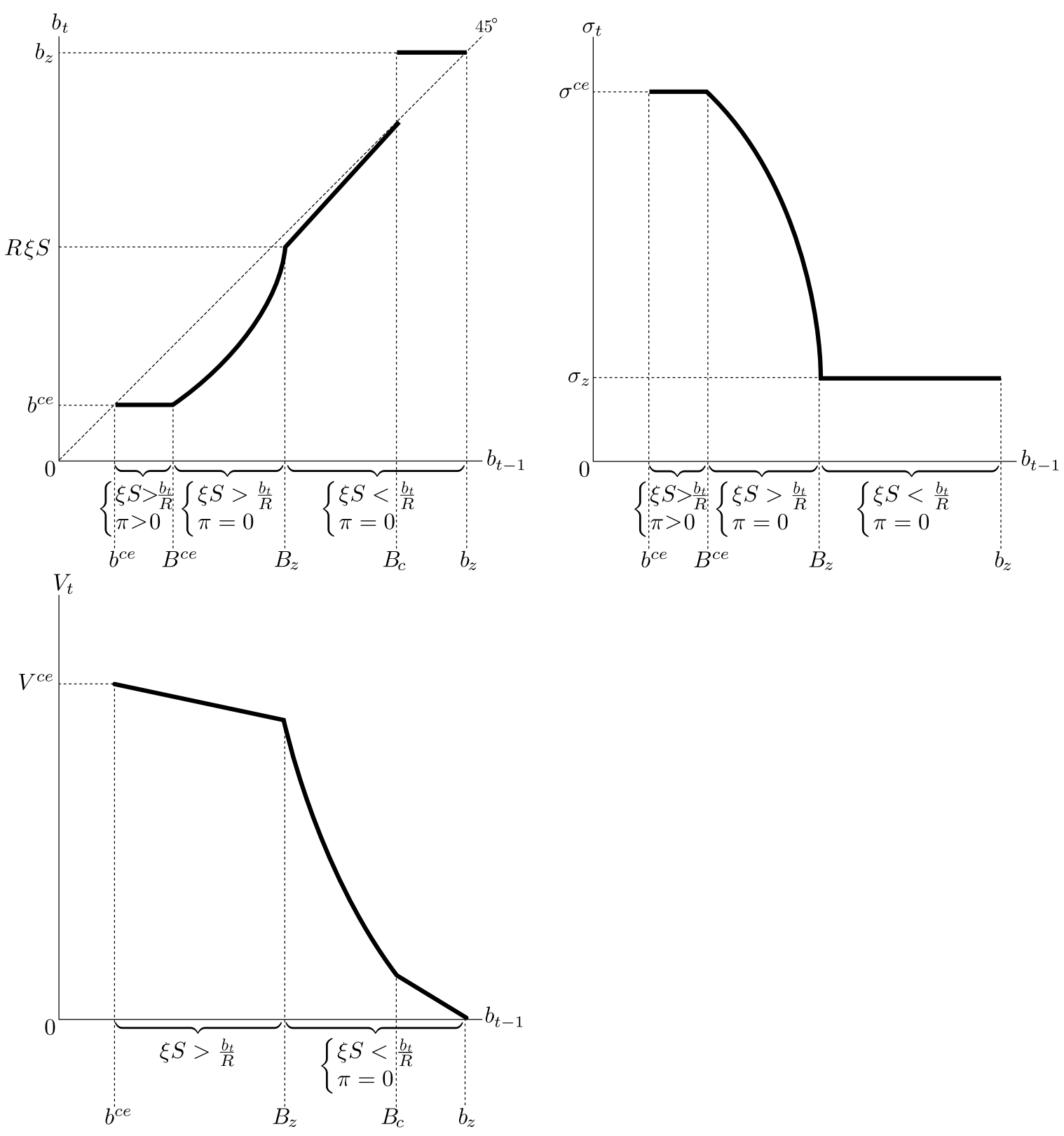

Figure 3: The policy functions and value function 
seems similar to the mechanism that generates kinks in the models of a zero lower bound on nominal interest rates (Christiano and Fisher, 2000; Guerrieri and Iacoviello, 2015). In this example, the policy function $\sigma_{t}=\sigma\left(b_{t-1}\right)$ is continuous at $b_{t-1}=B_{z}$ even though it has a kink. However, it is continuous only because we assume $\frac{\eta}{2-\eta}<\phi$ in this figure. If $\phi<\frac{\eta}{2-\eta}$, the policy function is no longer continuous, and it has a jump at $b_{t-1}=B_{z}$. The existence of the jump is explained as follows. The binding non-negativity condition $\pi_{t}=0$ and the borrowing constraint $\left(\sigma_{t}=\phi f\left(\sigma_{t}\right)+\xi S-\frac{b_{t}}{R}\right)$ imply that $\sigma_{t}$ solves the following equation:

$$
b_{t-1}-\xi S=(1+\phi) f\left(\sigma_{t}\right)-2 \sigma_{t},
$$

which may have two solutions. For $b_{t-1}=B_{z}=(1-\phi) f\left(\sigma_{z}\right)+\xi S$, there exist two solutions, $\sigma_{1}$ and $\sigma_{2}$, such that $\sigma_{1}=\sigma_{z}$ and $\sigma_{2}>\sigma_{1}$ if $\phi<\frac{\eta}{2-\eta}$. If $\phi>\frac{\eta}{2-\eta}$, then $\sigma_{2}<\sigma_{1}=\sigma_{z}$, and

if $\phi=\frac{\eta}{2-\eta}$, then $\sigma_{2}=\sigma_{1}=\sigma_{z}$. Therefore, if $\phi<\frac{\eta}{2-\eta}$, the policy function $\sigma\left(b_{t-1}\right)$ jumps from $\sigma_{z}$ to $\sigma_{2}\left(>\sigma_{z}\right)$ as $b_{t-1}$ decreases slightly from $B_{z}$. Because the continuity of $\sigma\left(b_{t-1}\right)$ at $b_{t-1}=B_{z}$ is necessary to prove Proposition 5 , we assume $\frac{\eta}{2-\eta}<\phi$.

Our result that inefficiency owing to outstanding debt can continue indefinitely contrasts sharply with the findings in the existing literature on financial frictions. In standard models, such as Carlstrom and Fuerst (1997) and Bernanke, Gertler and Gilchrist (1999), financial frictions have only temporary negative effects. In our model, a debt stock has a potentially indefinite negative effect on the output of the borrower.

\subsubsection{Numerical example of the deterministic model}

The numerical example of the deterministic case is shown in Figure 4. We assume that prices are invariant over time. The values of the parameters are chosen such that $\alpha=$ $0.31, \tau=0.3, A=0.73, w=0.65, r=0.02, r^{K}=0.12, R=1.014, \eta=0.72, \phi=0.5$, and $\xi=0.08$. Most of these parameter values are taken from Table 2 (See Section 4.3 for details). Figure 4 shows the response of the economy to a buildup of debt. Initially, the economy is in the steady state, where the level of debt is 0.30 . At $t=0$, debt $b_{-1}$ suddenly increases to 0.53 because of an exogenous shock (e.g., the breakout of a financial crisis). The value of $b_{-1}$ is chosen such that $B_{z}<b_{-1}<b_{z}$, where $B_{z}$ and $b_{z}$ are 0.44 and 4.63 , respectively. The firm repays as much debt as possible, meaning that the dividend is zero for periods $0-2$. Production is inefficient for periods $0-2$ and returns to the constrained-efficient level in period 3. In this example, the borrowing constraint is $\sigma_{t} \leq \phi f\left(\sigma_{t}\right)$ for periods 0 and 1 , and it is $\sigma_{t} \leq \phi f\left(\sigma_{t}\right)+\xi S-\frac{b_{t}}{R}$ from period 2 onward. Note that $\sigma_{0}=\sigma_{1}=0.065\left(=\sigma_{z}\right)$. In the case where the initial increase in debt $b_{-1}$ is larger, the borrowing constraint continues to stay at $\sigma_{t} \leq \phi f\left(\sigma_{t}\right)$ for arbitrarily longer periods, thereby allowing inefficient production, $\sigma_{t}=\sigma_{z}$, to continue persistently. This example shows that $\frac{b_{z}}{R}=4.56$ and $\xi S=0.37$, meaning that $\xi S<\frac{b_{z}}{R}$. 

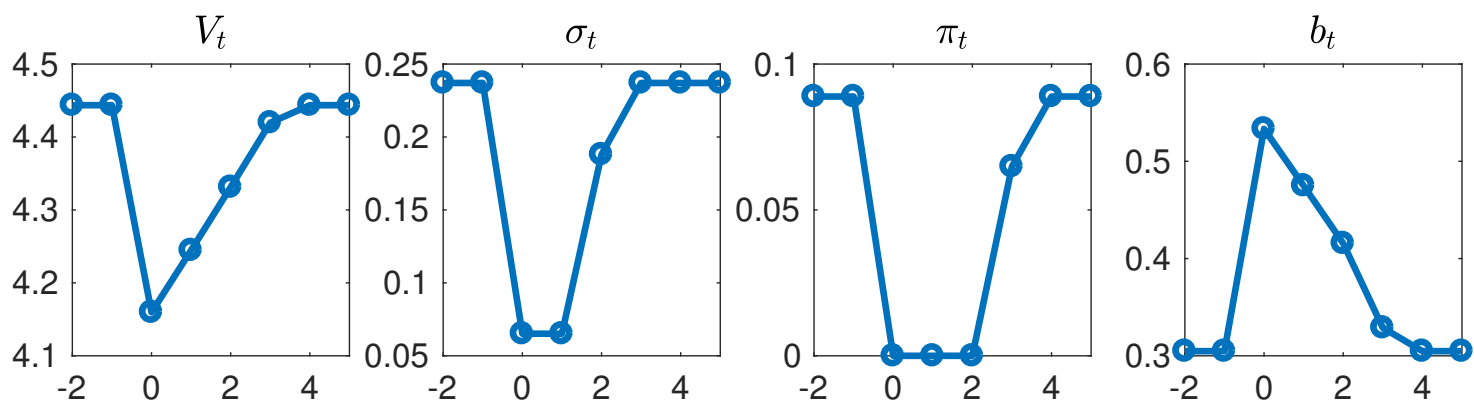

Figure 4: Responses to a buildup of debt

\section{$4 \quad$ Full model}

In this section, we embed the partial equilibrium model of borrowing constraints into a general equilibrium model of endogenous growth. We consider a closed economy in which the final good is produced competitively from varieties of intermediate goods. The firms are monopolistic competitors, and they produce their respective varieties of intermediate goods from the capital and labor inputs. This is a version of the expanding variety model, in which the new entry of firms increases aggregate productivity (Rivera-Batiz and Romer, 1991; Acemoglu, 2009). We follow Benassy (1998) in that labor is used to produce the intermediate goods and only labor is used to conduct $R \& D$ activities that expand the variety of goods. We assume that the monopolistically competitive firms, which are subject to borrowing constraints, produce intermediate goods and conduct R\&D activities.

\subsection{Basic setup}

A representative household owns a mass of firms, indexed by $i \in\left[0, N_{t-1}\right]$, that produce intermediate goods, where $N_{t-1}$ measures the varieties of intermediate goods in period $t$. Firm $i$ produces variety $i$ monopolistically and can borrow funds from the household. In what follows, we omit the bank for simplicity. The final good is produced competitively from intermediate goods $y_{i, t}$ by the following production function:

$$
Y_{t}=\left(\int_{0}^{N_{t-1}} y_{i, t}^{\eta} d i\right)^{\frac{1}{\eta}}
$$

where $0<\eta<1$. Because the final good producer maximizes $Y_{t}-\int_{0}^{N_{t-1}} p_{i, t} y_{i, t} d i$, where $p_{i, t}$ is the real price of intermediate good $i$, perfect competition in the final goods market implies that

$$
p_{i, t}=p\left(y_{i, t}\right)=A_{t} y_{i, t}^{\eta-1}
$$

where

$$
A_{t} \equiv Y_{t}^{1-\eta}
$$


Firm $i$ produces intermediate good $i$ from capital $k_{i, t}$ and labor $l_{i, p, t}$ by the following production function:

$$
y_{i, t}=k_{i, t}^{\alpha} l_{i, p, t}^{1-\alpha} .
$$

Each firm $i$ employs labor $l_{i, t}$ and capital $k_{i, t}$, produces intermediate goods $y_{i, t}$ from $l_{i, p, t}\left(\leq l_{i, t}\right)$ and $k_{i, t}$, and conducts R\&D with labor input $l_{i, t}-l_{i, p, t}$. The R\&D activity creates

$$
\kappa \bar{N}_{t-1}\left(l_{i, t}-l_{i, p, t}\right)
$$

units of new varieties of intermediate goods, where $\kappa$ is the parameter that represents the efficiency of R\&D activity and $\bar{N}_{t-1}$ is the social level of the variety of good, which represents the externality from the stock of knowledge on the R\&D activity. This externality ensures the existence of the balanced growth path (BGP). The law of motion for the measure of varieties is written as follows:

$$
N_{t}=N_{t-1}+\kappa \bar{N}_{t-1}\left(L_{t}-L_{p, t}\right),
$$

where $L_{t}=\int_{0}^{N_{t-1}} l_{i, t} d i$ and $L_{p, t}=\int_{0}^{N_{t-1}} l_{i, p, t} d i$. When a new variety is created, a new monopolistic firm that produces the variety is also born. Each new variety is produced by a newborn firm. The parent firm creates newborn firms and then treats them as members of its own dynasty. As the parent and newborn firms are technologically identical, the burden of inter-period debt for the parent firm is shared equally by all firms in the dynasty. In this general equilibrium model, the state of nature $x_{t}$ is given by $x_{t}=\left(N_{t-1},\left\{b_{i, t-1}\right\}_{i=0}^{N_{t-1}}\right)$ because prices are the equilibrium outcomes. Exogenous redistribution shocks may hit the distribution of debt, $\left\{b_{i, t-1}\right\}_{i=0}^{N_{t-1}}$, and make $x_{t}$ evolve stochastically. The transition of states is a Markov process, which is determined endogenously in equilibrium, and is taken as given by the individual households and firms. To simplify the notation, we use the time subscript $t$ instead of the state $x_{t}$ and simply omit $x_{t}$ in what follows on the understanding that all variables and functions with subscript $t$ depend on state $x_{t}$. Thus, the value of the firm is determined by the following dynamic programming equation in which we omit the subscript $i$ for simplicity:

subject to

$$
V_{t}\left(b_{t-1}\right)=\max \pi_{t}+\mathbb{E}_{t}\left[\frac{m_{t+1}}{m_{t}}\left\{1+\kappa \bar{N}_{t-1}\left(l_{t}-l_{p, t}\right)\right\} V_{t+1}\left(b_{t}\right)\right],
$$

$$
\begin{aligned}
& \pi_{t}=A_{t} k_{t}^{\alpha \eta} l_{p, t}^{(1-\alpha) \eta}-w_{t} l_{t}-r_{t}^{K} k_{t}-b_{t-1}+\left[1+\kappa \bar{N}_{t-1}\left(l_{t}-l_{p, t}\right)\right] \frac{b_{t}}{R_{t}}, \\
& w_{t} l_{t}+r_{t}^{K} k_{t} \leq \phi A_{t} k_{t}^{\alpha \eta} l_{p, t}^{(1-\alpha) \eta}+\max \left\{\xi S_{t}-\frac{b_{t}}{R_{t}}, 0\right\}\left[1+\kappa \bar{N}_{t-1}\left(l_{t}-l_{p, t}\right)\right], \\
& \pi_{t} \geq 0 \\
& l_{t} \geq l_{p, t}, \\
& b_{t} \leq b_{z, t}
\end{aligned}
$$


where $S_{t}$ and $b_{z, t}$ are taken as given and are the equilibrium outcomes, as we see shortly. The Lagrange multipliers, $\lambda_{t}, \mu_{t}, \lambda_{\pi, t}$, and $\lambda_{l, t}$, are associated with the budget constraint (24), the borrowing constraint (25), the non-negativity of profits (26), and the non-negativity of labor input for R\&D (27), respectively. In equilibrium, the liquidation value $S_{t}$ and the upper limit of borrowing $b_{z, t}$ are given in the same manner as in the previous section. Thus, the equilibrium condition that determines $S_{t}$ is

$$
S_{t}=\max _{b} \mathbb{E}_{t}\left[\frac{m_{t+1}}{m_{t}} V_{t+1}(b)\right]+\frac{b}{R_{t}} .
$$

The value of $b_{z, t}=b_{z}\left(x_{t}\right)$ is given by

$$
b_{z}\left(x_{t-1}\right)=\inf _{x_{t} \in \Lambda\left(x_{t-1}\right)}(1-\phi) f_{t}\left(\sigma_{z}\left(x_{t}\right), x_{t}\right)+\frac{b_{z}\left(x_{t}\right)}{R_{t}},
$$

where $f(\sigma, x)$ and $\sigma_{z}(x)$ are the same as in Section 3, and we assume the parameter restriction (9).

A representative household solves the following problem:

$$
\max _{C_{t}, L_{t}, B_{t}, K_{t}} \mathbb{E}_{0}\left[\sum_{t=0}^{\infty} \beta^{t} U\left(C_{t}, L_{t}\right)\right],
$$

subject to the budget constraint

$$
C_{t}+K_{t}-\frac{B_{t}}{1+r_{t}} \leq w_{t} L_{t}+\left(r_{t}^{K}+1-\rho\right) K_{t-1}-B_{t-1}+T_{t}
$$

where $\beta$ is the subjective discount factor, $C_{t}$ is consumption, $L_{t}$ is the total labor supply, $K_{t}$ is capital stock, $\rho$ is the depreciation rate of capital, $B_{t}$ is inter-period lending to the firms, and $T_{t}$ is a lump-sum transfer that consists of the tax and dividends. The period utility is

$$
U(C, L)=\frac{\left[C^{\frac{1}{1+\gamma}}(1-L)^{\frac{\gamma}{1+\gamma}}\right]^{1-\theta}}{1-\theta} .
$$

Let $m_{t}$ be the Lagrange multiplier associated with the budget constraint for the representative household, which is given by the FOC with respect to $C_{t}$ :

$$
m_{t}=\beta^{t} \frac{\partial}{\partial C} U\left(C_{t}, L_{t}\right) .
$$

The FOC with respect to $K_{t}$ and $B_{t}$ implies

$$
\frac{1}{1+r_{t}}=\mathbb{E}_{t}\left[\frac{1}{r_{t+1}^{K}+1-\rho}\right]=\mathbb{E}_{t}\left[\frac{m_{t+1}}{m_{t}}\right] .
$$


The market-clearing conditions are

$$
\begin{aligned}
& C_{t}+K_{t}-(1-\rho) K_{t-1}=Y_{t}, \\
& \int_{0}^{N_{t-1}} l_{i, t} d i=L_{t}, \\
& \int_{0}^{N_{t-1}} l_{i, p, t} d i=L_{p, t}, \\
& \int_{0}^{N_{t-1}} k_{i, t} d i=K_{t-1}, \\
& \int_{0}^{N_{t-1}} \frac{b_{i, t}}{R_{t}} d i=\frac{B_{t}}{1+r_{t}}, \\
& N_{t}=N_{t-1}+\kappa \bar{N}_{t-1}\left(L_{t}-L_{p, t}\right) .
\end{aligned}
$$

The equilibrium condition is

$$
\bar{N}_{t}=N_{t}
$$

Competitive equilibrium. - A competitive equilibrium consists of sequences of prices $\left\{r_{t}, r_{t}^{K}, w_{t}, m_{t}\right\}$, a household's decisions $\left\{C_{t}, L_{t}, K_{t}\right\}$, firms' decisions $\left\{\pi_{t}, l_{t}, l_{p, t}, k_{t}, b_{t}\right\}$, and a measure of varieties $N_{t}$, such that $(i)$ the representative household and firms solve their respective optimization problems, taking prices and $N_{t-1}$ as given, and (ii) the marketclearing conditions and equilibrium condition are all satisfied.

Debt-ridden firms: A firm that owes the maximum amount $b_{z, t}$ is called a debt-ridden firm in a similar manner to the previous section.

\subsection{BGP without debt-ridden firms}

In what follows, we assume for simplicity that $\theta \rightarrow 1$ and

$$
U(C, L)=\ln C+\gamma \ln (1-L)
$$

In this subsection, we focus on the deterministic case where state $x_{t}$ evolves deterministically and then characterize the BGP on which all firms are normal. The firms are normal when the dividend is positive, that is, $\pi_{t}>0$ for all $t$. On the BGP, labor and the growth rate are constant, that is, $L_{t}=L$ and $N_{t} / N_{t-1}=g$. We define

$$
E \equiv \frac{1-\eta}{(1-\alpha) \eta}
$$

We guess that $Y_{t}=Y \times N_{t-1}^{E}, A_{t}=A \times N_{t-1}^{(1-\eta) E}, C_{t}=C \times N_{t-1}^{E}, K_{t}=K \times N_{t}^{E}$, $w_{t}=w \times N_{t-1}^{E}, l_{t}=L / N_{t-1}, k_{t}=k \times N_{t-1}^{E-1}, V_{t}=V \times N_{t-1}^{E-1}$, and $\pi_{t}=\pi \times N_{t-1}^{E-1}$. The FOCs and constraints imply that there exists a unique BGP, which is given in Appendix D. For the numerical simulation, we set the parameters to the values for Japan, the 


\section{Common parameters}

\begin{tabular}{llr}
\hline \hline Parameter & Economic interpretation & value \\
\hline$\beta$ & the subjective discount factor & 0.98 \\
$\rho$ & the depreciation rate of capital & 0.1 \\
$\eta$ & the parameter for the aggregation function & 0.7 \\
\hline
\end{tabular}

Country-specific parameters

\begin{tabular}{llrrr}
\hline \hline Parameter & Economic interpretation & Japan & US & EU \\
\hline$\alpha$ & the share of labor in production & 0.31 & 0.34 & 0.37 \\
$\gamma$ & the inverse of the elasticity of labor supply & 2.49 & 3.25 & 3.59 \\
$\kappa$ & the efficiency of R\&D & 0.55 & 0.42 & 0.39 \\
$\phi$ & the collateral ratio of revenue & 0.50 & 0.64 & 0.62 \\
$\tau$ & the tax advantage for debt & 0.30 & 0.35 & 0.35 \\
$\xi$ & the collateral ratio of the foreclosure value & 0.08 & 0.95 & 0.91 \\
$L$ & the total labor supply in the steady state & 0.25 & 0.21 & 0.19 \\
$g_{T F P}$ & the growth rate of TFP in the steady state & 1.017 & 1.013 & 1.011 \\
$z$ & the ratio of debt-ridden firms at the shock period & 0.742 & 0.661 & 0.654 \\
\hline
\end{tabular}

Table 2: Parameter settings

United States, and the European Union (EU) ${ }^{13}$ shown in Table 2. The parameters of the borrowing constraints, $\phi$ and $\xi$, and the size of shock $z$ are calibrated to fit the data of Japan, the United States, and the European Union (EU), respectively, according to the data in Appendix E and the method described in Appendix F, where we identify and assess the parameter region that we use in our numerical experiments. It is an annual model. We adopt a simulation strategy under which the parameters $\gamma$ and $\kappa$ are calculated endogenously such that the two variables $L$ and $g_{T F P}$ attain the target values calculated from the data (Appendix E). Thus, the economic growth rate on the BGP is $2.51 \%$ per year for the Japanese economy. ${ }^{14}$ It is easily confirmed numerically that there exists a BGP for a wide range of parameter settings.

A debt-ridden firm does not conduct R\&D activity on the BGP under a wide range of parameter settings. The following claim provides the condition for a debt-ridden firm on the BGP to refrain from conducting the $\mathrm{R} \& \mathrm{D}$ activity.

\footnotetext{
${ }^{13}$ The EU comprises the following 28 countries: Austria, Belgium, Bulgaria, Croatia, Cyprus, Czech Republic, Denmark, Estonia, Finland, France, Germany, Greece, Hungary, Ireland, Italy, Latvia, Lithuania, Luxembourg, Malta, the Netherlands, Poland, Portugal, Romania, Slovakia, Slovenia, Spain, Sweden, and the United Kingdom.

${ }^{14}$ The economic growth rate on the BGP is given by $g^{E}=g_{T F P}^{\frac{1-\eta}{(1-\alpha) \eta} \frac{\eta}{1-\eta}}=g_{T F P}^{\frac{1}{1-\alpha}}=1.0251$, where $g$ is the growth rate of $N_{t}$ and $E=\frac{1-\eta}{(1-\alpha) \eta}$. See Appendix G.
} 
Claim 1. There exists a threshold $\bar{\phi} \in(0,1]$ such that for $\phi<\bar{\phi}$, a debt-ridden firm does not conduct R\&D on the BGP (i.e., $l_{z}=l_{z, p}$ ) given that the BGP exists.

The proof is given in Appendix G. The intuitive explanation is as follows. The debtridden firms' borrowing constraints are very tight due to the pressure from the huge amount of inter-temporal debt, and, thus, their effective costs of labor are very high. With our parameter values, the marginal product of labor in production for debt-ridden firms can be equalized to the marginal cost of labor, which is strictly larger than the marginal product of labor in R\&D. For this reason, these firms do not conduct R\&D. Figure 9 in Appendix F shows the parameter region in $(\phi, \xi)$ space where the BGP exists given that the other parameters are fixed. It is numerically confirmed that, in this figure, $\phi<\bar{\phi}$ is satisfied in the region where the BGP exists. Thus, the debt-ridden firms in our simulation do not conduct the R\&D on the BGP.

\subsection{Low growth equilibrium with debt-ridden firms}

Now, we consider the equilibrium where some firms are debt-ridden and the others are normal. In this subsection, we again focus on the deterministic case in which state $x_{t}$ evolves deterministically. We assume that firms $i \in\left[0, Z_{t}\right]$ are debt-ridden and firms $i \in\left(Z_{t}, N_{t}\right]$ are normal. We assume and justify numerically in the following simulation that the debt-ridden firms do not conduct $R \& D$ activity on the entire equilibrium path.

Define $z_{t} \equiv \frac{Z_{t}}{N_{t}}$. The initial value of $z_{t}$, denoted by $z$, is given exogenously. In our simulation, we assume $z<1$ and $\frac{b_{z, t}}{R_{t}}>\xi S_{t} \cdot{ }^{15}$

Numerical experiment: We can calculate the equilibrium dynamics numerically using a full nonlinear method. Linearization is not necessary for the deterministic simulation (see Appendix $\mathrm{H}$ for detrending and Appendix I for the details of the calculation of the dynamics). Figure 5 shows the results of the numerical simulation in which the economy is initially on the BGP, where $Z_{t}=0$, and an unexpected redistribution shock hits the economy in period 10 , making $z_{10}=z=0.74$. In other words, the sudden redistribution of wealth from firms to households makes $74.2 \%$ of all firms debt-ridden in period 10 . The parameter values for Figure 5 are given as those for Japan in Table 2. The features of the equilibrium path shown in Figure 5 are as follows:

- Slowdown of economic growth: Borrowing constraints are tighter after the buildup

\footnotetext{
${ }^{15}$ We cannot find the parameter set that makes $z=1$ and $\frac{b_{z, t}}{R_{t}}>\xi S_{t}$ simultaneously. If both $z=1$ and $\frac{b_{z, t}}{R_{t}}>\xi S_{t}$ hold simultaneously, there would exist a zero growth path on which all firms are debt-ridden and the economic growth rate is zero, because no firms conduct R\&D activities. In a simplified model in which capital $k$ does not exist and labor is the only input, it is proven analytically that $z=1$ and $\frac{b_{z, t}}{R_{t}}>\xi S_{t}$ cannot hold simultaneously for any parameter set.
} 

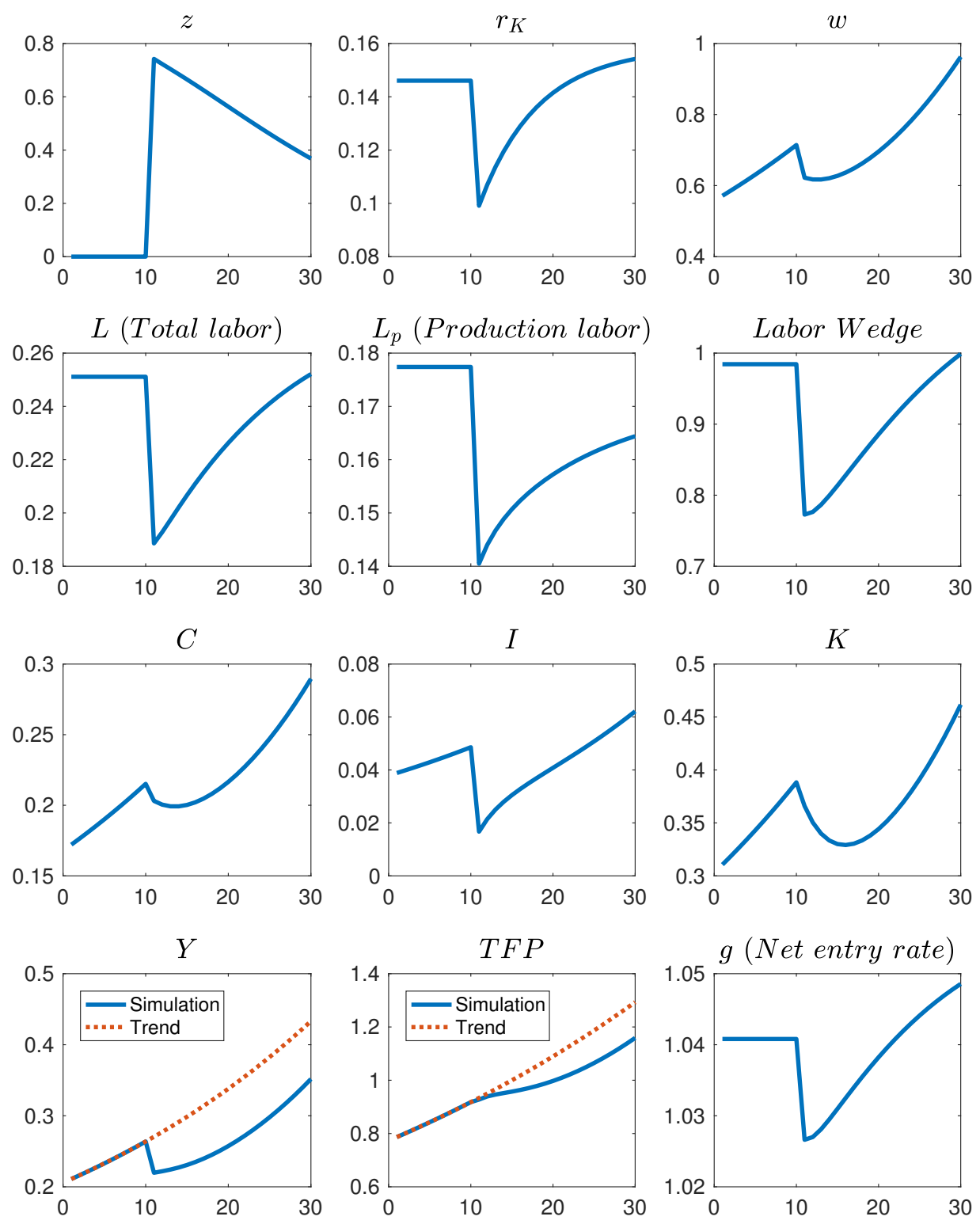

Figure 5: Responses to a buildup of debt (Japan) 
of debt. Thus, the aggregate inputs decrease and economic growth slows for an extended period.

- Persistently lower rates of interest and wages: These features are observed in the aftermath of the Great Recession and are the focus of the recent literature on secular stagnation and unconventional monetary policy.

- Decrease in TFP and net entry: The growth rate of the number of firms, $g_{t}=$ $N_{t} / N_{t-1}$, decreases. This feature is consistent with the observation that TFP and the net entry of firms decreased in Japan in the 1990s.

- Buildup of NPLs: In this example, there are $Z_{t}$ debt-ridden firms, and their debt stays at an inefficiently high level. This feature is consistent with the historical episodes of persistent stagnation with overly indebted firms and/or households, such as Japan in the 1990s.

- Labor wedge reduction: In this example, the labor wedge, $1-\tau_{L}$, diminishes persistently as a direct consequence of the tightening of the aggregate borrowing constraint on working capital loans for wage payments. This tighter borrowing constraint creates a larger gap between the wage rate and the marginal product of labor. The gap is measured by $\tau_{L}$. In this way, the persistent reduction in the labor wedge observed in the aftermath of a financial crisis can be accounted for by the emergence of debt-ridden firms. ${ }^{16}$

Next, we calibrate and conduct numerical simulations for the United States and the EU. The parameter values are given in Table 2. Figure 6 compares the TFP in the model with the actual TFP in Japan, the United States, and the EU, where the TFP in the model is defined by

$$
T F P_{t}=\frac{Y_{t}}{K_{t-1}^{\alpha} L_{t}^{1-\alpha}} .
$$

Similarly, Figure 7 compares the GDP of the numerical experiment with the actual real GDP per capita of the working age population (15-64 years old). We assume that the unexpected shock hits the economy in period 10 of the simulation, which corresponds to

\footnotetext{
${ }^{16}$ As Chari et al. (2007) posited, the labor wedge, $1-\tau_{L, t}$, is defined by $1-\tau_{L, t}=\frac{M R S_{t}}{M P L_{t}}$, where $M R S_{t}=$ $\frac{\gamma C_{t}}{1-L_{t}}=w_{t}$ and $M P L_{t}=\frac{\alpha Y_{t}}{L_{t}}$ in our model. Thus, the labor wedge can be calculated by $1-\tau_{L, t}=\frac{w_{t} L_{t}}{\alpha Y_{t}}$. In our model, the labor wedge $1-\tau_{L}$ is proportional to the labor share. Thus, both an economic slowdown and a shrinkage of the labor share (from the buildup of debt) are observed simultaneously in our model. This feature of our model contrasts with the countercyclicality of the labor share in business cycle frequencies (Schneider, 2011). However, our model seems compatible with countercyclicality in the short run. In our model, the buildup of debt causes the long-term variations in the labor wedge, whereas short-run countercyclicality can be caused by factors such as productivity shocks in business cycle frequencies (RíosRull and Santaeulàlia-Llopis, 2010).
} 
the asset-bubble collapse in 1990, in the case of Japan, and the financial crisis in 2009, in the case of the United States and the EU. For the United States and the EU, we extend the observed variables to 2025 . We posit that the variables grow in future periods by constant growth rates, which are equal to the average growth rates in 2011-2016 for the United States and the EU. These extensions are based on the implicit assumption that the US and EU economies have fallen into decade-long stagnation. We compare our simulation results with the extended data on the United States and the EU because a goal of our numerical experiment is to examine the capability of our model to account for decade-long recessions in the aftermath of financial crises. The figures show that the model fits the growth rate data fairly well. Figure 8 compares the labor wedge of the numerical experiment With the actual labor wedge. The simulated deterioration of the labor wedge is fairly consistent with the data from Japan, the United States, and the EU.

In any case, the numerical simulation of our model shows the overall slowdown of economic growth resulting from the debt shock, indicating the usefulness of our model in accounting for persistent recessions in the aftermath of financial crises.

\subsection{Policy implications}

The policy implications of the results presented in this paper seem noteworthy from a practical point of view. The shocks that cause persistent stagnation are exogenous technological changes in the existing literature. In our model, the one-time buildup of debt tightens the borrowing constraint and causes a persistent slowdown in economic growth even though there is no technological change. Thus, our model implies that reducing overly accumulated debt can restore economic growth. Note that the physical liquidation of debt-ridden borrowers is not necessary, but relieving them from excessive debt restores their efficiency and high economic growth at the aggregate level. This policy implication contrasts sharply with those of prior studies, in which debt reduction, per se, is not on the table, and policymakers can only mitigate recessions by implementing accommodative monetary and fiscal policies or designing ex-ante financial regulations.

The government intervention in debt reduction is justified as follows. In our model, the inefficiency of persistent stagnation cannot be resolved by the market mechanism for the following three reasons. First, constraint (5) implies that outside investors cannot relax the borrowing constraint of debt-ridden firms by purchasing new equity. Constraint (5) is an exogenous assumption in this analysis, but it may be justified by plausible market frictions, such as a lack of commitment and coordination failures (see the footnote 6 ). If constraint (5) did not exist, outside investors would purchase new equity of debt-ridden firms and make them constrained-efficient because they can earn strictly positive profits by investing new money in the debt-ridden firms. Second, the free entry of new firms is prohibited in our model. The entry of a new firm is equal to that of a new variety, 


\section{Japan}
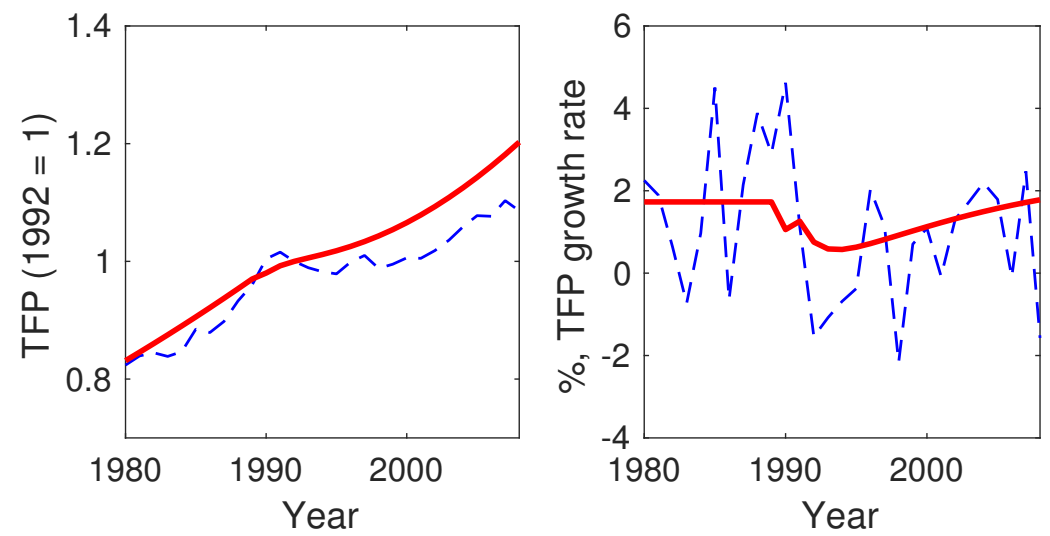

United States
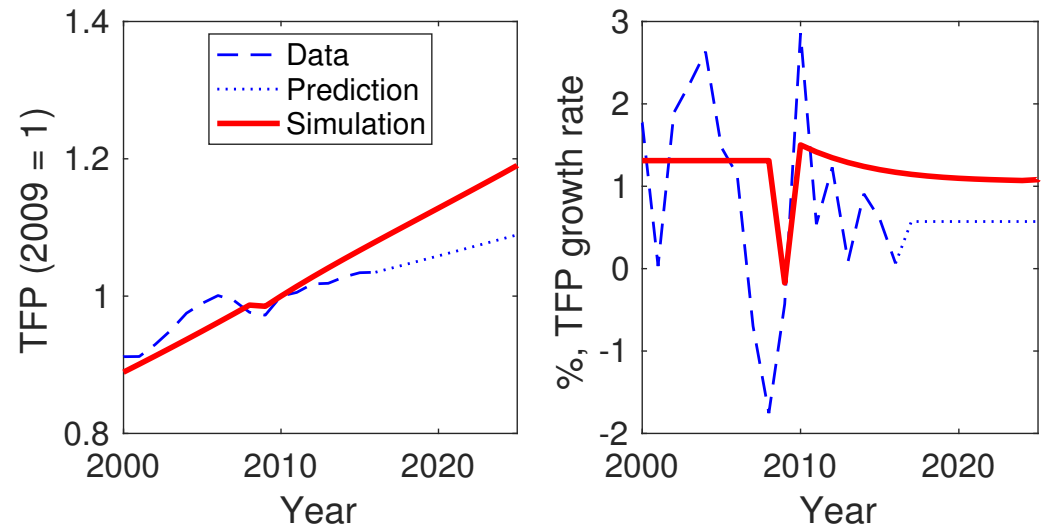

EU
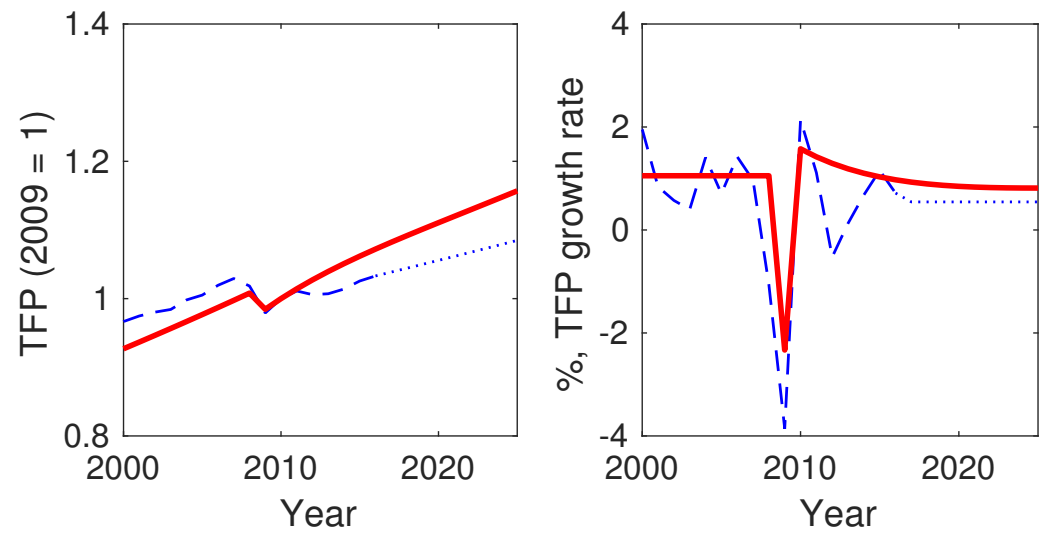

Figure 6: TFP for Japan, the United States, and the EU: Comparison between the data and the simulation

Note: In Japan, TFP is classified as the "market economy" sectors, which excludes education, medical services, government activities, and imputed housing rent.

Sources: Our calculation; The Research Institute of Economy, Trade and Industry, JIP 2014 database; Fernald (2012); European Commission, AMECO 


\section{Japan}
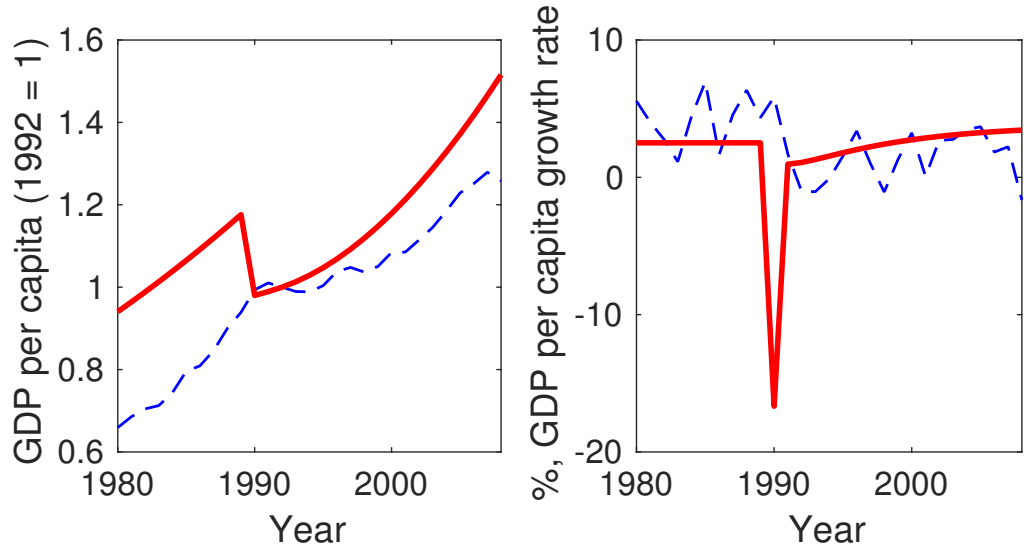

United States
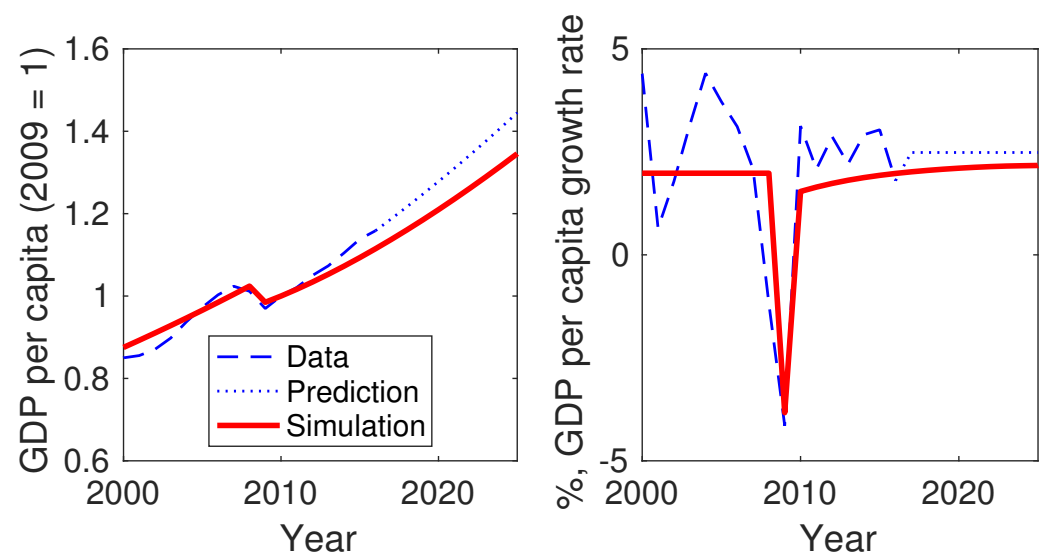

\section{EU}
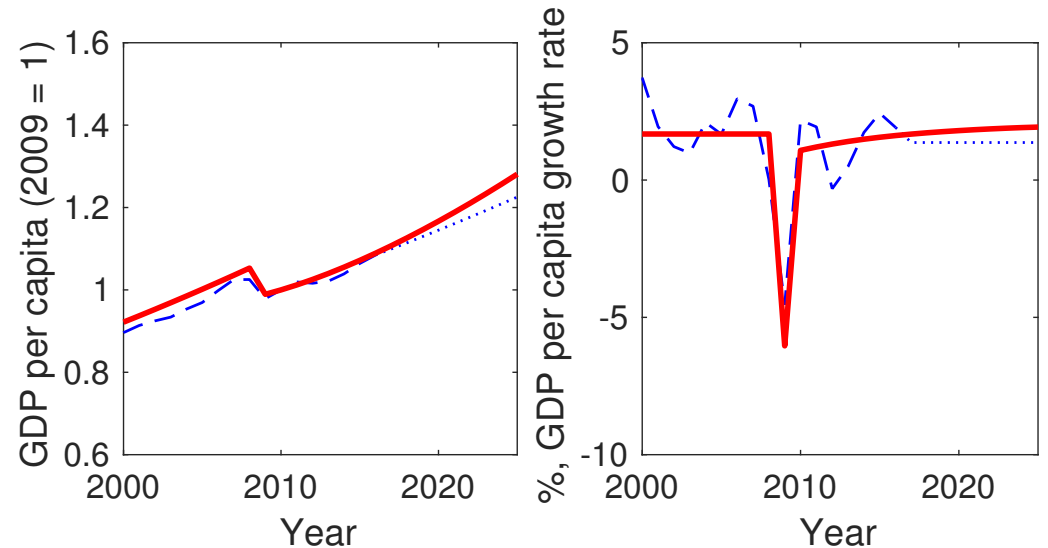

Figure 7: GDP for Japan, the United States, and the EU: Comparison between the data and the simulation

Sources: Our calculation; Cabinet Office, Government of Japan, Annual Report on National Accounts; Statistics Bureau of Japan, Labour Force Survey; U.S. Bureau of Economic Analysis, National Income and Product Accounts; U.S. Bureau of Labor Statistics, "Current Employment Status"; European Commission, AMECO 

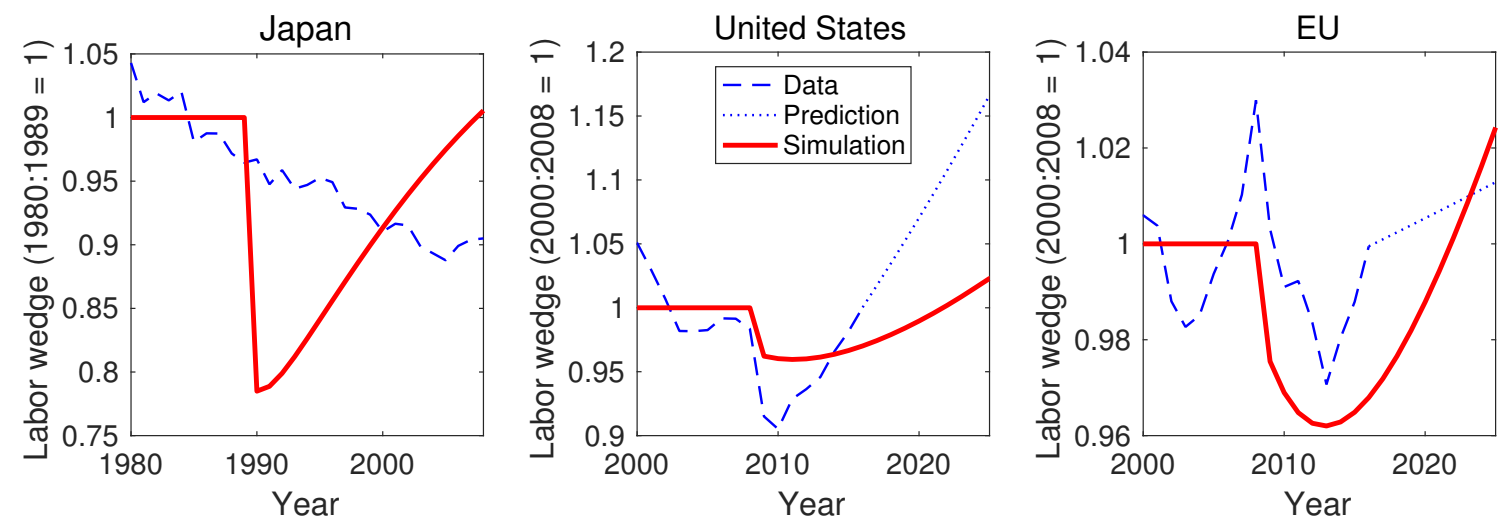

Figure 8: Labor wedge for Japan, the United States, and the EU: Comparison between the data and the simulation

Sources: Our calculation; Cabinet Office, Government of Japan, Annual Report on National Accounts; Statistics Bureau of Japan, Labour Force Survey; The Research Institute of Economy, Trade, and Industry, JIP 2014 database; U.S. Bureau of Economic Analysis, National Income and Product Accounts; U.S. Bureau of Labor Statistics, Current Employment Status; European Commission, AMECO

which occurs as a result of $R \& D$ activities by the incumbent firms. Thus, new entries of new varieties decrease as debt-ridden firms increase, and the growth of productivity slows. The productivity slowdown continues persistently because there is no entry from outside firms. ${ }^{17}$ Third, it is optimal for lenders to keep borrowers debt-ridden if the outstanding debt is large. Because the lenders can be repaid in full even when the borrowers are debtridden, they have no incentive to reduce their loans, whereas their inaction protracts the aggregate inefficiency. Thus, policy interventions by the government can be effective in restoring economic growth by promoting debt restructuring or wealth redistribution from lenders to borrowers. Policy measures may include regulatory reforms to make bankruptcy procedures less costly and debtor friendly and to promote debt-for-equity swaps to reduce outstanding debt as well as the injection of funds as a subsidy or equity to banks that forgive debt and write off NPLs. The injection of a bank subsidy or equity is usually interpreted as bank recapitalization because the banks become insolvent in most cases when a substantial number of their borrowers fall into a debt-ridden state. This policy implication is straightforward and robust in our model and seems reasonable from our experience of Japan's lost decade of the 1990s, the Great Recession in the United States, and the subsequent debt crises in Europe, whereas existing models may not clarify whether borrowers' relief from excessively accumulated debt is good for an economy hit by a crisis.

\footnotetext{
${ }^{17}$ The persistence of the productivity slowdown can be preserved even if we relax our assumption of no entry from outsiders as long as the cost of $R \& D$ is sufficiently higher for outsiders than it is for incumbent firms. It seems plausible to posit that the cost of R\&D is substantially higher for outsiders than for incumbents in any industry.
} 


\section{Conclusion}

Decade-long recessions are often observed after financial crises. In particular, the "secular stagnation" hypothesis has drawn much attention recently. In this study, we hypothesized that the buildup of large debt in the private sector causes a persistent economic slowdown even without technology shocks. This model may be considered to reflect a "debt supercycle" rather than secular stagnation, as the inefficiency can continue persistently but is removed if debt is reduced. Economic agents can become overly indebted because of, for example, the boom and bust of asset-price bubbles. We showed that borrowers who owe the maximum repayable debt fall into a debt-ridden state in which they can repay only the interest and cannot reduce the principal of the debt, which means that they continue inefficient production forever in the deterministic case.

The emergence of a substantial number of debt-ridden borrowers lowers economic growth by tightening the aggregate borrowing constraint. This tightening of aggregate borrowing constraints owing to the mass emergence of debt-ridden borrowers may manifest as a "financial shock" during or after a financial crisis. Because lenders have no incentive to reduce their loans to debt-ridden borrowers, a government intervention to facilitate debt restructuring (i.e., relief for debt-ridden borrowers from their excessive debt) may be necessary to enhance economic growth in the aftermath of a financial crisis. This policy implication is in a stark contrast to those of the existing literature, in which debt reduction, per se, has little effect and policymakers can only mitigate recessions by conducting accommodative monetary and fiscal policies or designing ex-ante financial regulations. Our policy recommendations are in line with those of partial debt forgiveness by Geanakoplos (2014).

The endogenous borrowing constraint of this study has a unique feature in that debt tightens the constraint and generates inefficiency, which can be permanent in the deterministic case. Therefore, it may serve as a useful building block for business cycle models, thereby enriching aggregate dynamics. Broader applications are left for future research.

\section{References}

Abreu, Dilip and Faruk Gul (2000) "Bargaining and Reputation," Econometrica, Vol. 68, No. 1, pp. 85-118, January.

Acemoglu, Daron (2009) Introduction To Modern Economic Growth, Princeton: Princeton University Press.

Adjemian, Stéphane, Houtan Bastani, Frédéric Karamé, Michel Juillard, Junior Maih, Ferhat Mihoubi, George Perendia, Johannes Pfeifer, Marco Ratto, and Sébastien Villemot (2011) "Dynare: Reference Manual Version 4," Dynare Working Papers 1, CEPREMAP. 
Albuquerque, Rui and Hugo A. Hopenhayn (2004) "Optimal Lending Contracts and Firm Dynamics," Review of Economic Studies, Vol. 71, No. 2, pp. 285-315, April.

Altavilla, Carlo, Matthieu Darracq Paries, and Giulio Nicoletti (2015) "Loan supply, credit markets and the euro area financial crisis," Working Paper Series 1861, European Central Bank.

Bartelsman, Eric J. and Mark Doms (2000) "Understanding Productivity: Lessons from Longitudinal Microdata," Journal of Economic Literature, Vol. 38, No. 3, pp. 569-594, September.

Benassy, Jean-Pascal (1998) "Is there always too little research in endogenous growth with expanding product variety?" European Economic Review, Vol. 42, No. 1, pp. 61 - 69 .

Bernanke, Ben S., Mark Gertler, and Simon Gilchrist (1999) "The Financial Accelerator in a Quantitative Business Cycle Framework," in John B. Taylor and Michael Woodford eds. Handbook of Macroeconomics, Vol. 1: Elsevier, Chap. 21, pp. 1341-1393.

Bilbiie, Florin, Fabio Ghironi, and Marc J. Melitz (2012) "Endogenous Entry, Product Variety, and Business Cycles," Journal of Political Economy, Vol. 120, No. 2, pp. $304-$ 345, April.

Caballero, Ricardo J., Takeo Hoshi, and Anil K. Kashyap (2008) "Zombie Lending and Depressed Restructuring in Japan," American Economic Review, Vol. 98, No. 5, pp. 1943-1977, December.

Carlstrom, Charles T. and Timothy S. Fuerst (1997) "Agency Costs, Net Worth, and Business Fluctuations: A Computable General Equilibrium Analysis," American Economic Review, Vol. 87, No. 5, pp. 893-910, December.

Cecchetti, Stephen G., Sunil Mohanty, and Fabrizio Zampolli (2011) "Achieving growth amid fiscal imbalances: the real effects of debt," Proceedings - Economic Policy Symposium - Jackson Hole, pp. 145-196.

Chari, Varadarajan V., Patrick J. Kehoe, and Ellen R. McGrattan (2007) "Business Cycle Accounting," Econometrica, Vol. 75, No. 3, pp. 781-836, May.

Christiano, Lawrence J. and Jonas D.M. Fisher (2000) "Algorithms for solving dynamic models with occasionally binding constraints," Journal of Economic Dynamics and Control, Vol. 24, No. 8, pp. 1179 - 1232.

Christiano, Lawrence J., Roberto Motto, and Massimo Rostagno (2014) "Risk Shocks," American Economic Review, Vol. 104, No. 1, pp. 27-65, January. 
Christiano, Lawrence J., Martin S. Eichenbaum, and Mathias Trabandt (2015) "Understanding the Great Recession," American Economic Journal: Macroeconomics, Vol. 7, No. 1, pp. 110-167, January.

Cole, Harold L. and Lee E. Ohanian (2004) "New Deal Policies and the Persistence of the Great Depression: A General Equilibrium Analysis," Journal of Political Economy, Vol. 112, No. 4, pp. 779-816, August.

Comin, Diego and Mark Gertler (2006) "Medium-Term Business Cycles," American Economic Review, Vol. 96, No. 3, pp. 523-551, June.

Cooley, Thomas, Ramon Marimon, and Vincenzo Quadrini (2004) "Aggregate Consequences of Limited Contract Enforceability," Journal of Political Economy, Vol. 112, No. 4, pp. 817-847, August.

Duval, Romain A, Gee Hee Hong, and Yannick Timmer (2017) "Financial Frictions and the Great Productivity Slowdown," IMF Working Papers 17/129, International Monetary Fund.

Eggertsson, Gauti B. and Neil R. Mehrotra (2014) "A Model of Secular Stagnation," NBER Working Papers 20574, National Bureau of Economic Research, Inc.

Fernald, John (2012) "A quarterly, utilization-adjusted series on total factor productivity," Working Paper Series 2012-19, Federal Reserve Bank of San Francisco. (updated March 2014).

Fukao, Kyoji and Tsutomu Miyagawa eds. (2008) Productivity and Japan's Economic Growth, Tokyo: University of Tokyo Press. (in Japanese).

Gale, Douglas and Martin Hellwig (1985) "Incentive-Compatible Debt Contracts: The One-Period Problem," Review of Economic Studies, Vol. 52, No. 4, pp. 647-663, October.

Geanakoplos, John (2014) "Leverage, Default, and Forgiveness: Lessons from the American and European Crises," Journal of Macroeconomics, Vol. 39, No. PB, pp. 313-333.

Giroud, Xavier and Holger M. Mueller (2017) "Firm Leverage, Consumer Demand, and Employment Losses during the Great Recession," Quarterly Journal of Economics, Vol. 132, No. 1, pp. 271-316, February.

Gordon, Robert J. (2012) "Is U.S. Economic Growth Over? Faltering Innovation Confronts the Six Headwinds," NBER Working Papers 18315, National Bureau of Economic Research, Inc. 
Guerrieri, Luca and Matteo Iacoviello (2015) "OccBin: A toolkit for solving dynamic models with occasionally binding constraints easily," Journal of Monetary Economics, Vol. 70, No. C, pp. 22-38, March.

Guerrón-Quintana, Pablo and Ryo Jinnai (2014) "Liquidity, trends, and the great recession," Working Papers 14-24, Federal Reserve Bank of Philadelphia.

Havik, Karel, Kieran Mc Morrow, Fabrice Orlandi, Christophe Planas, Rafal Raciborski, Werner Roeger, Alessandro Rossi, Anna Thum-Thysen, and Valerie Vandermeulen (2014) "The Production Function Methodology for Calculating Potential Growth Rates \& Output Gaps," European Economy - Economic Papers 535, Directorate General Economic and Financial Affairs (DG ECFIN), European Commission.

Hayashi, Fumio and Edward C. Prescott (2002) "The 1990s in Japan: A Lost Decade," Review of Economic Dynamics, Vol. 5, No. 1, pp. 206-235, January.

Ikeda, Daisuke and Takushi Kurozumi (2014) "Post-Crisis Slow Recovery and Monetary Policy," IMES Discussion Paper Series 14-E-16, Institute for Monetary and Economic Studies, Bank of Japan.

Jermann, Urban J. and Vincenzo Quadrini (2006) "Financial Innovations and Macroeconomic Volatility," NBER Working Papers, No. 12308, June.

_ (2007) "Stock market boom and the productivity gains of the 1990s," Journal of Monetary Economics, Vol. 54, No. 2, pp. 413-432, March.

(2012) "Macroeconomic Effects of Financial Shocks," American Economic Review, Vol. 102, No. 1, pp. 238-271, February.

Juillard, Michel (1996) "Dynare : a program for the resolution and simulation of dynamic models with forward variables through the use of a relaxation algorithm," CEPREMAP Working Papers (Couverture Orange) 9602, CEPREMAP.

Kaihatsu, Sohei and Takushi Kurozumi (2014) "What caused Japan's Great Stagnation in the 1990s? Evidence from an estimated DSGE model," Journal of the Japanese and International Economies, Vol. 34, No. C, pp. 217-235.

Kehoe, Timothy J. and Edward C. Prescott eds. (2007) Great Depressions of the Twentieth Century, Minneapolis: Federal Reserve Bank of Minneapolis.

Kiyotaki, Nobuhiro and John Moore (1997) "Credit Cycles," Journal of Political Economy, Vol. 105, No. 2, pp. 211-248. 
Kobayashi, Keiichiro (2011) "A Model of Financial Crises: Coordination failure due to bad assets," Discussion papers 11010, Research Institute of Economy, Trade and Industry (RIETI).

Kobayashi, Keiichiro and Masaru Inaba (2006) "Business cycle accounting for the Japanese economy," Japan and the World Economy, Vol. 18, No. 4, pp. 418-440, December.

Kobayashi, Keiichiro and Tomoyuki Nakajima (2017) "A Theory of Non-performing Loans and Debt Restructuring." mimeo.

Kobayashi, Keiichiro and Daichi Shirai (2016) "Heterogeneity and redistribution in financial crises," Macroeconomic Dynamics, Vol. 20, No. 6, pp. 1527-1549, September.

Krugman, Paul R. (1988) "Financing vs. forgiving a debt overhang," Journal of Development Economics, Vol. 29, No. 3, pp. 253-268, November.

Lamont, Owen (1995) "Corporate-Debt Overhang and Macroeconomic Expectations," American Economic Review, Vol. 85, No. 5, pp. 1106-1117, December.

Lo, Stephanie and Kenneth Rogoff (2015) "Secular stagnation, debt overhang and other rationales for sluggish growth, six years on," BIS Working Papers 482, Bank for International Settlements.

Mian, Atif, Amir Sufi, and Emil Verner (2017) "Household Debt and Business Cycles Worldwide," The Quarterly Journal of Economics, Vol. 132, No. 4, pp. 1755-1817.

Mulligan, Casey B. (2002) "A Dual Method of Empirically Evaluating Dynamic Competitive Equilibrium Models with Market Distortions, Applied to the Great Depression \& World War II," NBER Working Papers 8775, National Bureau of Economic Research, Inc.

Myers, Stewart C. (1977) "Determinants of corporate borrowing," Journal of Financial Economics, Vol. 5, No. 2, pp. 147-175, November.

Nishimura, Kiyohiko G., Takanobu Nakajima, and Kozo Kiyota (2005) "Does the natural selection mechanism still work in severe recessions?: Examination of the Japanese economy in the 1990s," Journal of Economic Behavior \& Organization, Vol. 58, No. 1, pp. 53-78, September.

Ohanian, Lee E. (2001) "Why Did Productivity Fall So Much during the Great Depression?" American Economic Review, Vol. 91, No. 2, pp. 34-38, May.

Otsu, Keisuke (2011) "Accounting for Japanese Business Cycles: A Quest for Labor Wedges," Studies in Economics 1106, School of Economics, University of Kent. 
Peek, Joe and Eric S. Rosengren (2005) "Unnatural Selection: Perverse Incentives and the Misallocation of Credit in Japan," American Economic Review, Vol. 95, No. 4, pp. 1144-1166, September.

Pescatori, Andrea and Murat Tasci (2011) "Search frictions and the labor wedge," Working Paper 1111, Federal Reserve Bank of Cleveland.

Reinhart, Carmen M. and Vincent R. Reinhart (2010) "After the Fall," NBER Working Papers, No. 16334, September.

Reinhart, Carmen M. and Kenneth S. Rogoff (2009) This Time Is Different: Eight Centuries of Financial Folly, Princeton: Princeton University Press.

Ríos-Rull, José-Víctor and Raül Santaeulàlia-Llopis (2010) "Redistributive shocks and productivity shocks," Journal of Monetary Economics, Vol. 57, No. 8, pp. 931-948, November.

Rivera-Batiz, Luis A. and Paul M. Romer (1991) "Economic Integration and Endogenous Growth," The Quarterly Journal of Economics, Vol. 106, No. 2, pp. 531-555, May.

Rogoff, Kenneth (2016) "Debt Supercycle, Not Secular Stagnation," in Olivier Blanchard, Raghuram Rajan, Kenneth Rogoff, and Lawrence H. Summers eds. Progress and Confusion: The State of Macroeconomic Policy: MIT Press, Chap. 2, pp. 19-28.

Rotemberg, Julio J. and Michael Woodford (1997) "An Optimization-based Econometric Framework for the Evaluation of Monetary Policy," in Ben S. Bernanke and Julio J. Rotemberg eds. NBER Macroeconomics Annual 1997, Cambridge, MA: MIT Press, pp. 297-346.

Schneider, Dorothee (2011) "The Labor Share: A Review of Theory and Evidence," SFB 649 Discussion Papers SFB649DP2011-069, Humboldt University, Collaborative Research Center 649.

Shimer, Robert (2009) "Convergence in Macroeconomics: The Labor Wedge," American Economic Journal: Macroeconomics, Vol. 1, No. 1, pp. 280-97, January.

Stokey, Nancy L. and Robert E. Lucas, Jr., with Edward C. Prescott (1989) Recursive Methods in Economic Dynamics, Cambridge, MA: Harvard University Press.

Summers, Lawrence H. (2013) "IMF Economic Forum: Policy Responses to Crises." speech at the IMF Fourteenth Annual Research Conference, Washington, DC, 9 November.

Townsend, Robert M. (1979) "Optimal contracts and competitive markets with costly state verification," Journal of Economic Theory, Vol. 21, No. 2, pp. 265-293, October. 


\section{Appendices}

\section{A Proof of Lemma 2}

The proof of (i) is as follows. As $\tau=0$, the envelope condition (17) implies that $\frac{\partial}{\partial b} W(b, x)=-\lambda_{\pi} \leq 0$, that is, $W\left(b_{-1}, x\right)$ is weakly decreasing in $b_{-1}$. (ii) follows immediately from the facts that $B^{*}(x ; S)-b_{-1}$ is the dividend when $b_{-1}<B^{*}(x ; S)$ and the firm chooses $\sigma=\sigma^{*}(x)$ and that Assumption 2 implies that if $\sigma_{t}=\sigma^{*}\left(x_{t}\right)$, then $\sigma_{t+j}=\sigma^{*}\left(x_{t+j}\right)$ for all $j$. (iii) is shown as follows. When $B^{*}(x ; S)<b_{-1} \leq B_{z}(x ; S)$, we have $\frac{b^{*}(x ; S)}{R(x)}<\frac{b(x ; S)}{R(x)} \leq \xi S(x)$. This inequality and the definition of $b^{*}(x ; S)$ imply that the borrowing constraint is tight and $\sigma(x)<\sigma^{*}(x)$. Thus, $W\left(b_{-1}, x\right)<W^{*}(x)$. Now, suppose that $\pi>0$ in this case. Then, the firm can relax the borrowing constraint by reducing $\pi$ and $b$ and can increase $W\left(b_{-1}, x\right)$. This is a contradiction. Therefore, $\pi$ should be zero. When $b_{-1}>B_{z}(x ; S)$, it is clear that $W\left(b_{-1}, x\right)<W^{*}(x)$, and there exists $T$ such that the borrowing constraint is $\sigma_{t} \leq \phi f\left(\sigma_{t}, x_{t}\right)$ for $0 \leq t<T$, and $\sigma_{t} \leq \phi f\left(\sigma_{t}, x_{t}\right)+\xi S_{t}-\frac{b_{t}}{R_{t}}$ for $t \geq T$ in the sequential problem corresponding to the Bellman equation (11). Suppose $\pi_{0}>0$. Then, the firm can relax the borrowing constraint at $T$ by reducing $\pi_{0}$ and $b_{0}$ and can increase $W\left(b_{-1}, x\right)$. This is a contradiction. Thus, $\pi_{0}$ should be zero.

\section{B Proof of Proposition 5}

We prove Proposition 5 using the Schauder fixed point theorem (see, for example, Theorem 17.4 in Stokey and Lucas with Prescott, 1989). First, we define several parameters.

Definition 2. Define $r_{\min }, R_{\max }$, and $f_{\max }$ as follows:

$$
\begin{aligned}
& r_{\min }=\inf _{x \in \Lambda} r(x), \\
& R_{\max }=\sup _{x \in \Lambda} R(x), \\
& f_{\max }=\sup _{x \in \Lambda} \frac{\partial}{\partial \sigma} f\left(\sigma_{z}(x), x\right) .
\end{aligned}
$$

Note that $f_{\max }$ is the upper bound for $\frac{\partial}{\partial \sigma} f(\sigma, x)$ because $\sigma \geq \sigma_{z}(x)$ for all $x$, and $f(\sigma, x)$ is increasing and concave in $\sigma$. It is easily shown that

$$
f_{\max }=\frac{\eta}{\phi}
$$

Proposition 1 shows that, given $S\left(x_{t}\right)$, there exists a solution to (6) in which the value function can be denoted as $V(b, x ; S)$. Define the operator $T$ that maps $S\left(x_{t}\right)$ to $T S\left(x_{t}\right)$, where

$$
T S\left(x_{t}\right) \equiv \max _{b} \mathbb{E}_{t}\left[\frac{m_{t+1}}{m_{t}} V\left(b, x_{t+1} ; S\right)\right]+\frac{b}{R_{t}} .
$$


If the mapping $T: G \rightarrow G$ is continuous and the family $T(G)$ is equicontinuous, then the Schauder fixed point theorem applies, and it is shown that $T$ has a fixed point in $G$. Then, Proposition 5 is proven.

$T$ is clearly a mapping from $G$ to $G$, because $T(G) \subseteq G$. The continuity of $T$ follows directly from the continuity of $V(b, x ; S)$ with respect to $S$, which is shown in the following lemma.

Lemma 10. $V(b, x ; S)$ is continuous with respect to $S$, that is, for all $\varepsilon>0$, there exists $\delta>0$ such that if $\left|S-S^{\prime}\right|<\delta$ for any $S, S^{\prime} \in G$, then $\left|V(b, x ; S)-V\left(b, x ; S^{\prime}\right)\right|<\varepsilon$, where the norms are the sup norm.

Proof. The equivalence between the functional equation (6) and the corresponding infinite horizon problem shown in Theorem 9.2 of Stokey and Lucas with Prescott (1989) implies that

$$
\begin{aligned}
& V(b, x ; S)=\max _{\left\{\sigma_{t}, b_{t}\right\}_{t=0}^{\infty}} \mathbb{E}_{0}\left[\sum_{t=0}^{\infty} \frac{m_{t}}{m_{0}} \pi_{t}\right], \\
& \text { subject to } \quad \pi_{t}=f\left(\sigma_{t}, x_{t}\right)-\sigma_{t}-b_{t-1}+\frac{b_{t}}{R_{t}}, \\
& \sigma_{t} \leq \phi f\left(\sigma_{t}, x_{t}\right)+\max \left\{\xi S\left(x_{t}\right)-\frac{b_{t}}{R_{t}}, 0\right\}, \\
& b_{t} \leq b_{z}\left(x_{t}\right), \\
& \pi_{t} \geq 0, \\
& b_{-1}=b, \\
& x_{0}=x .
\end{aligned}
$$

The solution to the above problem is a path: $\left\{\sigma_{t}, b_{t}\right\}_{t=0}^{\infty}$. Assumptions 1 and 2 directly imply that there are three stages in this path, that is, given $b_{-1}$, there exist two integers, $t_{1}$ and $t_{2}$, where $0 \leq t_{1} \leq t_{2} \leq \infty$, such that

- Stage $1\left(B_{z, t}<b_{t-1} \leq \bar{B}_{z, t}\right)$ : $\xi S\left(x_{t}\right)<\frac{b_{t}}{R_{t}}$ for $0 \leq t<t_{1}$;

- Stage $2\left(B_{t}^{c e}<b_{t-1} \leq B_{z, t}\right): \xi S\left(x_{t}\right) \geq \frac{b_{t}}{R_{t}}$ and $\sigma_{t}<\sigma^{c e}\left(x_{t}\right)$ for $t_{1} \leq t<t_{2}$;

- Stage $3\left(b_{t-1} \leq B_{t}^{c e}\right): \xi S\left(x_{t}\right) \geq \frac{b_{t}}{R_{t}}$ and $\sigma_{t}=\sigma^{c e}\left(x_{t}\right)$ for $t \geq t_{2}$.

Note that the values of $t_{1}$ and $t_{2}$ are history-dependent, but the history dependence does not affect the following proof. Assumption 1 implies that once the economy enters Stage 2 , it never returns to Stage 1. Assumption 2 implies that once the economy enters Stage 3 , it never returns to Stage 2. As we saw in Section 3.3, $\pi_{t}=0$ in Stages 1 and 2, and $\pi_{t}>0$ in Stage 3.

Now, we evaluate $|V(b, x ; S)-V(b, x ; S+\delta / \xi)|$, where $S+\delta / \xi=S(x)+\delta / \xi$ for a small $\delta>0$. We use $\left\{\sigma_{t}(\delta), b_{t}(\delta)\right\}_{t=0}^{\infty}=\left\{\sigma_{t}+\hat{\sigma}_{t}(\delta), b_{t}-\hat{b}_{t}(\delta)\right\}_{t=0}^{\infty}$ to denote the solution to the 
above infinite horizon problem, with $S$ replaced by $S+\delta / \xi$. The corresponding dividend stream is written as $\left\{\pi_{t}(\delta)\right\}_{t=0}^{\infty}=\left\{\pi_{t}+\hat{\pi}_{t}(\delta)\right\}_{t=0}^{\infty}$. The boundary of stages, $\left\{t_{1}, t_{2}\right\}$, changes to $\left\{t_{1}(\delta), t_{2}(\delta)\right\}$. We assume that $\delta$ is sufficiently small, such that

$$
(\Theta+1) \delta<\inf _{x \in \Lambda}(1-\phi) f\left(\sigma_{z}(x), x\right)-\nabla,
$$

where $\Theta$ is defined in (35) below. Note that Assumption 3 warrants the existence of $\delta(>0)$.

Stage 1: For $t \leq t_{1}(\delta), \frac{b_{t}}{R_{t}}>\xi S_{t}+\delta$. Thus, for $t \leq t_{1}(\delta)$, the change from $\xi S$ to $\xi S+\delta$ does not change the variables; $\left(\sigma_{t}(\delta), b_{t}(\delta)\right)=\left(\sigma_{t}, b_{t}\right)$ or $\left(\hat{\sigma}_{t}(\delta), \hat{b}_{t}(\delta)\right)=$ $(0,0)$. The dividend is also zero: $\pi_{t}(\delta)=\pi_{t}=0$. Therefore, as (28) implies that $\delta<\inf _{x \in \Lambda} f\left(\sigma_{z}(x), x\right)-\sigma_{z}(x)$, it is clear that $t_{1}-1 \leq t_{1}(\delta) \leq t_{1}$. We evaluate the value of $b_{t_{1}-1}(\delta)$, which is the initial debt at the beginning of $t_{1}$, in the case where $\xi S_{t}$ changes to $\xi S_{t}+\delta$ in the above borrowing constraint.

- Case where $t_{1}(\delta)=t_{1}$ :

In this case, it is obvious that $b_{t}(\delta)=b_{t}$ for all $t \leq t_{1}-1$. Thus, $b_{t_{1}-1}(\delta)=b_{t_{1}-1}$.

- Case where $t_{1}(\delta)=t_{1}-1$ :

In this case, $b_{t_{1}-2}(\delta)=b_{t_{1}-2}$ and $\xi S_{t_{1}-1} \geq \frac{b_{t_{1}-1}(\delta)}{R_{t_{1}-1}}$. The budget and borrowing constraints in period $t_{1}-1$ imply

$$
b_{t_{1}-2}-\xi S_{t_{1}-1}-\delta=(1+\phi) f\left(\sigma_{t_{1}-1}(\delta), x_{t_{1}-1}\right)-2 \sigma_{t_{1}-1}(\delta) \text {. }
$$

In the original problem with $\xi S_{t}$, the budget and borrowing constraints imply

$$
b_{t_{1}-2}-\xi S_{t_{1}-1}>(1+\phi) f\left(\sigma_{z, t_{1}-1}, x_{t_{1}-1}\right)-2 \sigma_{z, t_{1}-1} .
$$

The parameter restriction that $\frac{\eta}{2-\eta}<\phi$ in Assumption 3 implies that $(1+\phi) \frac{\partial}{\partial \sigma} f(\sigma, x)-$ $2 \leq(1+\phi) f_{\max }-2<0$, which implies that function $(1+\phi) f(\sigma, x)-2 \sigma$ is decreasing in $\sigma$. Thus, $\hat{\sigma}_{t_{1}-1}(\delta)>0$, and (29) and (30) imply

$$
0 \leq(1+\phi) f\left(\sigma_{z, t_{1}-1}, x_{t_{1}-1}\right)-2 \sigma_{z, t_{1}-1}-\left[(1+\phi) f\left(\sigma_{t_{1}-1}(\delta), x_{t_{1}-1}\right)-2 \sigma_{t_{1}-1}(\delta)\right] \leq \delta .
$$

The concavity of $f(\sigma, x)$ and $(1+\phi) \frac{\partial}{\partial \sigma} f(\sigma, x)-2<0$ imply that

$$
\begin{aligned}
& (1+\phi) f\left(\sigma_{t_{1}-1}(\delta), x_{t_{1}-1}\right)-2 \sigma_{t_{1}-1}(\delta)< \\
& \quad(1+\phi) f\left(\sigma_{z, t_{1}-1}, x_{t_{1}-1}\right)-2 \sigma_{z, t_{1}-1}-\left[2-(1+\phi) f_{\max }\right] \hat{\sigma}_{t_{1}-1}(\delta) .
\end{aligned}
$$

Inequalities (31) and (32) imply that

$$
0 \leq \hat{\sigma}_{t_{1}-1}(\delta) \leq \frac{\delta}{2-(1+\phi) f_{\max }} .
$$


Then, $\frac{b_{t_{1}-1}(\delta)}{R_{t_{1}-1}}=\phi f\left(\sigma_{t_{1}-1}(\delta), x_{t_{1}-1}\right)-\sigma_{t_{1}-1}(\delta)+\xi S_{t_{1}-1}+\delta$ must satisfy

$$
\left[\frac{1-(1+\phi) f_{\max }}{2-(1+\phi) f_{\max }}\right] \delta \leq \frac{b_{t_{1}-1}(\delta)}{R_{t_{1}-1}}-\frac{b_{t_{1}-1}}{R_{t_{1}-1}} \leq\left[\frac{2-f_{\max }}{2-(1+\phi) f_{\max }}\right] \delta .
$$

Therefore, there exists a positive number $C_{-1}$ such that $b_{t_{1}-1}-C_{-1} \delta<b_{t_{1}-1}(\delta)<$ $b_{t_{1}-1}+C_{-1} \delta$.

Stage 2: $\quad$ Note that $\pi_{t}(\delta)=0$ for $t \leq t_{2}(\delta)-1$. We denote $t=t_{1}+n$ and count time by $n$. The above analysis of Stage 1 implies that $b_{t_{1}-1}(\delta)$ satisfies $b_{t_{1}-1}-C_{-1} \delta<$ $b_{t_{1}-1}(\delta)<b_{t_{1}-1}+C_{-1} \delta$. We change the subscript of the variables from $t$ to $n$. Define $\bar{n}$ as the solution to

$$
\xi \bar{\omega}=\sum_{i=1}^{\bar{n}} \frac{(1-\phi) \underline{\mathrm{f}}_{z}}{\left(1+r_{\max }\right)^{i}} .
$$

Note that Assumption 1 warrants that this equation has a finite solution $\bar{n}$ and that $\bar{n}$ does not depend on $S(x)$. Then,

$$
t_{2}(\delta)-t_{1}(\delta) \leq \bar{n}
$$

In period $n=0$, which corresponds to $t=t_{1}$, we have $f\left(\sigma_{0}(\delta)\right)-\sigma_{0}(\delta) \leq f\left(\sigma_{0}\right)-\sigma_{0}+$ $\left(f_{\max }-1\right) \hat{\sigma}_{0}(\delta)$. The budget constraint implies that $\frac{\hat{b}_{0}(\delta)}{R_{0}} \leq\left(f_{\max }-1\right) \hat{\sigma}_{0}(\delta)+C_{-1} \delta$. Then, the borrowing constraint implies that $\hat{\sigma}_{0}(\delta) \leq \phi f_{\max } \hat{\sigma}_{0}(\delta)+\delta+\left(f_{\max }-1\right) \hat{\sigma}_{0}(\delta)+C_{-1} \delta$, which can be rewritten as $\hat{\sigma}_{0}(\delta)=\frac{\left(1+C_{-1}\right) \delta}{2-(1+\phi) f_{\max }}$. We define

$$
A_{0} \equiv \frac{f_{\max }-1}{2-(1+\phi) f_{\max }}(>0) .
$$

Then, $\left(f_{\max }-1\right) \hat{\sigma}_{0}(\delta)=\left(1+C_{-1}\right) A_{0} \delta$ and $\frac{b_{0}(\delta)}{R_{0}} \geq \frac{b_{0}}{R_{0}}-\left(1+C_{-1}\right) A_{0} \delta$. In period $n=1$, $f\left(\sigma_{1}(\delta)\right)-\sigma_{1}(\delta) \leq f\left(\sigma_{1}\right)-\sigma_{1}+\left(f_{\max }-1\right) \hat{\sigma}_{1}(\delta)$. The budget constraint implies that $\frac{\hat{b}_{1}(\delta)}{R_{1}} \leq\left(f_{\max }-1\right) \hat{\sigma}_{1}(\delta)+\left(1+C_{-1}\right) R_{\max } A_{0} \delta$. Then, the borrowing constraint implies that $\hat{\sigma}_{1}(\delta) \leq \phi f_{\max } \hat{\sigma}_{1}(\delta)+\delta+\left(f_{\max }-1\right) \hat{\sigma}_{1}(\delta)+\left(1+C_{-1}\right) R_{\max } A_{0} \delta$, which can be rewritten as $\hat{\sigma}_{1}(\delta)=\frac{\left[1+\left(1+C_{-1}\right) R_{\max } A_{0}\right]}{2-(1+\phi) f_{\max }} \delta$. We define

$$
A_{1} \equiv A_{0}\left[1+\left(1+C_{-1}\right) R_{\max } A_{0}\right]
$$

Then, $\left(f_{\max }-1\right) \hat{\sigma}_{1}(\delta)=A_{1} \delta$ and $\frac{b_{1}(\delta)}{R_{1}} \geq \frac{b_{1}}{R_{1}}-\left[\left(1+C_{-1}\right) R_{\max } A_{0}+A_{1}\right] \delta$. In period $n=2$, $f\left(\sigma_{2}(\delta)\right)-\sigma_{2}(\delta) \leq f\left(\sigma_{2}\right)-\sigma_{2}+\left(f_{\max }-1\right) \hat{\sigma}_{2}(\delta)$. The budget constraint implies that $\frac{\hat{b}_{2}(\delta)}{R_{2}} \leq\left(f_{\max }-1\right) \hat{\sigma}_{2}(\delta)+\left[\left(1+C_{-1}\right) R_{\max }^{2} A_{0}+R_{\max } A_{1}\right] \delta$. Then, the borrowing constraint implies that $\hat{\sigma}_{2}(\delta) \leq \phi f_{\max } \hat{\sigma}_{2}(\delta)+\delta+\left(f_{\max }-1\right) \hat{\sigma}_{2}(\delta)+\left[\left(1+C_{-1}\right) R_{\max }^{2} A_{0}+R_{\max } A_{1}\right] \delta$, which can be rewritten as $\hat{\sigma}_{2}(\delta)=\frac{\left[1+\left(1+C_{-1}\right) R_{\max }^{2} A_{0}+R_{\max } A_{1}\right]}{2-(1+\phi) f_{\max }} \delta$. We define

$$
A_{2} \equiv A_{0}\left[1+\left(1+C_{-1}\right) R_{\max }^{2} A_{0}+R_{\max } A_{1}\right]
$$


Then, $\left(f_{\max }-1\right) \hat{\sigma}_{2}(\delta)=A_{2} \delta$ and $\frac{b_{2}(\delta)}{R_{2}} \geq \frac{b_{2}}{R_{2}}-\left[\left(1+C_{-1}\right) R_{\max }^{2} A_{0}+R_{\max } A_{1}+A_{2}\right] \delta$. Similarly, the following claim is proven by induction. To simplify the notation, we define

$$
A_{-1} \equiv \frac{C_{-1} A_{0}}{R_{\max }}
$$

Then, $A_{1}=A_{0}\left(1+R_{\max } A_{0}+R_{\max }^{2} A_{-1}\right)$ and $A_{2}=A_{0}\left(1+R_{\max } A_{1}+R_{\max }^{2} A_{0}+R_{\max }^{3} A_{-1}\right)$.

Claim 2. Suppose the economy is in Stage 2 in period $n$ (for $0 \leq n \leq \bar{n}$ ). Then,

$$
\frac{\hat{b}_{n}(\delta)}{R_{n}} \leq\left(\sum_{i=0}^{n+1} R_{\max }^{i} A_{n-i}\right) \delta
$$

where $A_{n}$ is defined by

$$
A_{n} \equiv A_{0}\left[1+R_{\max }\left(\sum_{i=0}^{n+1} R_{\max }^{i} A_{n-i}\right)\right] .
$$

Proof. This claim holds true for $n=0,1,2$, as we see above. Suppose (33) holds true for $n=j$. Then, for $n=j+1$, the budget constraint and borrowing constraint imply that

$$
\begin{aligned}
& 0 \leq\left(f_{\max }-1\right) \hat{\sigma}_{j+1}(\delta)+R_{\max }\left(\sum_{i=0}^{j+1} R_{\max }^{i} A_{j-i}\right) \delta-\frac{\hat{b}_{j+1}(\delta)}{R_{j+1}}, \\
& \hat{\sigma}_{j+1}(\delta) \leq \phi f_{\max } \hat{\sigma}_{j+1}(\delta)+\delta+\frac{\hat{b}_{j+1}(\delta)}{R_{j+1}} .
\end{aligned}
$$

These equations imply that

$$
\left(f_{\max }-1\right) \hat{\sigma}_{j+1}(\delta) \leq A_{0}\left[1+R_{\max }\left(\sum_{i=0}^{j} R_{\max }^{i} A_{j-i}\right)\right] \delta .
$$

Defining $A_{j+1} \equiv A_{0}\left[1+R_{\max }\left(\sum_{i=0}^{j} R_{\max }^{i} A_{j-i}\right)\right]$, this equation is written as $\left(f_{\max }-\right.$ 1) $\hat{\sigma}_{j+1}(\delta)=A_{j+1} \delta$, and (34) implies that $\frac{\hat{b}_{j+1}(\delta)}{R_{j+1}} \leq A_{j+1} \delta+R_{\max }\left(\sum_{i=0}^{j} R_{\max }^{i} A_{j-i}\right) \delta=$ $\left(\sum_{i=0}^{j+1} R_{\max }^{i} A_{j+1-i}\right) \delta$. Therefore, it has been shown that (33) holds true for $0 \leq n \leq \bar{n}$ as long as period $n$ is in Stage 2 .

Now, as $t_{2}(\delta)-t_{1}(\delta) \leq \bar{n}$, it holds true that for $n \leq t_{2}(\delta)-t_{1}(\delta)$,

$$
\frac{\hat{b}_{n}(\delta)}{R_{n}} \leq \Theta \delta
$$

where the constant, $\Theta$, is defined by

$$
\Theta \equiv\left(\sum_{i=0}^{\bar{n}+1} R_{\max }^{i} A_{\bar{n}-i}\right)
$$


Stage 3: Now, we use subscript $t$ instead of $n$. We can show that $t_{2}-1 \leq t_{2}(\delta) \leq t_{2}$ as follows. Define $B_{t}^{c e}(\delta) \equiv f\left(\sigma_{t}^{c e}, x_{t}\right)-\sigma_{t}^{c e}+\frac{b_{t}^{c e}(\delta)}{R_{t}}$ and $\frac{b_{t}^{c e}(\delta)}{R_{t}} \equiv \phi f\left(\sigma_{t}^{c e}, x_{t}\right)-\sigma_{t}^{c e}+\xi S_{t}+\delta$. Thus, $B_{t}^{c e}(\delta)=B_{t}^{c e}+\delta$ and $\frac{b_{t}^{c e}(\delta)}{R_{t}}=\frac{b_{t}^{c e}}{R_{t}}+\delta$. We know that $b_{t_{2}-1}<B_{t_{2}}^{c e}$ and

$$
b_{t}>B_{t+1}^{c e}, \quad \text { for } t \leq t_{2}-2 .
$$

The variables $b_{t}(\delta)$ and $B_{t+1}^{c e}(\delta)$ for $t_{1}(\delta) \leq t \leq t_{2}-3$ satisfy the following inequality:

$$
\begin{aligned}
b_{t}(\delta)-B_{t+1}^{c e}(\delta) & \geq b_{t}-B_{t+1}^{c e}-(\Theta+1) \delta \\
& >\inf _{x \in \Lambda}(1-\phi) f\left(\sigma_{z}(x), x\right)+\frac{b_{t+1}}{R_{t+1}}-B_{t+1}^{c e}-(\Theta+1) \delta \\
& >\inf _{x \in \Lambda}(1-\phi) f\left(\sigma_{z}(x), x\right)+\frac{B_{t+2}^{c e}}{R_{t+1}}-B_{t+1}^{c e}-(\Theta+1) \delta \\
& >\inf _{x \in \Lambda}(1-\phi) f\left(\sigma_{z}(x), x\right)-\nabla-(\Theta+1) \delta>0 .
\end{aligned}
$$

The first inequality is due to $b_{t}(\delta) \geq b_{t}-\Theta \delta$ and $B_{t}^{c e}(\delta)=B_{t}^{c e}+\delta$. The second inequality is due to $b_{t}=\frac{b_{t+1}}{R_{t+1}}+f\left(\sigma_{t+1}, x_{t+1}\right)-\sigma_{t+1} \geq \frac{b_{t+1}}{R_{t+1}}+\inf (1-\phi) f\left(\sigma_{z, t}, x_{t}\right)$. The third inequality is due to (36). The fourth inequality is due to the definition of $\nabla$ in Assumption 3. The final inequality is due to (28). Thus, we have shown that the economy is in Stage 2 for $t \leq t_{2}-2$. Therefore, it must be the case that $t_{2}(\delta)=t_{2}-1$ or $t_{2}$. We evaluate $|V(b, x ; S)-V(b, x ; S+\delta / \xi)|$ for each case.

- Case where $t_{2}(\delta)=t_{2}$ :

In this case,

$$
\begin{aligned}
\pi_{t_{2}}(\delta) & =f\left(\sigma_{t_{2}}^{c e}, x_{t_{2}}\right)-\sigma_{t_{2}}^{c e}+\frac{b_{t_{2}}^{c e}(\delta)}{R_{t_{2}}}-b_{t_{2}-1}(\delta) \\
& \leq f\left(\sigma_{t_{2}}^{c e}, x_{t_{2}}\right)-\sigma_{t_{2}}^{c e}+\frac{b_{t_{2}}^{c e}}{R_{t_{2}}}+\delta-b_{t_{2}-1}+\Theta \delta \\
& =\pi_{t_{2}}+(\Theta+1) \delta .
\end{aligned}
$$

The inequality is due to $\frac{b_{t_{2}}^{c e}(\delta)}{R_{t_{2}}}=\frac{b_{t_{2}}^{c e}}{R_{t_{2}}}+\delta$ and $b_{t_{2}-1}(\delta) \geq b_{t_{2}-1}-\Theta \delta$. For $t \geq t_{2}+1$,

$$
\begin{aligned}
\pi_{t}(\delta) & =f\left(\sigma_{t}^{c e}, x_{t}\right)-\sigma_{t}^{c e}+\frac{b_{t}^{c e}(\delta)}{R_{t}}-b_{t-1}^{c e}(\delta) \\
& =\pi_{t}+\left(1-R_{t-1}\right) \delta .
\end{aligned}
$$

In this case, using the fact that $t_{2}(\delta) \geq 0$,

$$
\begin{aligned}
|V(b, x ; S)-V(b, x ; S+\delta / \xi)| & \leq \mathbb{E}_{0}\left[\sum_{t=0}^{\infty} \frac{m_{t}}{m_{0}}\left|\pi_{t}-\pi_{t}(\delta)\right|\right] \\
& \leq(\Theta+1) \delta+\sum_{t=1}^{\infty} \frac{R_{\max }-1}{\left(1+r_{\min }\right)^{t}} \delta \\
& =\left(\Theta+1+\frac{R_{\max }-1}{r_{\min }}\right) \delta .
\end{aligned}
$$


- Case where $t_{2}(\delta)=t_{2}-1$ :

In the original firm's problem with $S$, it holds true that $b_{t_{2}-2}>B_{t_{2}-1}^{c e}$ and $b_{t_{2}-1} \leq$ $B_{t_{2}}^{c e}$, whereas in the modified firm's problem with $S+\delta / \xi$, it holds true that $b_{t_{2}-2}(\delta) \leq$ $B_{t_{2}-1}^{c e}(\delta)$, where $b_{t_{2}-2}(\delta) \geq b_{t_{2}-2}-\Theta \delta$. In the original problem, the budget constraint with $\pi_{t_{2}-1}=0$ and the borrowing constraint imply

$$
(1+\phi) f\left(\sigma_{t_{2}-1}, x_{t_{2}-1}\right)-\sigma_{t_{2}-1}=b_{t_{2}-2}-\xi S_{t_{2}-1} .
$$

In the modified problem, there exists $\hat{C}\left(b_{t_{2}-2}\right)$ such that $0<\hat{C}\left(b_{t_{2}-2}\right) \leq \Theta$ and

$$
b_{t_{2}-2}-\hat{C}\left(b_{t_{2}-2}\right) \delta=B_{t_{2}-1}^{c e}(\delta) .
$$

This equation and the borrowing constraint $\sigma_{t_{2}-1}^{c e}=\phi f\left(\sigma_{t_{2}-1}^{c e}, x_{t_{2}-1}\right)+\xi S_{t_{2}-1}+\delta-$ $b_{t_{2}-1}^{c e}(\delta) / R_{t_{2}-1}$ together imply that

$$
(1+\phi) f\left(\sigma_{t_{2}-1}^{c e}, x_{t_{2}-1}\right)-\sigma_{t_{2}-1}^{c e}=b_{t_{2}-2}-\xi S_{t_{2}-1}-\left(\hat{C}\left(b_{t_{2}-2}\right)+1\right) \delta .
$$

The derivative of function $(1+\phi) f(\sigma, x)-2 \sigma$ satisfies

$$
-2<(1+\phi) \frac{\partial}{\partial \sigma} f(\sigma, x)-2<(1+\phi) f_{\max }-2<0 .
$$

The rightmost inequality is due to $f_{\max }=\eta / \phi$ and $\frac{\eta}{2-\eta}<\phi$. Then, because $(1+$ $\phi) f(\sigma, x)-2 \sigma$ is concave and continuously differentiable with respect to $\sigma$, the equations (37) and (38), together with inequality (39), imply that

$$
\sigma_{t_{2}-1}^{c e}-\frac{\hat{C}\left(b_{t_{2}-2}\right)+1}{2-(1+\phi) f_{\max }} \delta \leq \sigma_{t_{2}-1} \leq \sigma_{t_{2}-1}^{c e}-\frac{\hat{C}\left(b_{t_{2}-2}\right)+1}{2} \delta .
$$

The fact that $0<\hat{C}\left(b_{t_{2}-2}\right) \leq \Theta$ implies that

$$
\sigma_{t_{2}-1}^{c e}-\Phi \delta \leq \sigma_{t_{2}-1} \leq \sigma_{t_{2}-1}^{c e}-\frac{1}{2} \delta
$$

where $\Phi \equiv \frac{\Theta+1}{2-(1+\phi) f_{\max }}$. This inequality and the concavity and differentiability of $f(\sigma, x)$ imply that

$$
\frac{b_{t_{2}-1}^{c e}(\delta)}{R_{t_{2}-1}}+(\eta \Phi+1) \delta<\frac{b_{t_{2}-1}}{R_{t_{2}-1}}<\frac{b_{t_{2}-1}^{c e}(\delta)}{R_{t_{2}-1}}+(\Phi-1) \delta
$$

because $b_{t_{2}-1} / R_{t_{2}-1}=\phi f\left(\sigma_{t_{2}-1}, x_{t_{2}-1}\right)-\sigma_{t_{2}-1}+\xi S_{t_{2}-1}$. Now, we evaluate $\pi_{t}(\delta)$ for $t=t_{2}-1, t_{2}, t_{2}+1, \cdots$. We know $\pi_{t_{2}-1}=0$ in the original problem. The inequalities (40) and (41), together with $b_{t_{2}-2}(\delta) \geq b_{t_{2}-2}-\Theta \delta$, imply that

$$
\begin{aligned}
\pi_{t_{2}-1}(\delta) & \leq f\left(\sigma_{t_{2}-1}^{c e}, x_{t_{2}-1}\right)-\sigma_{t_{2}-1}^{c e}+\frac{b_{t_{2}-1}^{c e}(\delta)}{R_{t_{2}-1}}-b_{t_{2}-2}+\Theta \delta \\
& \leq f\left(\sigma_{t_{2}-1}+\Phi \delta, x_{t_{2}-1}\right)-\sigma_{t_{2}-1}-\frac{1}{2} \delta+\frac{b_{t_{2}-1}}{R_{t_{2}-1}}-(\eta \Phi+1) \delta-b_{t_{2}-2}+\Theta \delta \\
& <\left[\left(f_{\max }-\eta\right) \Phi+\Theta-\frac{3}{2}\right] \delta .
\end{aligned}
$$


Similarly,

$$
\begin{aligned}
\pi_{t_{2}}(\delta) & =f\left(\sigma_{t_{2}}^{c e}, x_{t_{2}}\right)-\sigma_{t_{2}}^{c e}+\frac{b_{t_{2}}^{c e}(\delta)}{R_{t_{2}}}-b_{t_{2}-1}^{c e}(\delta) \\
& \leq f\left(\sigma_{t_{2}}^{c e}, x_{t_{2}}\right)-\sigma_{t_{2}}^{c e}+\frac{b_{t_{2}}^{c e}}{R_{t_{2}}}+\delta-b_{t_{2}-1}+R_{t_{2}-1}(\Phi-1) \delta \\
& =\pi_{t_{2}}+\left[1+R_{t_{2}-1}(\Phi-1)\right] \delta
\end{aligned}
$$

For $t \geq t_{2}+1$, the same result holds as in the case where $t_{2}(\delta)=t_{2}$ :

$$
\pi_{t}(\delta)=\pi_{t}+\left(1-R_{t-1}\right) \delta .
$$

Define $\Psi \equiv \sup _{x \in \Lambda}|1+R(x)(\Phi-1)|$. Then, using $t_{2}-1 \geq 0$,

$$
\begin{aligned}
|V(b, x ; S)-V(b, x ; S+\delta / \xi)| & \leq \mathbb{E}_{0}\left[\sum_{t=0}^{\infty} \frac{m_{t}}{m_{0}}\left|\pi_{t}-\pi_{t}(\delta)\right|\right] \\
& \leq\left[\left(f_{\max }-\eta\right) \Phi+\Theta-\frac{3}{2}\right] \delta+\frac{\Psi}{1+r_{\min }} \delta+\sum_{t=2}^{\infty} \frac{R_{\max }-1}{\left(1+r_{\min }\right)^{t}} \delta \\
& =\left[\left(f_{\max }-\eta\right) \Phi+\Theta-\frac{3}{2}+\frac{\Psi}{1+r_{\min }}+\frac{R_{\max }-1}{\left(1+r_{\min }\right) r_{\min }}\right] \delta .
\end{aligned}
$$

The above analysis of Stages 1-3 implies that there exists a positive number $C$ that does not depend on $(\varepsilon, \delta, S)$ such that for a sufficiently small and positive number $\delta$ that satisfies (28),

$$
|V(b, x ; S+\delta / \xi)-V(b, x ; S)|<C \delta .
$$

This inequality implies that, for any small $\varepsilon>0$, there exists $\delta \leq \frac{\varepsilon}{C}$, such that $\mid V\left(b, x ; S^{\prime}\right)-$ $V(b, x ; S) \mid<\varepsilon$ if $\left|S^{\prime}-S\right|<\delta$. Thus, $V(b, x ; S)$ is continuous with respect to $S$.

Given the continuity of $V$, it is clear that $T$ is continuous with respect to $S$; that is, for any $\varepsilon>0$, there exists $\delta>0$ such that $\left|T S^{\prime}-T S\right|<\varepsilon$ if $\left|S^{\prime}-S\right|<\delta$. The equicontinuity of $T(G)$ is also shown as follows.

Lemma 11. $T(G)$ is an equicontinuous family; that is, for all $\varepsilon>0$, there exists $\delta>0$ such that for all $T S(x) \in T(G),\left|T S\left(x^{\prime}\right)-T S(x)\right|<\varepsilon$ if $\left|x^{\prime}-x\right|<\delta$.

Proof. Pick a small $\varepsilon(>0)$ arbitrarily. We fix $\varepsilon$ throughout this proof. As $T S$ is defined as $T S(x)=\max _{b} \mathbb{E}\left[\frac{m^{\prime}}{m(x)} V\left(b, x^{\prime}, S\right)\right]+\frac{b}{R(x)}$, the continuity of $V$ with respect to $x$ (see Proposition 1) implies that there exists $\delta>0$ such that $\left|T S\left(x^{\prime}\right)-T S(x)\right|<\frac{\varepsilon}{2}$, if $\left|x^{\prime}-x\right|<\delta$. Note that the maximum value of $\delta$ that satisfies the above condition must depend on $S \in G$.

Define $\delta(S)$ by

$$
\delta(S) \equiv \sup \left\{\delta|| T S\left(x^{\prime}\right)-T S(x) \mid<\frac{\varepsilon}{2}, \text { if }\left|x^{\prime}-x\right|<\delta\right\}
$$


Pick an arbitrary sequence of positive real numbers $\left\{\delta_{n}\right\}_{n=0}^{\infty}$ that satisfies $0<\delta_{n+1}<\delta_{n}$ and $\lim _{n \rightarrow \infty} \delta_{n}=0$. Define

$$
G_{n} \equiv\left\{S \mid \delta(S) \geq \delta_{n}, S \in G\right\}
$$

Clearly,

$$
G_{n} \subseteq G_{n+1} \subseteq G, \quad \text { and } \quad \lim _{n \rightarrow \infty} G_{n}=G .
$$

Now, the following claim holds.

Claim 3. For all $\delta>0$, there exists $n$ such that for all $S \in G$, there exists $S_{n} \in G_{n}$ such that $\left|S-S_{n}\right| \leq \delta$.

Proof. Suppose that this claim is false. Then, there exists $\delta>0$ such that for all $n>0$, there exists $S_{n}^{c} \in G$ such that $\left|S_{n}^{c}-S_{n}\right|>\delta$ for all $S_{n} \in G_{n}$. We denote the set of $S_{n}^{c}$ by $G_{n}^{c}(\delta)$. The assumption implies that $G_{n}^{c}(\delta) \neq \emptyset$, for all $n$. Clearly, $G_{n} \cap G_{n}^{c}(\delta)=\emptyset$, $G_{n} \cup G_{n}^{c}(\delta) \subseteq G$, and $G_{n+1}^{c}(\delta) \subseteq G_{n}^{c}(\delta) \subseteq G$. Taking the limit of $n \rightarrow \infty$ implies that $\lim _{n \rightarrow \infty} G_{n}^{c}(\delta) \neq \emptyset$, which contradicts $\lim _{n \rightarrow \infty} G_{n}=G$.

The continuity of $T$ implies that there exists $\delta_{1}$ such that $\left|T S^{\prime}-T S\right|<\frac{\varepsilon}{4}$ if $\left|S^{\prime}-S\right| \leq \delta_{1}$. The above claim implies that there exists $n$ such that, for all $S \in G$, there exists $S_{n} \in G_{n}$ that satisfy $\left|S-S_{n}\right| \leq \delta_{1}$. By definition, $\left|T S_{n}\left(x^{\prime}\right)-T S_{n}(x)\right| \leq \frac{\varepsilon}{2}$ if $\left|x^{\prime}-x\right|<\delta_{n}$. Now, we show the equicontinuity of $T(G)$. For a given $\varepsilon(>0)$, we choose $\delta_{1}$ and $G_{n}$ as above. Given $\left(\varepsilon, \delta_{1}, \delta_{n}\right)$, it holds that for all $S \in G$, there exists $S_{n} \in G_{n}$ such that the following inequality holds for any $x$ and $x^{\prime}(\in \Lambda)$ that satisfy $\left|x-x^{\prime}\right| \leq \delta_{n}$ :

$$
\begin{aligned}
\left|T S\left(x^{\prime}\right)-T S(x)\right| & =\left|T S\left(x^{\prime}\right)-T S_{n}\left(x^{\prime}\right)-T S(x)+T S_{n}(x)+T S_{n}\left(x^{\prime}\right)-T S_{n}(x)\right| \\
& \leq\left|T S\left(x^{\prime}\right)-T S_{n}\left(x^{\prime}\right)\right|+\left|T S(x)-T S_{n}(x)\right|+\left|T S_{n}\left(x^{\prime}\right)-T S_{n}(x)\right| \\
& \leq \frac{\varepsilon}{4}+\frac{\varepsilon}{4}+\frac{\varepsilon}{2}=\varepsilon .
\end{aligned}
$$

Thus, it has been shown that $T(G)$ is equicontinuous.

As the mapping $T: G \rightarrow G$ is continuous and the family $T(G)$ is equicontinuous, then, given that $G$ is nonempty, closed, bounded, and convex, the Schauder fixed point theorem implies that $T$ has a fixed point in $G$.

\section{Proof of Proposition 9}

As Lemma 4 holds in the deterministic case, it is sufficient to show that $\bar{B}_{c, t}$ is strictly smaller than $\bar{B}_{z, t}=b_{z, t-1}$ to prove Proposition 9 . 
Define $\Delta_{t} \equiv f_{t}\left(\sigma_{z, t}\right)-\sigma_{z, t}$. We also define $V_{t}^{(i)}\left(b_{t-1}\right)$ for $i=1,2$ by $V_{t}^{(i)}\left(b_{t-1}\right)=$ $W_{t}^{(i)}\left(b_{t-1}\right)-\frac{1+r_{t-1}}{R_{t-1}} b_{t-1}$. These functions are written as follows when the borrowing constraint is (20) for periods $t$ and $t+1$ :

$$
\begin{aligned}
& V_{t}^{(1)}\left(b_{t-1}\right)=\Delta_{t}^{z}-b_{t-1}+\frac{b_{z, t}}{R_{t}}+\frac{1}{1+r_{t}} V_{t+1}\left(b_{z, t}\right)=\Delta_{t}^{z}-b_{t-1}+\frac{b_{z, t}}{R_{t}}, \\
& V_{t}^{(2)}\left(b_{t-1}\right)=\frac{1}{1+r_{t}} V_{t+1}\left(R_{t}\left\{b_{t-1}-\Delta_{t}^{z}\right\}\right), \\
& V_{t}\left(b_{t-1}\right)=\max \left\{V_{t}^{(1)}\left(b_{t-1}\right), V_{t}^{(2)}\left(b_{t-1}\right)\right\} .
\end{aligned}
$$

We can show the following lemma.

Lemma 12. If $V_{t}^{(1)}\left(b_{t-1}\right)<V_{t}^{(2)}\left(b_{t-1}\right)$, then $V_{t+j}\left(b_{t+j-1}\right)=V_{t+j}^{(2)}\left(b_{t+j-1}\right)$ for all $j \in$ $\{1,2, \cdots, J\}$, where $b_{t+j-1}=R_{t+j-1}\left\{b_{t+j-2}-\Delta_{t+j-1}^{z}\right\}$ and $J$ is defined by $J=\min \left\{j \mid b_{t+j}<\right.$ $\left.B_{z, t+j+1}\right\}$.

Proof. The proof is by contradiction. Suppose, on the contrary, that $V_{t}^{(1)}\left(b_{t-1}\right)<V_{t}^{(2)}\left(b_{t-1}\right)$ and $V_{t+1}\left(b_{t}\right)=V_{t+1}^{(1)}\left(b_{t}\right)$, where $b_{t}=R_{t}\left\{b_{t-1}-\Delta_{t}^{z}\right\}$. It is calculated that

$$
\begin{aligned}
V_{t}^{(2)}\left(b_{t-1}\right) & =\frac{1}{1+r_{t}} V_{t+1}\left(R_{t}\left\{b_{t-1}-\Delta_{t}^{z}\right\}\right)=\frac{1}{1+r_{t}} V_{t+1}^{(1)}\left(R_{t}\left\{b_{t-1}-\Delta_{t}^{z}\right\}\right) \\
& =\frac{1}{1+r_{t}}\left[\Delta_{t+1}^{z}-R_{t}\left\{b_{t-1}-\Delta_{t}^{z}\right\}+\frac{b_{z, t+1}}{R_{t+1}}\right]=\frac{R_{t}}{1+r_{t}}\left[\Delta_{t}^{z}-b_{t-1}+\frac{b_{z, t}}{R_{t}}\right] \\
& =\frac{R_{t}}{1+r_{t}} V^{(1)}\left(b_{t-1}\right)<V_{t}^{(1)}\left(b_{t-1}\right) .
\end{aligned}
$$

The last inequality is due to $\frac{R_{t}}{1+r_{t}}<1$. This inequality contradicts the assumption. Thus, it has been shown that if $V_{t}^{(1)}\left(b_{t-1}\right)<V_{t}^{(2)}\left(b_{t-1}\right)$, then $V_{t+1}^{(2)}\left(b_{t}\right) \geq V_{t+1}^{(1)}\left(b_{t}\right)$ and $V_{t+1}\left(b_{t}\right)=$ $V_{t+1}^{(2)}\left(b_{t}\right)$. The above argument continues to hold in period $t+j$ as long as the borrowing constraint is $(20)$, which means that $j=1,2, \cdots, J$.

This lemma implies that if $V_{t}^{(1)}\left(b_{t-1}\right)<V_{t}^{(2)}\left(b_{t-1}\right)$, then $V_{t+j}^{(2)}\left(b_{t+j-1}\right)=\frac{1}{1+r_{t+j}} V_{t+j+1}^{(2)}\left(b_{t+j}\right)$ for $j=1,2, \cdots, J$, and, therefore, $V_{t}^{(2)}\left(b_{t-1}\right)=\tilde{V}_{t}^{(2)}\left(b_{t-1}\right)$, where

$$
\tilde{V}_{t}^{(2)}\left(b_{t-1}\right) \equiv \frac{1}{\prod_{j=0}^{J}\left(1+r_{t+j}\right)} V_{t+J+1}\left(b_{t+J}\right)
$$

where $J$ and $b_{t+J}$ are defined in the above lemma.

First, we restrict our attention to the case where debt $b_{t-1}$ takes discrete values. We assume that $b_{t-1} \in \Gamma_{t-1}$, where $\Gamma_{t-1}=\left\{b_{t-1}^{[n]} \mid n=1,2, \cdots, \infty\right\}$, where $b_{t-1}^{[n]}$ is specified below shortly. Under this assumption, we show that there exists $n^{*}$ such that $b_{t-1}^{\left[n^{*}\right]}$ is the closest to $\bar{B}_{c, t}$ among all of the elements of $\Gamma_{t-1}$. We then proceed to the case where $b_{t-1}$ takes a continuous value. We define

$$
B_{t}^{S}=R_{t} \xi S_{t}
$$


The definition of $b_{t-1}^{[n]}$ is the debt that becomes $\frac{B_{t+n-1}^{S}}{R_{t+n-1}}$ in period $t+n-1$ if the firm repays $\Delta_{t+j}^{z}$ in period $t+j$ for $j=0,1, \cdots, n-1$. Thus, it is written as follows:

$$
b_{t-1}^{[n]}=\sum_{j=0}^{n-1} \frac{\Delta_{t+j}^{z}}{\prod_{i=0}^{j-1} R_{t+i}}+\frac{B_{t+n-1}^{S}}{\prod_{j=0}^{n-1} R_{t+j}},
$$

where we define $\prod_{j=0}^{-1} R_{t+j}=1$. The upper limit of the debt is also written as follows:

$$
b_{z, t-1}=\sum_{j=0}^{\infty} \frac{\Delta_{t+j}^{z}}{\prod_{i=0}^{j-1} R_{t+i}} .
$$

Now, let us consider the discrete case where $b_{t-1} \in \Gamma_{t-1}$. Then, $V_{t}^{(1)}\left(b_{t-1}^{[n]}\right)=\Delta_{t}^{z}-$ $b_{t-1}^{[n]}+\frac{b_{z, t}}{R_{t}}=b_{z, t-1}-b_{t-1}^{[n]}$ is written as follows:

$$
V_{t}^{(1)}\left(b_{t-1}^{[n]}\right)=\frac{1}{\prod_{j=0}^{n-1} R_{t+j}}\left[b_{z, t+n-1}-B_{t+n-1}^{S}\right] .
$$

$\tilde{V}_{t}^{(2)}\left(b_{t-1}^{[n]}\right)$ is written as follows:

$$
\tilde{V}_{t}^{(2)}\left(b_{t-1}^{[n]}\right)=\frac{1}{\prod_{j=0}^{n-1}\left(1+r_{t+j}\right)} V_{t+n}\left(B_{t+n-1}^{S}\right) .
$$

Therefore,

$$
\frac{V_{t}^{(1)}\left(b_{t-1}^{[n]}\right)}{\tilde{V}_{t}^{(2)}\left(b_{t-1}^{[n]}\right)}=\left[\frac{b_{z, t+n-1}-B_{t+n-1}^{S}}{V_{t+n}\left(B_{t+n-1}^{S}\right)}\right] \prod_{j=0}^{n-1}\left(\frac{1+r_{t+j}}{R_{t+j}}\right) .
$$

As it is always the case that $B_{t}^{S}=\xi R_{t} S_{t} \leq \xi R_{t} \omega_{t}$ and $V_{t}(b) \leq \omega_{t}$, the above equation implies that

$$
\frac{V_{t}^{(1)}\left(b_{t-1}^{[n]}\right)}{\tilde{V}_{t}^{(2)}\left(b_{t-1}^{[n]}\right)} \geq\left[\frac{b_{z, t+n-1}-\xi R_{t+n-1} \omega_{t+n-1}}{\omega_{t+n}}\right] \prod_{j=0}^{n-1}\left(\frac{1+r_{t+j}}{R_{t+j}}\right) .
$$

Then, it is immediate from (9), (23), and (42) that there exists a finite integer $n^{*}(>0)$ such that $V_{t}^{(1)}\left(b_{t-1}^{[n]}\right)>\tilde{V}_{t}^{(2)}\left(b_{t-1}^{[n]}\right)$ for all $n \geq n^{*}$. Because the parameters are chosen such that $B_{t}^{S}<b_{z, t}$ (see (9)), it is immediate from the definition of $b_{t-1}^{[n]}$ that $b_{t-1}^{\left[n^{*}\right]}<b_{z, t-1}$. Thus, we have established that the threshold value $b_{t-1}^{\left[n^{*}\right]}$ exists and is strictly smaller than $b_{z, t-1}$ in the discrete case where $b_{t-1} \in \Gamma_{t-1}$.

Let us proceed to the continuous case where $b_{t-1}$ is not restricted to an element of $\Gamma_{t-1}$ but is a positive real number. We know from Lemma 4 that $\bar{B}_{c, t} \leq b_{z, t-1}$. We prove $\bar{B}_{c, t}<b_{z, t-1}$ by contradiction.

Suppose that $\bar{B}_{c, t}=b_{z, t-1}$. We know that $V_{t}^{(2)}\left(b_{t-1}\right)$ is continuous and decreasing in $b_{t-1}$ and that $V_{t}^{(1)}\left(b_{t-1}\right)$ is a linear function of $b_{t-1}$. These facts imply that there must exist a small positive number $\varepsilon(>0)$ such that for all $b_{t-1} \in\left[b_{z, t-1}-\varepsilon, b_{z, t-1}\right), V_{t}^{(1)}\left(b_{t-1}\right) \leq$ $\tilde{V}_{t}^{(2)}\left(b_{t-1}\right)$. However, this result obviously contradicts $V_{t}^{(1)}\left(b_{t-1}^{[n]}\right)>\tilde{V}_{t}^{(2)}\left(b_{t-1}^{[n]}\right)$ for all $n \geq$ $n^{*}$, because there exists $n\left(>n^{*}\right)$ such that $b^{[n]} \in\left[b_{z, t-1}-\varepsilon, b_{z, t-1}\right)$, as $\lim _{n \rightarrow \infty} b_{t-1}^{[n]}=b_{z, t-1}$. Thus, it cannot hold that $\bar{B}_{c, t}=b_{z, t-1}$. Therefore, $\bar{B}_{c, t}<b_{z, t-1}$. 


\section{The BGP}

The detrended variables of the BGP are determined by the following system of equations:

$$
\begin{aligned}
& A=Y^{1-\eta}, \\
& Y=K^{\alpha} L_{p}^{1-\alpha}=A K^{\alpha \eta} L_{p}^{(1-\alpha) \eta}, \\
& C+\left(g^{E}-1+\rho\right) K=Y, \\
& w=\frac{\gamma C}{1-L}, \\
& w=\frac{(1-\alpha) \eta(1+\phi \mu)}{1+\mu} \frac{Y}{L_{p}} \\
& r^{K}=\frac{\alpha \eta(1+\phi \mu)}{1+\mu} \frac{Y}{K}, \\
& 1+r=\frac{g^{E}}{\beta}, \\
& R=1+(1-\tau) r, \\
& \mu=1-\frac{\beta}{g^{E}} R, \\
& 1=\frac{\beta}{g^{E}}\left(r^{K}+1-\rho\right), \\
& g=\left[1+\kappa\left(L-L_{p}\right)\right], \\
& \pi=Y-w L-r^{K} K-B\left[1-\frac{g^{E}}{R}\right], \\
& V_{n}=\frac{\pi}{1-\beta}, \\
& S=\frac{\beta}{g} V_{n}+\frac{g^{E-1}}{R} B, \\
& w L+r^{K} K=\phi Y+\left[g \xi S-\frac{g^{E} B}{R}\right] \\
& \frac{\beta}{g} \kappa V_{n}=(1+\mu) w-\kappa g^{E-1} \frac{B}{R}-\mu \kappa\left[\xi S-\frac{g^{E-1} B}{R}\right] .
\end{aligned}
$$

where $\mu$ is the Lagrange multiplier associated with the borrowing constraint and $B$ is the total amount of corporate lending, which satisfies $B=b$, where $b$ is the outstanding debt for a firm. There are 16 equations for 16 unknowns: $\left\{g, A, Y, K, L, L_{p}, C, w, \mu, r, r^{K}, R, \pi, B, V_{n}, S\right\}$.

The following condition must be satisfied on the BGP:

$$
\xi S>g^{E-1} \frac{B}{R} .
$$

Then, the variables for debt-ridden firms on the BGP, $\left\{k_{z}, l_{z}, b_{z}, \frac{\mu_{z}}{\lambda_{z}}, \frac{\lambda_{l, z}}{\lambda_{z}}\right\}$, are calculated 
as follows:

$$
\begin{aligned}
& w=\frac{(1-\alpha) \eta\left(1+\phi \frac{\mu_{z}}{\lambda_{z}}\right)}{1+\frac{\mu_{z}}{\lambda_{z}}} A k_{z}^{\alpha \eta} l_{z}^{(1-\alpha) \eta-1,} \\
& r^{K}=\frac{\alpha \eta\left(1+\phi \frac{\mu_{z}}{\lambda_{z}}\right)}{1+\frac{\mu_{z}}{\lambda_{z}}} A k_{z}^{\alpha \eta-1} l_{z}^{(1-\alpha) \eta}, \\
& w l_{z}+r^{K} k_{z}=\phi A k_{z}^{\alpha \eta} l_{z}^{(1-\alpha) \eta}, \\
& 0=A k_{z}^{\alpha \eta} l_{z}^{(1-\alpha) \eta}-w l_{z}-r^{K} k_{z}+g^{E-1} \frac{b_{z}}{R}-b_{z}, \\
& 0=\left(1+\frac{\mu_{z}}{\lambda_{z}}\right) w-\kappa g^{E-1} \frac{b_{z}}{R}-\frac{\lambda_{l, z}}{\lambda_{z}} .
\end{aligned}
$$

The following conditions must be satisfied on the BGP:

$$
\begin{aligned}
& \frac{\lambda_{l, z}}{\lambda_{z}}>0, \\
& \xi S<g^{E-1} \frac{b_{z}}{R}<S .
\end{aligned}
$$

\section{E Data}

Table 3 provides data sources that are used for calibration and figures. Note that the European Commission's Annual macro-economic (AMECO) database is constructed by Havik et al. (2014).

The actual data of $L_{t}$ is used for the labor wedge in the figures and is constructed by

$$
L_{t}=\frac{\text { Average annual hours worked per employee }}{\text { Total hours }} \times \frac{\text { Employees }}{15-64 \text { aged population }},
$$

where the total hours is defined as 24 hours $\times 12$ months $\times 20$ days $=5760$ hours.

The average annual hours worked per employee for the EU is only available starting from 2008 because Estonia and Malta are only available starting from 2000 and Croatia is only available starting from 2008. We calculate the average annual hours as the weighted average excluding these countries in the years with deficient data, where the weight is proportional to the number of employees.

Similarly, Eurostat provides the population aged 15-64 for the EU only from 2001 because of missing data in Croatia before 2001. However, the World Bank World Development Indicators provide "Population ages 15-64 (\% of total)". We complement the Eurostat data with World Bank data.

\section{F Calibration and parameter region}

Table 2 reports the values of the calibrated parameters. First, the parameters $\beta, \rho$, and $\eta$ are common values for all countries. We set the discount factor $\beta$ equal to 0.98 , the 


\begin{tabular}{llll}
\hline \hline Variable(s) & Japan & United States & EU \\
\hline$Y, C$ & SNA & NIPA & AMECO \\
$T F P$ & JIP & Fernald (2012) & AMECO \\
$\alpha$ & JIP & Fernald (2012) & Havik et al. (2014) \\
Average hours worked & JIP & NIPA & AMECO \\
Employees & LFS & BLS & AMECO \\
$15-64$ aged population & OECD & OECD & Eurostat; WDI \\
\hline
\end{tabular}

Table 3: Data sources

Note: SNA: Cabinet Office, Government of Japan, Annual Report on National Accounts

NIPA: U.S. Bureau of Economic Analysis, National Income and Product Accounts

AMECO: European Commission, Macro-economic database AMECO

JIP: The Research Institute of Economy, Trade, and Industry, JIP 2014 database

LFS: Statistics Bureau of Japan, Labor Force Survey

BLS: U.S. Bureau of Labor Statistics, Current Employment Status

OECD: OECD, Working age population (indicator). doi: 10.1787/d339918b-en

WDI: World Bank, World Development Indicators

depreciation rate $\rho$ equal to 0.1 , and the parameter for the aggregation function $\eta$ equal to 0.7 . These are the standard settings for an annual model in the literature.

Second, we calibrate the country-specific parameters and some BGP values. The tax advantage $\tau$ is set equal to 0.3 for Japan and 0.35 for the United States and the EU. These numbers are the corporate income tax rates in Japan and the United States, respectively. The share of labor in production $(\alpha)$, the total labor supply on the BGP $(L)$, and the growth rate of TFP on the BGP $\left(g_{T F P}\right)$ are set from the data. Then, $g_{T F P}$ is defined by $g_{T F P}=g^{\frac{1-\eta}{\eta}}$, as we see in Appendix E, and $L$ is set to the ratio of total labor supply.

The sample period is from 1981 to 2008 for Japan and from 1997 to 2016 for the United States and the EU. We assume that the economy is on the BGP before a financial crisis. In the case of Japan, the financial crisis starts in 1990, whereas, in the case of the United States and EU, it starts in 2009. Then, $\alpha, L$, and $g_{T F P}$ in Japan are taken as the average for 1981-1989, and for the United States and the EU they are taken as the average for 1997-2007. When we calculate the variables on the BGP, $L$ and $g_{T F P}$ are given by the data. Hence, the inverse of the elasticity of labor supply $\gamma$ and the efficiency of R\&D $\kappa$ are determined endogenously in the system of the BGP, which is given in Appendix D.

Lastly, the parameters $(\phi, \xi, z)$ are identified by the simulated least squares criterion; that is, they are determined as the solution to the following minimization of the residual sum of squares (RSS) using a grid search method:

$$
\min _{\phi, \xi, z}\left(\mathbf{X}_{t}-\hat{\mathbf{X}}_{t}\right)^{\prime}\left(\mathbf{X}_{t}-\hat{\mathbf{X}}_{t}\right)
$$




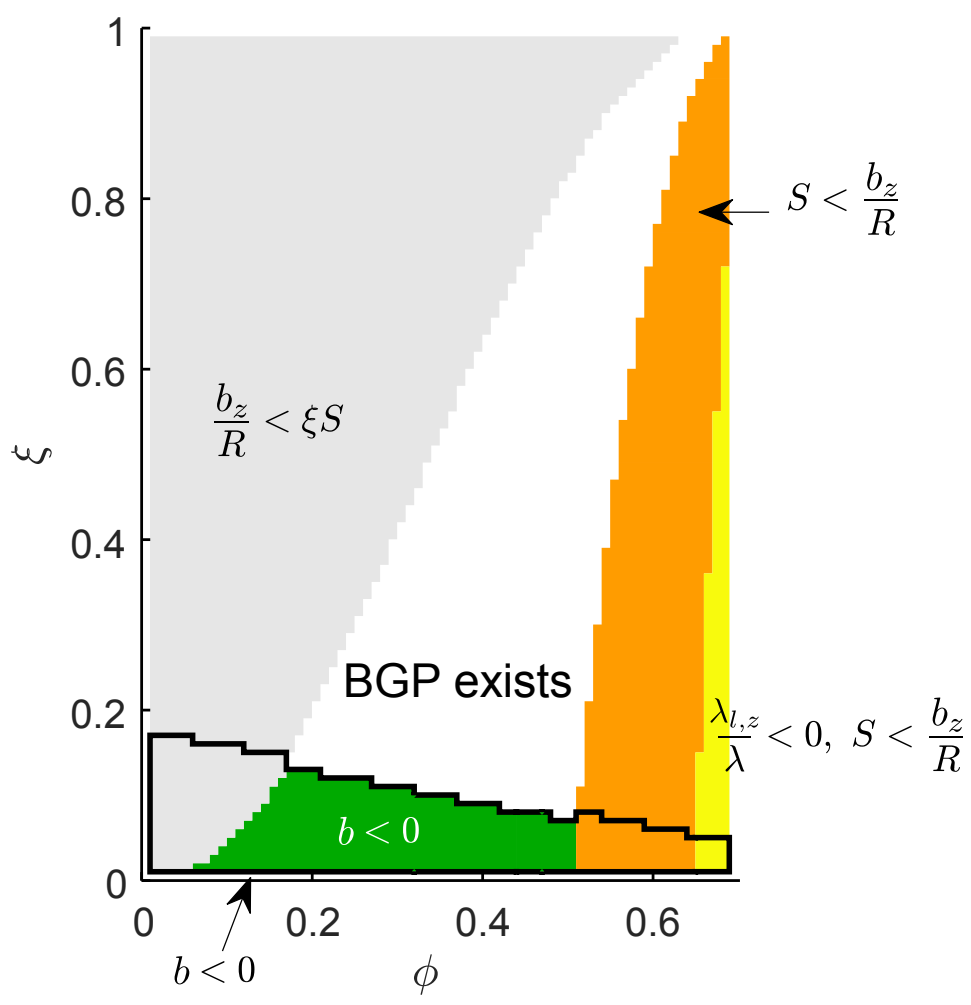

Figure 9: Domain of $(\phi, \xi)$ for the BGP

subject to

$$
\begin{aligned}
& 0<\phi<\eta, \quad 0<\xi<1, \quad \frac{\lambda_{l z}}{\lambda_{z}}>0, \quad \xi S<g^{E-1} \frac{b_{z}}{R}<S, \quad b_{n}>0, \\
& g^{E}>\operatorname{mean}\left(g_{t}^{E}\right), \quad t=1990-2008 \text { in Japan; } t=2009-2025 \text { in EU and the United States }
\end{aligned}
$$

where $\mathbf{X}_{t}$ is the observed variables vector and $\hat{\mathbf{X}}_{t}$ is the simulation-generated variables vector. $\mathbf{X}_{t}=[$ TFP growth rate; Real GDP per caita growth rate]. We extend the observed variables to 2025 by extrapolating the average growth rates in 2011-2016 for the United States and the EU. The simulation-generated variables, $\hat{\mathbf{X}}_{t}=\left[T F P_{t} / T F P_{t-1}-\right.$ $\left.1 ; Y_{t} / Y_{t-1}-1\right]$, are calculated by the method presented in Appendix I, taking $(\gamma, \kappa, \phi, \xi, \chi, z)$ as the given exogenous parameters, where the debt shock hits the economy in period 10 (i.e., $z_{t}=0$ for $t \leq 9$ and $z_{10}=z$ ). Period 10 corresponds to 1990 for Japan and 2009 for the United States and the EU. Minimization is done for the period 1990-2008 in the case of Japan and for 2009-2025 in the case of the United States and the EU.

We restrict the domain of the parameters $(\phi, \xi)$ for the above minimization to the region that enables all constraints to be satisfied on the BGP. Figure 9 denotes the domain of the parameters $(\phi, \xi)$ as the white region, whereas the values of the other parameters are given as those for Japan in Table 2 .

To calibrate the parameters, we choose the optimum parameters to minimize the distance between the simulation implied by our model and the actual data. This procedure 

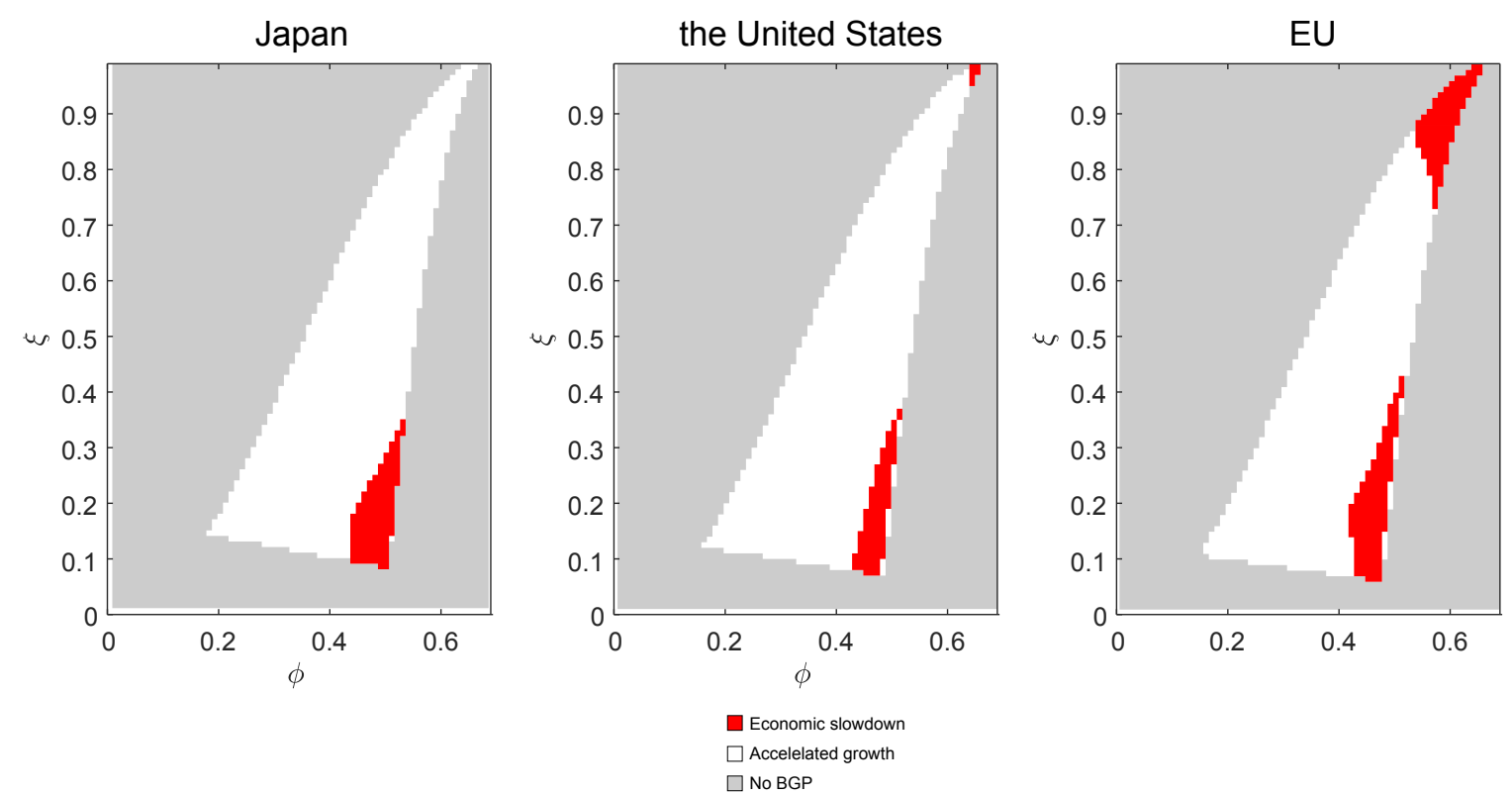

Figure 10: Domain of $(\phi, \xi)$ for an economic slowdown

is similar to impulse response matching, as described in, for example, Rotemberg and Woodford (1997), who choose the parameters to minimize the distance between the impulse responses implied by a reduced-form VAR and those implied by a DSGE model. ${ }^{18}$

As we saw in Figures 5-8, our model with the parameter values chosen by the above minimization exhibits an economic slowdown. However, economic growth may not slow down if the values of the parameters are different. The white region in Figure 10 shows the values of $(\phi, \xi)$, for which economic growth is accelerated when the economy is hit by a debt shock with maximum $z$. An economic slowdown occurs only in the red region of Figure 10. In the white region, economic growth is accelerated because a larger amount of labor is used in the $\mathrm{R} \& \mathrm{D}$ sector than before. More labor is used for $\mathrm{R} \& \mathrm{D}$ activities because the marginal product of labor becomes lower in the production sector. When a debt shock hits the economy, the marginal product of labor in the R\&D sector can become higher or lower than that in the production sector, depending on the values of the parameters $(\phi$, $\xi)$.

\section{G Proof of Claim 1}

As we saw in Appendix D, the FOC with respect to $l_{z}$ for a debt-ridden firm is

$$
\frac{\lambda_{l, z}}{\lambda_{z}}=\left(1+\frac{\mu_{z}}{\lambda_{z}}\right) w-\kappa g^{E-1} \frac{b_{z}}{R}
$$

\footnotetext{
${ }^{18}$ Our method can be regarded as a variant of impulse response matching if the actual data are interpreted as a response to a one-time shock of debt buildup.
} 
The first term on the right-hand side of (43) is the marginal cost of labor input. The second term is the marginal gain from $\mathrm{R} \& \mathrm{D}$ activity. If $\lambda_{l, z} / \lambda_{z}>0$, then the constraint $l_{z, p} \leq l_{z}$ is binding, where $l_{z, p}$ is the labor input for production, and the debt-ridden firm does not conduct R\&D. With some tedious calculation, we can rewrite (43) to

$$
\begin{aligned}
\frac{\lambda_{l, z}}{\lambda_{z}}=\frac{\eta(1-\phi)}{\phi(1-\eta)} \underbrace{\frac{\left\{\phi-1+\left(1+\left[\gamma\left(1-\left[g^{E}-1+\rho\right]\right)-r^{K}\right] \frac{\alpha \eta \frac{1+\phi \mu}{1+\mu}}{r^{K}}\right) \mathcal{W}\right\}}{\mathcal{W}-\frac{(1+\mu) \mathcal{Z}}{\mathcal{U}}}}_{\equiv \Omega_{w}} Y \\
-\frac{\kappa g^{E-1}(1-\phi)\left[\frac{\phi}{\eta\left(\frac{1+\phi \mu}{1+\mu}\right)}\right]^{\frac{\eta}{1-\eta}}}{R-g^{E-1}} Y,
\end{aligned}
$$

where $\mathcal{X} \equiv \frac{\beta \kappa(1+\mu \xi)}{g(1-\beta)}, \mathcal{U} \equiv \mathcal{X}\left(1-\frac{g^{E}}{R}\right)-\kappa \frac{g^{E-1}}{R}[1-\mu(1-\xi)], \mathcal{Z} \equiv \frac{\xi \beta}{1-\beta}\left(1-\frac{g^{E}}{R}\right)+(1-$ $\xi) \frac{g^{E}}{R}, \mathcal{W}=\frac{\xi \beta}{1-\beta}+1-\frac{\mathcal{X Z}}{\mathcal{U}}, R=1+(1-\tau) r, \mu=1-\frac{\beta}{g^{E}} R$, and $r^{K}=\frac{g^{E}}{\beta}-1+\rho . R-g^{E-1}$ is always positive under a standard parameter setting. ${ }^{19}$ The definition of $\Omega_{w} \equiv \frac{w}{Y}$ implies that there exist $\underline{\Omega}$ and $\bar{\Omega}$ such that $0<\underline{\Omega} \leq \Omega_{w} \leq \bar{\Omega}<\infty$ for any $\phi \in[0,1]$. We divide (44) by $Y$ and take the limit of $\phi \rightarrow 0$ using the fact that $\underline{\Omega} \leq \Omega_{w} \leq \bar{\Omega}$ :

$$
\begin{aligned}
& \lim _{\phi \rightarrow 0} \frac{\eta(1-\phi)}{\phi(1-\eta)} \Omega_{w}=\infty, \\
& \lim _{\phi \rightarrow 0} \frac{\kappa g^{E-1}(1-\phi)\left[\frac{\phi}{\eta\left(\frac{1+\phi \mu}{1+\mu}\right)}\right]^{\frac{\eta}{1-\eta}}}{R-g^{E-1}}=0 .
\end{aligned}
$$

These results imply that there exists $\bar{\phi} \in(0,1]$ such that if $\phi<\bar{\phi}$, then $\lambda_{l, z} / \lambda_{z}>0$.

\section{H Detrending for a firm's problems}

We detrend the variables as follows: $A_{t}=\tilde{A}_{t} N_{t-1}^{(1-\eta) E}, Y_{t}=\tilde{Y}_{t} N_{t-1}^{E}, C_{t}=\tilde{C}_{t} N_{t-1}^{E}, K_{t}=$ $\tilde{K}_{t} N_{t}^{E}, k_{z, t}=\tilde{k}_{z, t} N_{t-1}^{E-1}, k_{n, t}=\tilde{k}_{n, t} N_{t-1}^{E-1}, l_{z, t}=\tilde{l}_{z, t} / N_{t-1}, l_{n, t}=\tilde{l}_{n, t} / N_{t-1}, w_{t}=\tilde{w}_{t} N_{t-1}^{E}$, $\pi_{t}=N_{t-1}^{E-1} \tilde{\pi}_{t}, b_{n, t}=\tilde{b}_{n, t} N_{t-1}^{E-1}, b_{z, t}=\tilde{b}_{z, t} N_{t-1}^{E-1}, V_{n, t}=\tilde{V}_{n, t} N_{t-1}^{E-1} z_{t}=Z_{t} / N_{t-1}$, and $g_{t}=N_{t} / N_{t-1}$.

Detrending TFP: $\quad$ Suppose that $T F P=T \tilde{F} P \cdot N^{a}$. The equation $Y=T F P \cdot K^{\alpha} L^{1-\alpha}$ implies that

$$
\tilde{Y} N^{\frac{1-\eta}{(1-\alpha) \eta}}=T \tilde{F} P \cdot N^{a} \tilde{K}^{\alpha} N^{\frac{(1-\eta) \alpha}{(1-\alpha) \eta}} L^{1-\alpha}
$$

${ }^{19} R-g^{E-1}>0$ can be written as $\tau<\frac{g^{E}-\beta g^{E-1}}{g^{E}-\beta} \equiv f(g)$, where $E=\frac{1-\eta}{(1-\alpha) \eta}>0$. Thus, it holds that

$$
f(g)=1+\beta \frac{1-\frac{1}{g^{1-E}}}{g^{E}-\beta}>1
$$

for all $g>1$. As $\tau<1$, the inequality $\tau<f(g)$ is always satisfied, meaning that $R-g^{E-1}>0$. 
which implies that $a=\frac{1-\eta}{\eta}$ and, thus,

$$
T F P=T \tilde{F} P \cdot N^{\frac{1-\eta}{\eta}} .
$$

\section{Transition dynamics with $z>0$}

In this appendix, we describe the transition dynamics in the case where the economy is initially on the BGP and a proportion $z$ of firms are suddenly imposed with the maximum debt $b_{z}$ at time 10 , where $0<z<1$. The economy eventually converges to the BGP. All agents have perfect foresight on the path after the one-time buildup of debt, which is the only unexpected event. In this setting, we can apply a deterministic simulation with an occasionally binding borrowing constraint by using Dynare (see Adjemian et al., 2011). In our model, the borrowing constraint is always binding both in transition and on the BGP. The equilibrium is calculated by solving a full nonlinear system of simultaneous equations using a modified Newton-Raphson algorithm. The details of the algorithm can be found in Juillard (1996). This algorithm solves $31 \times 300$ simultaneous equations, where 31 is the number of endogenous variables and 300 is the number of simulation periods.

Altogether, 31 variables- $\left\{\tilde{A}_{t}, \tilde{Y}_{t}, \tilde{K}_{t}, \tilde{C}_{t}, L_{t}, R_{t}, \tilde{l}_{n, p, t}, \tilde{l}_{z, p, t}, \tilde{l}_{z, t}, \tilde{l}_{n, t}, \tilde{k}_{z, t}, \tilde{k}_{n, t}, \tilde{b}_{z, t}, \tilde{b}_{n, t}, \tilde{y}_{z, t}\right.$, $\left.\tilde{y}_{n, t}, g_{t}, r_{t}, r_{t}^{K}, \tilde{w}_{t}, z_{t}, \tilde{V}_{n, t}, \tilde{S}_{t}, \tilde{\pi}_{n, t}, \tilde{\pi}_{z, t}, \frac{\mu_{z, t}}{\lambda_{z, t}}, \frac{\mu_{n, t}}{\lambda_{n, t}}, \frac{\lambda_{l, n, t}}{\lambda_{n, t}}, \frac{\lambda_{l, z, t}}{\lambda_{z, t}}, \lambda_{\pi, n, t}, \lambda_{n, t}\right\}$-are calculated from the following 31 equations:

$$
\begin{aligned}
& \tilde{A}_{t}=\tilde{Y}_{t}^{1-\eta}, \\
& \tilde{Y}_{t}=\left\{z_{t} \tilde{y}_{z, t}^{\eta}+\left(1-z_{t}\right) \tilde{y}_{n, t}^{\eta}\right\}^{\frac{1}{\eta}}, \\
& L_{t}=z_{t} \tilde{l}_{z, t}+\left(1-z_{t}\right) \tilde{l}_{n, t}, \\
& \tilde{K}_{t-1}=z_{t} \tilde{k}_{z, t}+\left(1-z_{t}\right) \tilde{k}_{n, t}, \\
& \tilde{C}_{t}+g_{t}^{E} \tilde{K}_{t}-(1-\rho) \tilde{K}_{t-1}=\tilde{Y}_{t}, \\
& \tilde{w}_{t}=\frac{\gamma \tilde{C}_{t}}{1-L_{t}}, \\
& 1=\frac{\beta \tilde{C}_{t}}{g_{t}^{E} \tilde{C}_{t+1}}\left(r_{t+1}^{K}+1-\rho\right), \\
& 1+r_{t}=\frac{g_{t}^{E}}{\beta} \frac{\tilde{C}_{t+1}}{\tilde{C}_{t}}, \\
& R_{t}=1+(1-\tau) r_{t}, \\
& g_{t}=\left[1+\kappa\left(1-z_{t}\right)\left(\tilde{l}_{n, t}-\tilde{l}_{n, p, t}\right)\right], \\
& z_{t}=g_{t} z_{t+1}, \\
& \tilde{S}_{t}=g_{t}^{E-1}\left[\frac{\tilde{V}_{n, t+1}}{1+r_{t}}+\frac{\tilde{b}_{n, t}}{R_{t}}\right],
\end{aligned}
$$


equations for both normal firms and debt-ridden firms, $i=n, z$ :

$$
\begin{aligned}
& \tilde{w}_{t}=\frac{(1-\alpha) \eta\left(1+\phi \frac{\mu_{i, t}}{\lambda_{i, t}}\right)}{1+\frac{\mu_{i, t}}{\lambda_{i, t}}} \tilde{A}_{t} \tilde{k}_{i, t}^{\alpha \eta} \tilde{l}_{i, p, t}^{(1-\alpha) \eta-1}, \\
& r_{t}^{K}=\frac{\alpha \eta\left(1+\phi \frac{\mu_{i, t}}{\lambda_{i, t}}\right)}{1+\frac{\mu_{i, t}}{\lambda_{i, t}}} \tilde{A}_{t} \tilde{k}_{i, t}^{\alpha \eta-1} \tilde{l}_{i, p, t}^{(1-\alpha) \eta}, \\
& \tilde{y}_{i, t}=\tilde{k}_{i, t}^{\alpha} \tilde{l}_{i, p, t}^{1-\alpha} \\
& \tilde{\pi}_{i, t}=\tilde{A}_{t} \tilde{k}_{i, t}^{\alpha \eta} \tilde{l}_{i, p, t}^{(1-\alpha) \eta}-\tilde{w}_{t} \tilde{l}_{i, t}-r_{t}^{K} \tilde{k}_{i, t}+\frac{\tilde{b}_{i, t}}{R_{t}}\left[1+\kappa\left(\tilde{l}_{i, t}-\tilde{l}_{i, p, t}\right)\right] g_{t}^{E-1}-\tilde{b}_{i, t-1},
\end{aligned}
$$

equations for normal firms only:

$$
\begin{aligned}
& \tilde{l}_{n, p, t} \leq \tilde{l}_{n, t}, \quad \frac{\lambda_{l, n, t}}{\lambda_{n, t}}\left(\tilde{l}_{n, t}-\tilde{l}_{n, p, t}\right)=0, \\
& \frac{\beta \tilde{C}_{t}}{g_{t} \tilde{C}_{t+1}} \frac{\kappa \tilde{V}_{n, t+1}}{\lambda_{n, t}}=\left(1+\frac{\mu_{n, t}}{\lambda_{n, t}}\right) \tilde{w}_{t}-\kappa g_{t}^{E-1} \frac{\tilde{b}_{n, t}}{R_{t}}-\frac{\lambda_{l, n, t}}{\lambda_{n, t}}-\kappa \frac{\mu_{n, t}}{\lambda_{n, t}} \max \left\{\xi \tilde{S}_{t}-\frac{g_{t}^{E-1} \tilde{b}_{n, t}}{R_{t}}, 0\right\}, \\
& \left\{\begin{array}{l}
\text { if } \xi \tilde{S}_{t}-\frac{g_{t}^{E-1} \tilde{b}_{n, t}}{R_{t}} \leq 0, \quad 1=\frac{\beta \tilde{C}_{t}}{g_{t}^{E} \tilde{C}_{t+1}} \frac{\lambda_{n, t+1}}{\lambda_{n, t}} R_{t}, \\
\text { if } \xi \tilde{S}_{t}-\frac{g_{t}^{E-1} \tilde{b}_{n, t}}{R_{t}}>0, \quad 1-\frac{\mu_{n, t}}{\lambda_{n, t}}=\frac{\beta \tilde{C}_{t}}{g_{t}^{E} \tilde{C}_{t+1}} \frac{\lambda_{n, t+1}}{\lambda_{n, t}} R_{t},
\end{array}\right. \\
& \left\{\begin{array}{l}
\text { if } \mu_{n, t}>0, \quad \tilde{w}_{t} \tilde{l}_{n, t}+r_{t}^{K} \tilde{k}_{n, t}=\phi \tilde{A}_{t} \tilde{k}_{n, t}^{\alpha \eta} l_{n, p, t}^{(1-\alpha) \eta}+\left[1+\kappa\left(\tilde{l}_{n, t}-\tilde{l}_{n, p, t}\right)\right] \max \left\{\xi \tilde{S}_{t}-\frac{g_{t}^{E-1} \tilde{b}_{n, t}}{R_{t}}, 0\right\}, \\
\text { if } \mu_{n, t} \leq 0, \quad \mu_{n, t}=0,
\end{array}\right. \\
& \tilde{V}_{n, t}=\tilde{\pi}_{n, t}+\frac{\beta \tilde{C}_{t}}{g_{t} \tilde{C}_{t+1}}\left[1+\kappa\left(\tilde{l}_{n, t}-\tilde{l}_{n, p, t}\right)\right] \tilde{V}_{n, t+1}, \\
& \left\{\begin{array}{l}
\text { if } \lambda_{\pi, n, t} \leq 0, \quad \lambda_{n, t}=1, \\
\text { if } \lambda_{\pi, n, t}>0, \quad \tilde{\pi}_{n, t}=0, \\
\lambda_{n, t}=1+\lambda_{\pi, n, t},
\end{array}\right.
\end{aligned}
$$

equations for debt-ridden firms only:

$$
\begin{aligned}
& \tilde{l}_{z, t}=\tilde{l}_{z, p, t}, \\
& \tilde{\pi}_{z, t}=0, \\
& \tilde{w}_{t} \tilde{l}_{z, t}+r_{t}^{K} \tilde{k}_{z, t}=\phi \tilde{A}_{t} \tilde{k}_{z, t}^{\alpha \eta} l_{z, p, t}^{(1-\alpha) \eta} \Longrightarrow \frac{\mu_{z, t}}{\lambda_{z, t}}=\frac{\eta-\phi}{\phi(1-\eta)}, \\
& \frac{\lambda_{l, z, t}}{\lambda_{z, t}}=\left(1+\frac{\mu_{z, t}}{\lambda_{z, t}}\right) \tilde{w}_{t}-\kappa g_{t}^{E-1} \frac{\tilde{b}_{z, t}}{R_{t}}>0 .
\end{aligned}
$$

The equilibrium variables must satisfy the following conditions:

$$
\begin{aligned}
& \frac{g_{t}^{E-1} \tilde{b}_{n, t}}{R_{t}}<\xi \tilde{S}_{t}, \\
& \xi \tilde{S}_{t}<\frac{g_{t}^{E-1} \tilde{b}_{z, t}}{R_{t}}<\tilde{S}_{t} .
\end{aligned}
$$

